\title{
SEX VARIABILITY
}

$$
\text { by }
$$

Hazel summerfeld, B.S. in Ed.

SUBMITTED IN PARTIAL FULFIIMENT OF THE

REQUIREMENTS FOR THE DEGREE OF

MASTER OF ARTS

in the

GRADUATE SCHOOL

$$
\text { of the }
$$

UNIVERSITY OF MISSOURI

$$
\text { approor wityple }
$$


SEX VARIABIIITY

by

Hazel Summerfield, B.S. in Ed.

SUBMITTED IN PARTIAL FULFILMENT OF THE

REQUIREMENTS FOR THE DEGREE OF

MASTER OF ARTS

in the

GRADUATE SCHOOL

of the

UNIVIRSITY OF MISSOURI 
The question of variation has long been of interest to scientists. Since the time of Darwin we find investigators endeavoring to determine which sex is the more variable. In a well known controversy on this subject between Havelock Ellis and Karl Pearson, the conflicting opinions are clearly illustrated as shown by the following quotations:-

"A precise knowledge of the actual facts of the life of men and women forbids us to dogmatise rigidly concerning the respective spheres of men and women. It is a matter which experience alone can demonstrate in detail...... It lays the axe at the root of many pseudo-scientific superstitions..... Yet there are certain general conclusions which have again and again presented themselves, even when we have been occupied in considering very diverse aspects of the physical and psychic phenomena of human life. One of these is the greater variability of the male; this is true for almost the whole of the field we have covered, and it has social and practical consequences of the widest significance. The whole of our human civilization would have been a different thing, if in early zoological epochs the male had not acquired a greater variational tendency than the female." ( $x$ )

In criticism of this viev Karl Pearson asserts:-

"Unfortunately the writer of these very sentences has done much to perpetuate some of the worst of the pseudoscientific superstitions to which he refers, notably that of the greater variability of the male human being..... The object

(x) H. Ellis "Man and Woman"--London--1897. 
of this essay is to lay the axe to the root of this pseudoscientific superstition. It will not be necessary to prove that the male is either more or less variable than the female, but merely to show that when the proper statistics are considered and are dealt with scientifically there is no evidence to show a preponderating variability in man." ( $x)$

By "proper statistics" Pearson explains that he means those obtained by testing."a normal sample of the population as free as possible from pathological abnormalities, and fairIy numerous". He admits the difficulty of finding such and makes a study of all available physical data with apologies for its meagerness and the unreliability of some of it. Unfortunately he has not touched the question of the variability with reference to mental characteristics. The great need of empirical data for a study of this phase of the question has led me to give certain standard mental tests to eleven hundred school children. I have also worked up the results which several persons have obtained by giving the same or similar tests to other groups.

Before discussing either physical or mental data, I shall give the opinions of earlier investigators in this field, dividing them into four groups as follows:-

1. Those who believe in greater male variability.

2. Those who maintain that the female is more variable.

3. Those who assert that there is no difference.

4. Those who find contradictory evidence sufficient to prevent them from forming a decided opinion.

(x) Karl Fearson "The Chances of Death" London 1897. Volume 1--Page 37 . 
The personnel of the groups follows with a brief indication of the material upon which each based his decision.

GROUP I. Advocites of Greater Male Variability.

1. Darwin--A study of the evolution of man.

2. E. I. Thorndike---Calculated the data of Helen B. Thompson and a few original measures of reaction time, spelling and arithmetical ability.

3. Geddes and Thompson---A study of the evolution of sex.

4. Brooks-m-A study of the evolution of sex.

5. Havelock Ellis---Anatomical and pathological data and a. study of eminent men.

6. Fox and Thornaike---Arithmetical abilities of 28 boys and 42 girls.

7. C. Burt and R. C. Moore--Tests of Wallesey school children.

8. Bobertisg---Pesults of Binet tests.

9. J. Jacobs---Studies in Jewish statistics.

10. Edward Carpenter---Study of the evolution of woman.

11. Professor Marshal1---study of Boyd's tables of brain measurements.

12. Results of the tapping test.

13. Clark Wissler--Tests upon 42 college students.

GROUP II. Advocates of Greater Female Variability.

1. Meckel-.-Pathological data.

2. Karl Pearson---Fhysical data.

3. H. I. Hollingworth---Judgments of persuisivements using advertisements and 40 college students as subjects. 
GROUP II. Continued.

4. Gertrude Kupper---The responses to appeals of 200 children.

5. Stone--Aritrmetical abilities of 250 boys and $250 \mathrm{girls}$.

6. I. S. Hollingworth---Review of the literature leads one to to believe that the females are more variable.

GROUP III. Advocates of Equal Variability.

1. Courtis---Arithmetic tests.

2. H. H. Goddard---Binet tests.

3. Terman---Binet tests of 1000 children.

4. Trabue.

5. H. T. Woolley.

GROUP IV. Writerg With Contradictory Evidence.

1. Bonser---

a) Arithmetical abilities-- -358 boys and 372 girls.

- Boys $66 \%$ as variable as girls.

b) - Controlled association and selective judgment---Two trials for each test revealed boys more variable in one trial and girls in the other.

c) Literary interpretation---Boys more variable.

d). Speliing---Boys more variable.

2. Wrn. Brown---

a). Cancellation of $E$ and R-- Females more variable.

b) - Cancellation of $S, A, N$ and $0---$ Ifales more variable.

c). Motor performance--Equal variability.

d). Addition test--Males more variable in speed and females more variable in accuracy. 
e) Mủler-lyer illusion test--Male children more variable and female adults more variable.

3. Iipmann---Binet tests.

a). $53 \%$ of series--Males more variable.

b). $37 \%$ of series---Females more variable.

c). $10 \%$ of series---Equal variability.

4. G. C. Meyer---

a). Incidental memory for bills, coins and stamps. 337 males and 367 females diviced into 182 groups. 65 groups show greater variability for the males. 107 groups show greater variability for the females. 10 groups show equal variability.

b). Incidental memory for words---773 males and 890 females. Females vary more in the High School and fourth grades. The males vary more in the fifth, sixth, seventh and eighth grades.

5. E. K. Strong-- A study of the relative merits of advertisements by the method of relative position. Subjects-15 men and 10 women. Two trials. In one the A. D. for women was $69 \%$ greeter then that of men. In the other tritil the men were more variable.

In comparing these groups we find that the first, advocating greater male variability, contains more names than any of the other groups. However, when considered chronologically, we observe that the third group contains the later investigators. From this we might conclude that the later studies indicate that there is practically no sex difference 
in varicbility in spite of their limitations as to number of subjects and range of traits and functions measured.

Having stated my problem and briefly mentioned the import of previous investigations, I shall review, in tabular form, all physicel data that throw light on the subject. In these tables I have used abbreviations for the various races, sources of information and units of measurement and comparison. The abbreviations, with their equivalents, follow:Abbreviations for Races.

1. A. Br....-Ancient Britons.

2. A. Gaul...-Ancient Gaulish.

3. A. Ger...-Ancient German.

4. Ain........ Aino.

5. Alt. B.---Alt-Bayerisch.

6. Am.-....-American.

7. An. Can.-.-fncient inhabitants of the Canaries.

8. And......-- Andamanese.

9. A. Rom.-.--Ancient Roman.

10. A. Sa....-Anglo-Saxon.

11. Au. A.----Australian Aborigines.

12. A. Sw.-..-Ancient Swiss.

13. Bad.....--Badensien.

14. Bav.....-Bavarian.

15. Bel.....--Belgian.

16. Egy.-..--Egyptian.

17. Eng.-...--English.

18. Eng. L...--English living. 
Abbreviations for Races. Continued.

19. Eng. Mar.--Fnglish Married.

20. Eng. Sin..-- Inglish Single (unmarried).

21. Eng. W.-... Inglish Whitechapel skulls.

22. E. S.-man-minglish scotch.

23. Etr.-.m.- Etruscan.

24. Fr.......-French.

25. Fr. C....--French Cite.

26. Fr. Ca.....-French Catacomb skulis.

27. Fr. W.-...-French West Find (of Paris).

28. Frie......-Friesian.

29. Ger.--n-m---German.

30. It.......--Italian.

31. Kan.--n-m-Kanakas.

32. Iib.-.m=----Iibyan.

33. Naq.......-Naquadas.

34. Neg.....-Negro (African).

35. Neol......-Neolithic man.

36. Ob. F....--Ober-frankisch.

37. Panj......-Panjabi.

38. Per.-n-m--meruvian.

39. Poly.....--Polynesian.

40. Rom.-------Roman.

41. Sax.-..----Saxon.

42. Scan.....-.-Scandinavian.

43. S. \& Den.---Aborigines of Sweden and Denmark. Abbreviations for Sources.

1. Dav ......--C. B. Davenport.

2. Gal......--Frances Galton. 
Abbreviations for Sources. Contirued.

3. Pe...-.--Karl Pearson.

4. Po.........W. T. Porter.

Abbreviations for Units of Measurements and Comparison.

1. No.....-Number of individuals measured.

2. S. D.-.--Standard deviation.

*4. C. V...-..Coefficient of variability.

All of the data furnished by Davenport, Galton and Pearson are comparable because they have used the same units of measurement and have found the C. V. by dividing the S. D. by the mean (average). I have not taken the time to change the figures of S. D. Porter, who computed the C. V. by dividing the P. E. by the mean, into those used by the other three men because, for the purpose of comparison of the varisbilities of the sexes, it was not necessary. For this reason I have not discussed the differences between the S. D.s or the C.V.s of the four groups of data. 4. P.W.-- - - - - Probable error.(.6745 X S.D.) 
STATURE.

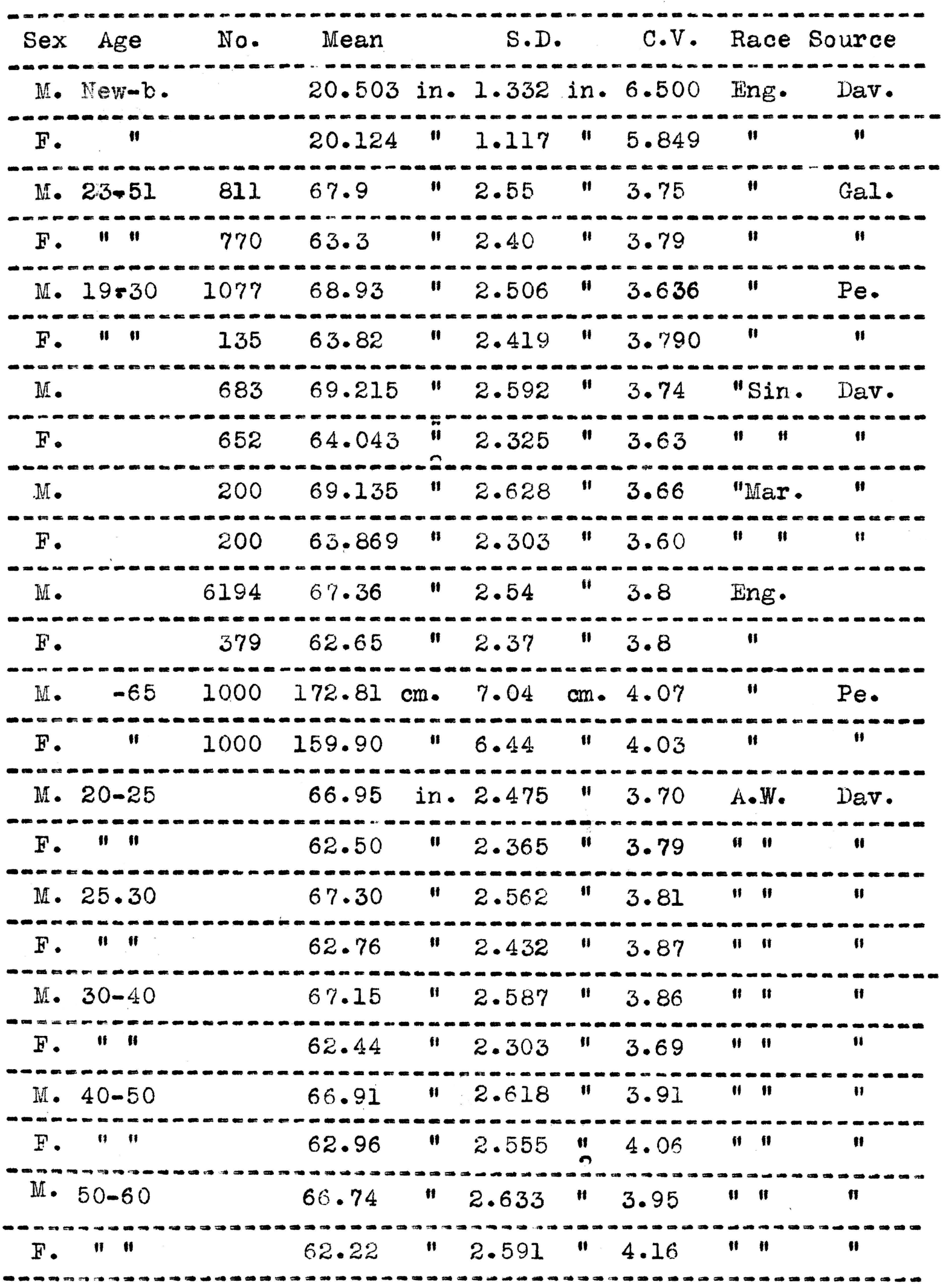


STATURE. Cont'd.

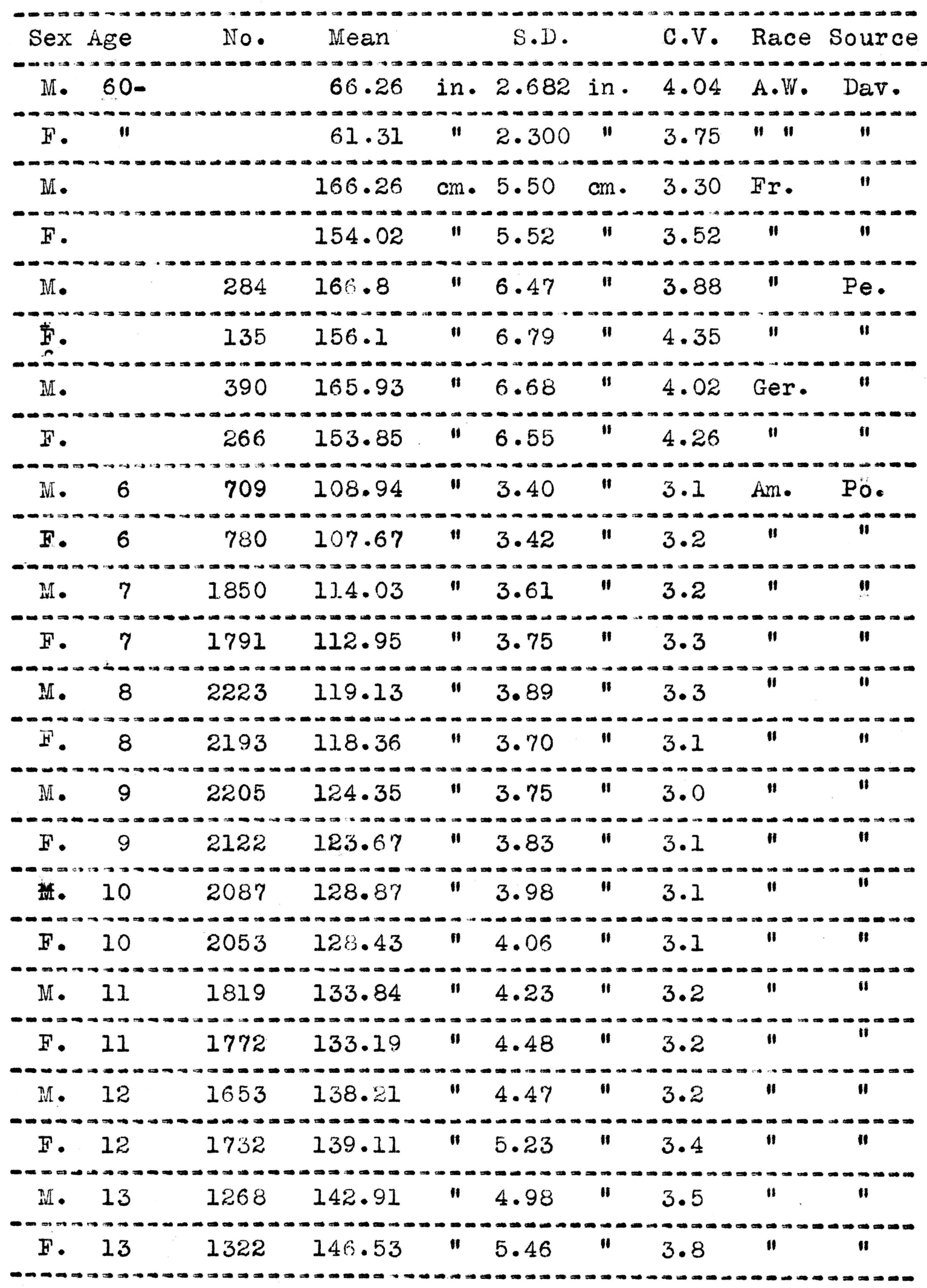


STATIRE.Cont'd.

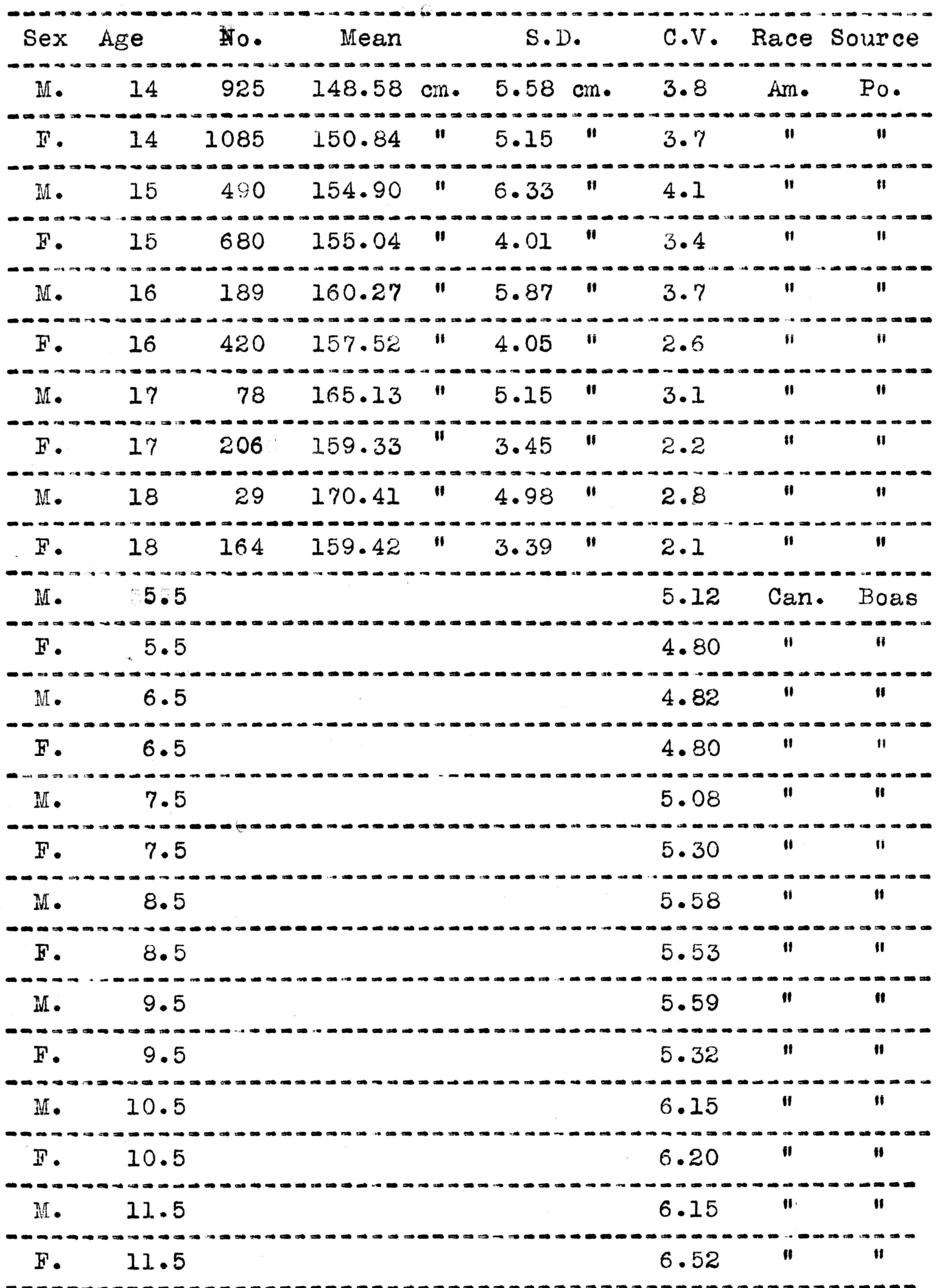


STATURE. Cont'd.

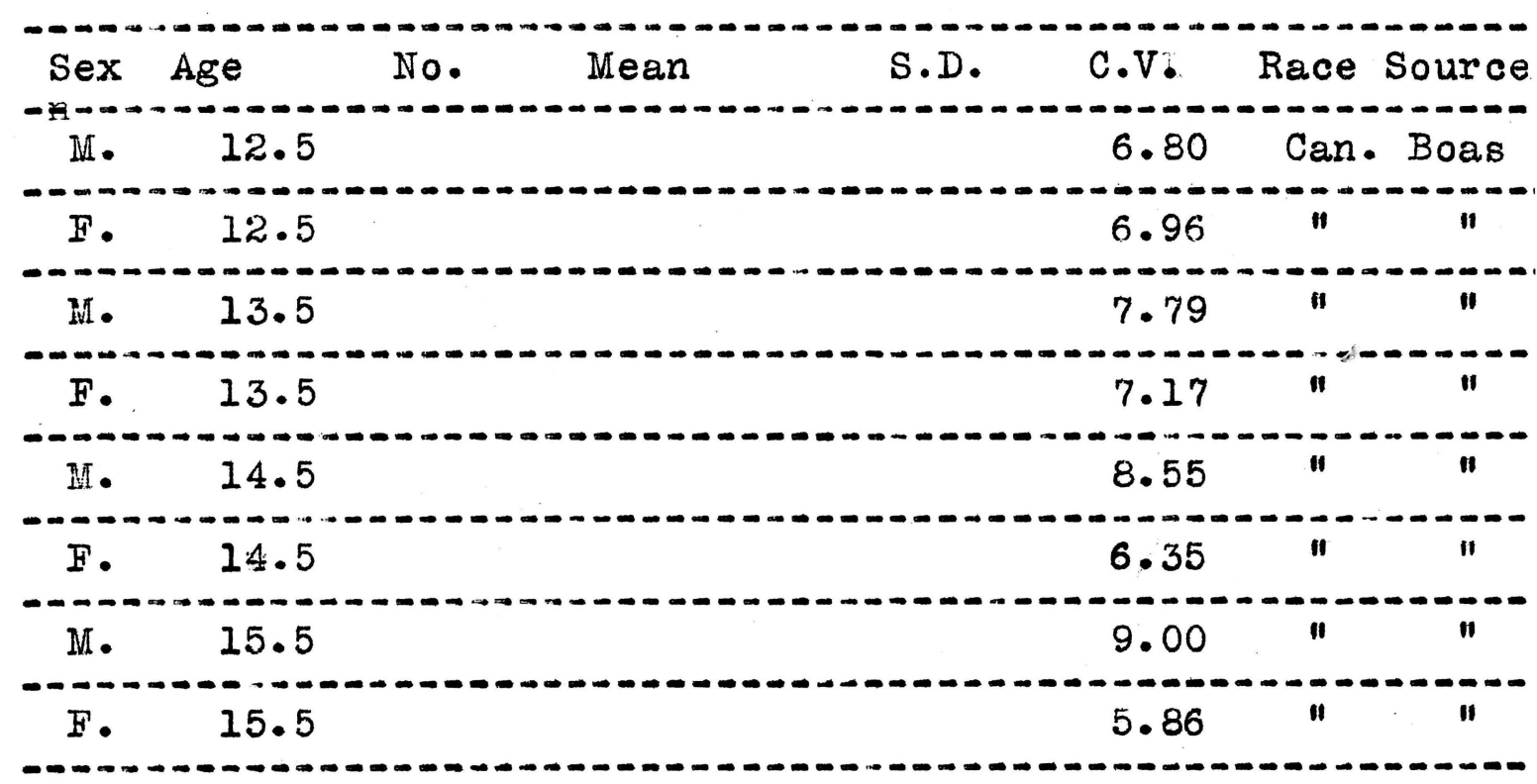

The above table presents data from many sources and of individuals of different ages. It is therefore very difficult exactly to determine its significance. I shall first consider the results by races.

Averaging the six groups of English adult gata I find the males more variable by .003 of $1 \%$, so I may safely say the sexes are equal in variability so far as trose data are concerned. New-born British boys are slightly more variable to the extent of . 651 of $1 \%$.

French and German adult statistics indicate a preponderance of variability on the side of the female but the series are much less extensive than the English.

I have treated the measures of the Australian Whites separately and discover here that the ferales are .008 of $1 . \%$ more variable, indicating practically equal sex variability. 
The most complete series of measurements are those of American children in the St. Louis schools. The boys are more variable when the $\mathrm{C.V}$. for all ages are averaged but the difference is very slight, being only.223 of $1 \%$. One interesting point is that they are more variable in the ages from fourteen to eighteen inclusive, the preponderance being .7 of $1 \%$.

Another study of school chilaren is that of Boas with Canadians as subjects and here again the boys are a trifle more variable. The figures are .53 of $1 \%$ greater for the males and the difference is especially noticeable in the three highest ages.

In summing up the evidence, then, there seems to be little preponderance of variability for either sex to an extent worth considering, However, both Porter and Boas seem to show a slight though definite tendency toward greater male variability in later adolescence. 
HEIGHT SITTING.

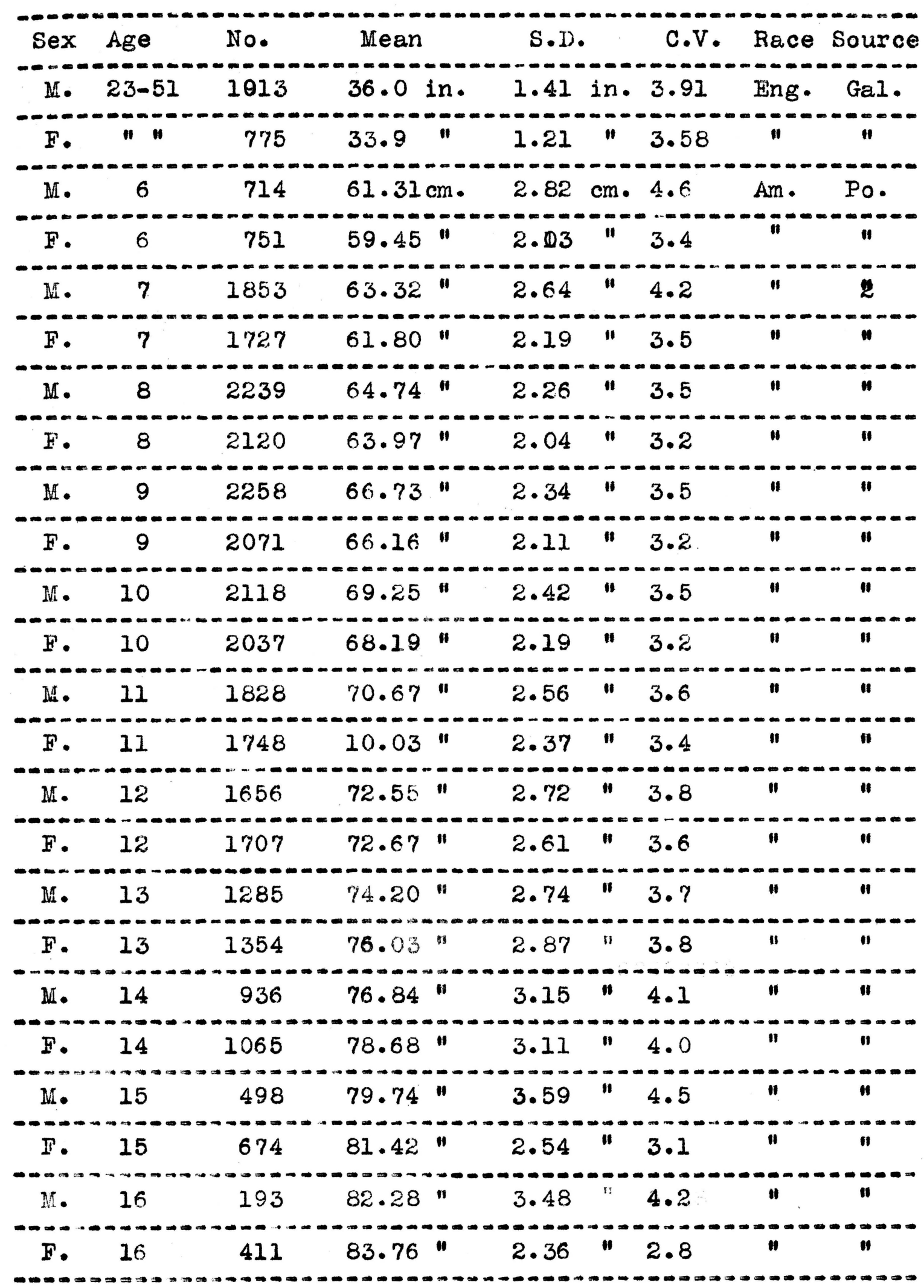




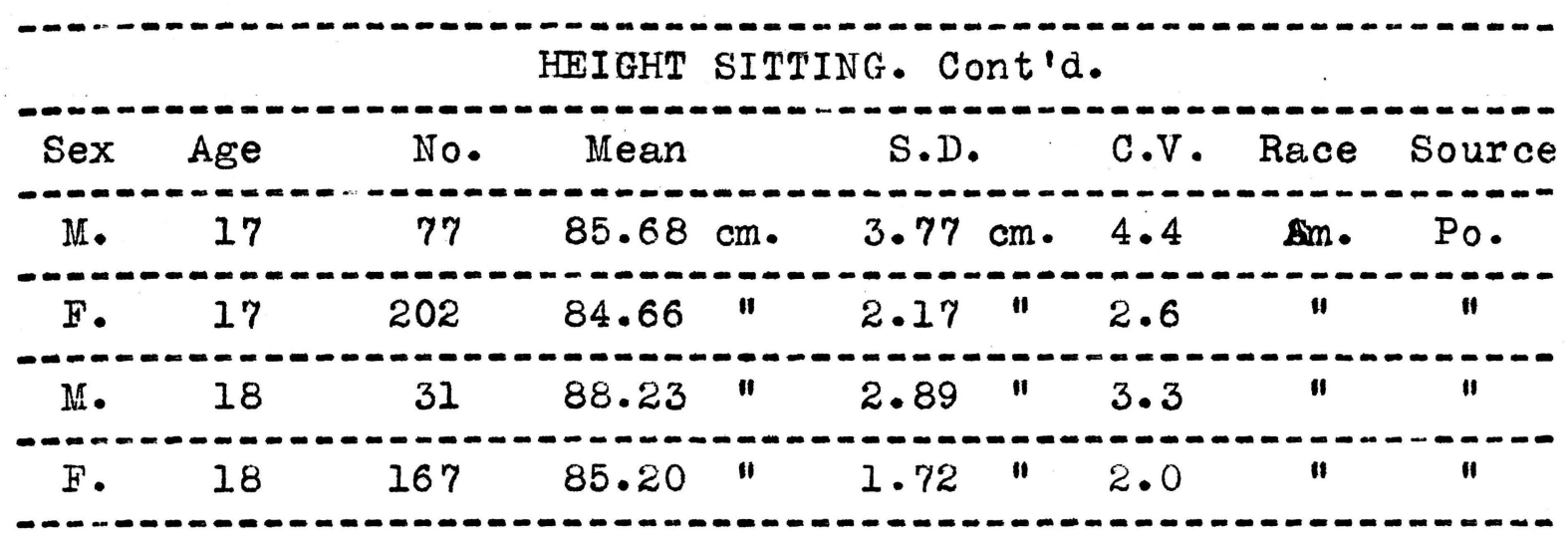

In sitting height therenis but one comparison of adult statistics and that is one made by Galton and shows the males more variable by .33 of $1 \%$.

The only other available data on this measure are those of Porter on American children. Here the males are more variable in every age but that of thirteen years. The average variability from sixteen to eighteen years is . 7 of $1 \%$ greater for the males. In discussion of this, Pearson concludes that less variability in sitting height is a secondary sex characteristic of the female and these limited data certainly indicate it. 
SPAN OF' ARMS.

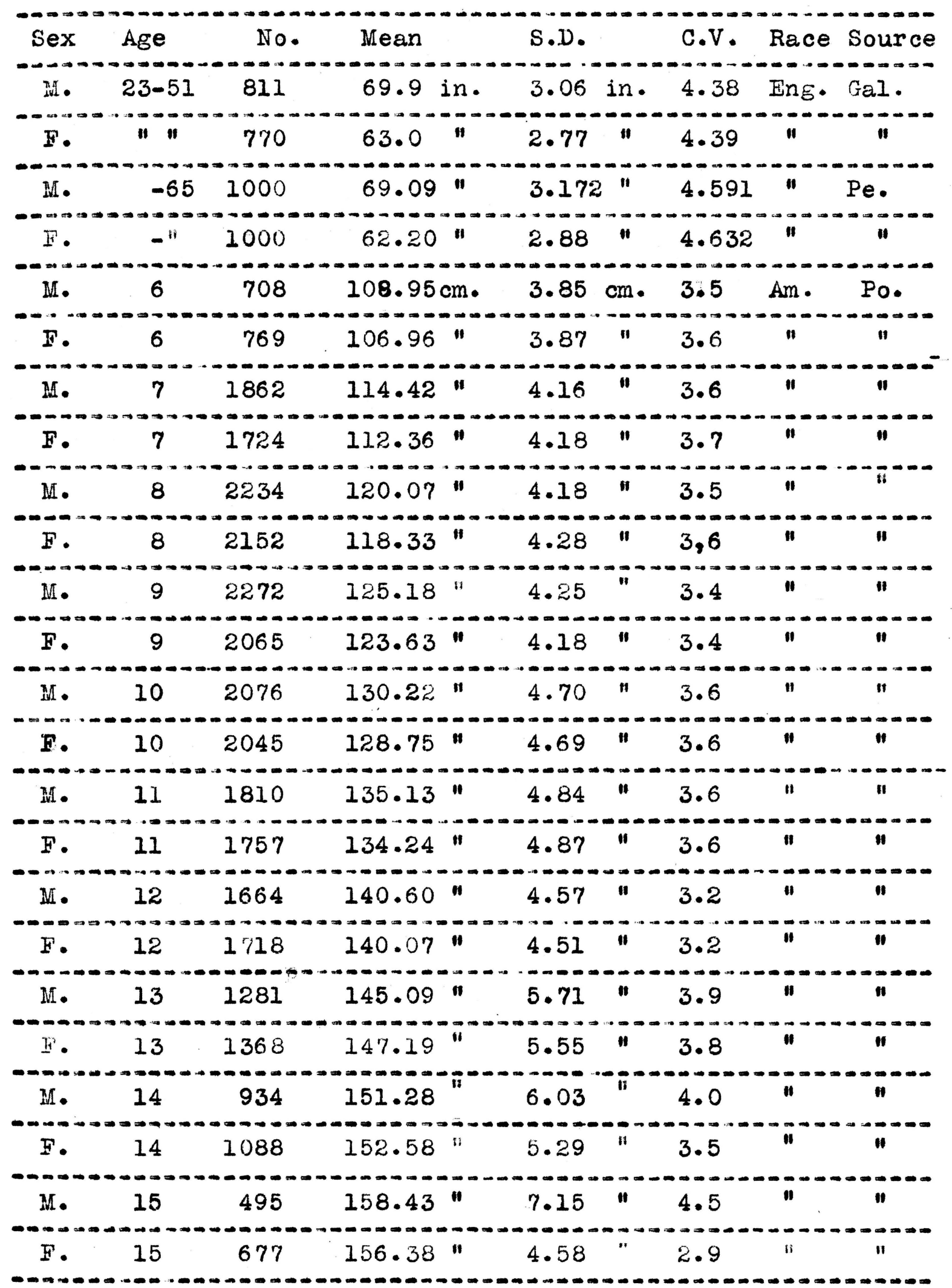




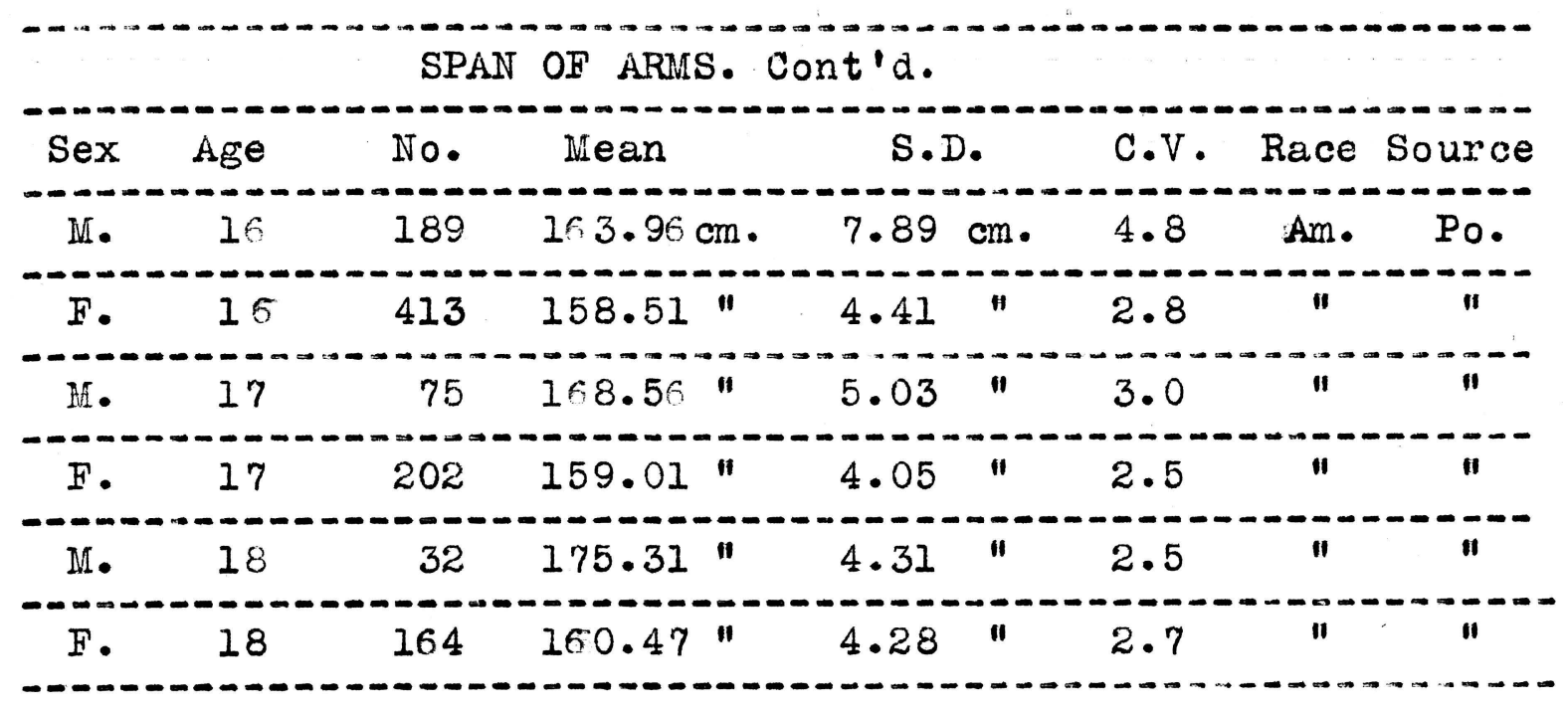

Galton and Pearson each furnish us with a series of adult English span statistics and both point to greater female variability.

On the other hand, in American children, the preponderance is on the side of the males when all ages are averaged. Again I find the older boys, ranging from 13 to 17 years inclusive, more variable, and the slightly greater female variability in the eighteenth year might be due to the fact that there were only 32 males measured. Girls are more variable at ages 6,7 , and 8 ; the sexes have equal variability at ages 9, 10, 11, and 12; and from 13 on to 17 the males are more variable. 
IONG-BONES.

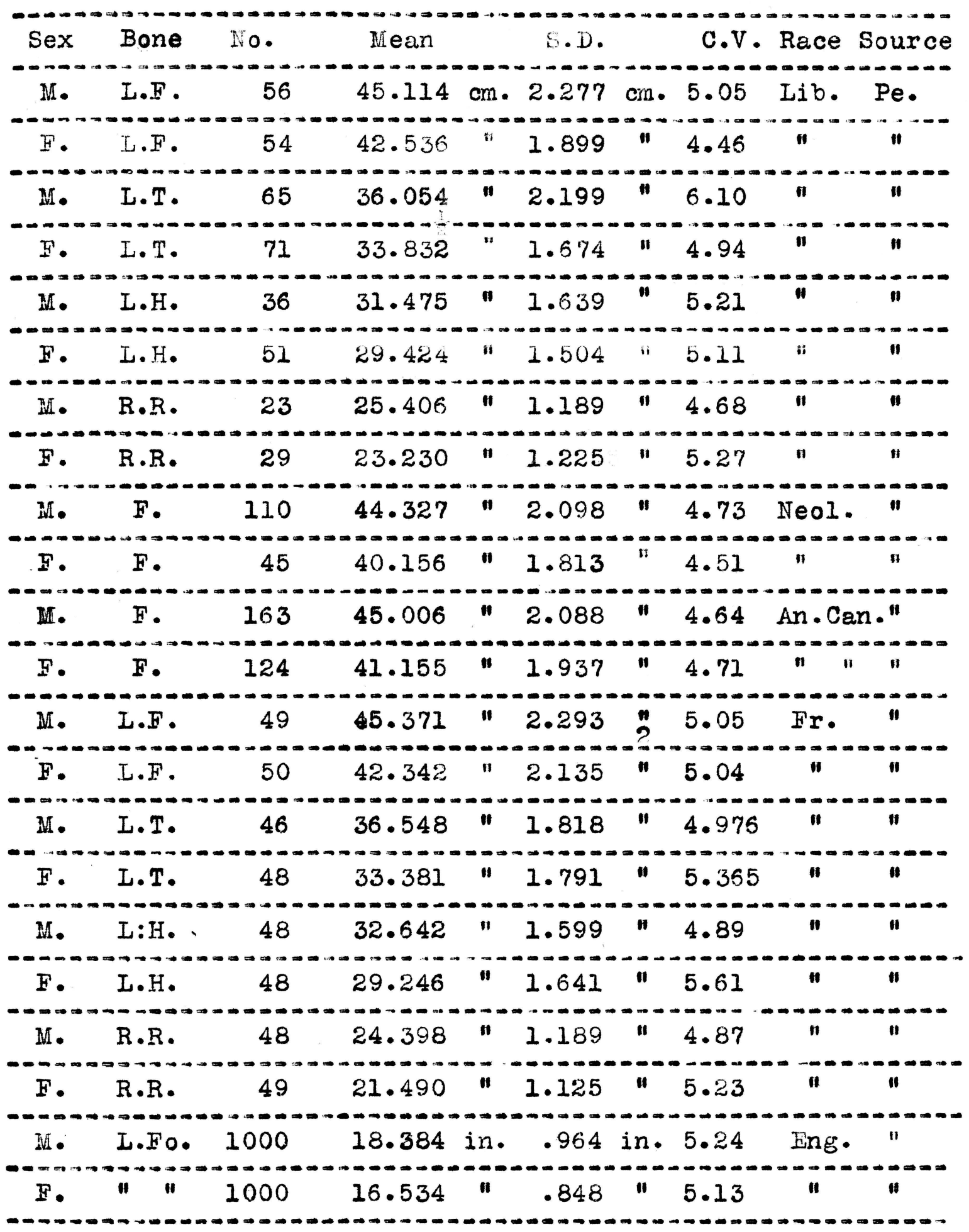


LONG BONES. Cont'd.

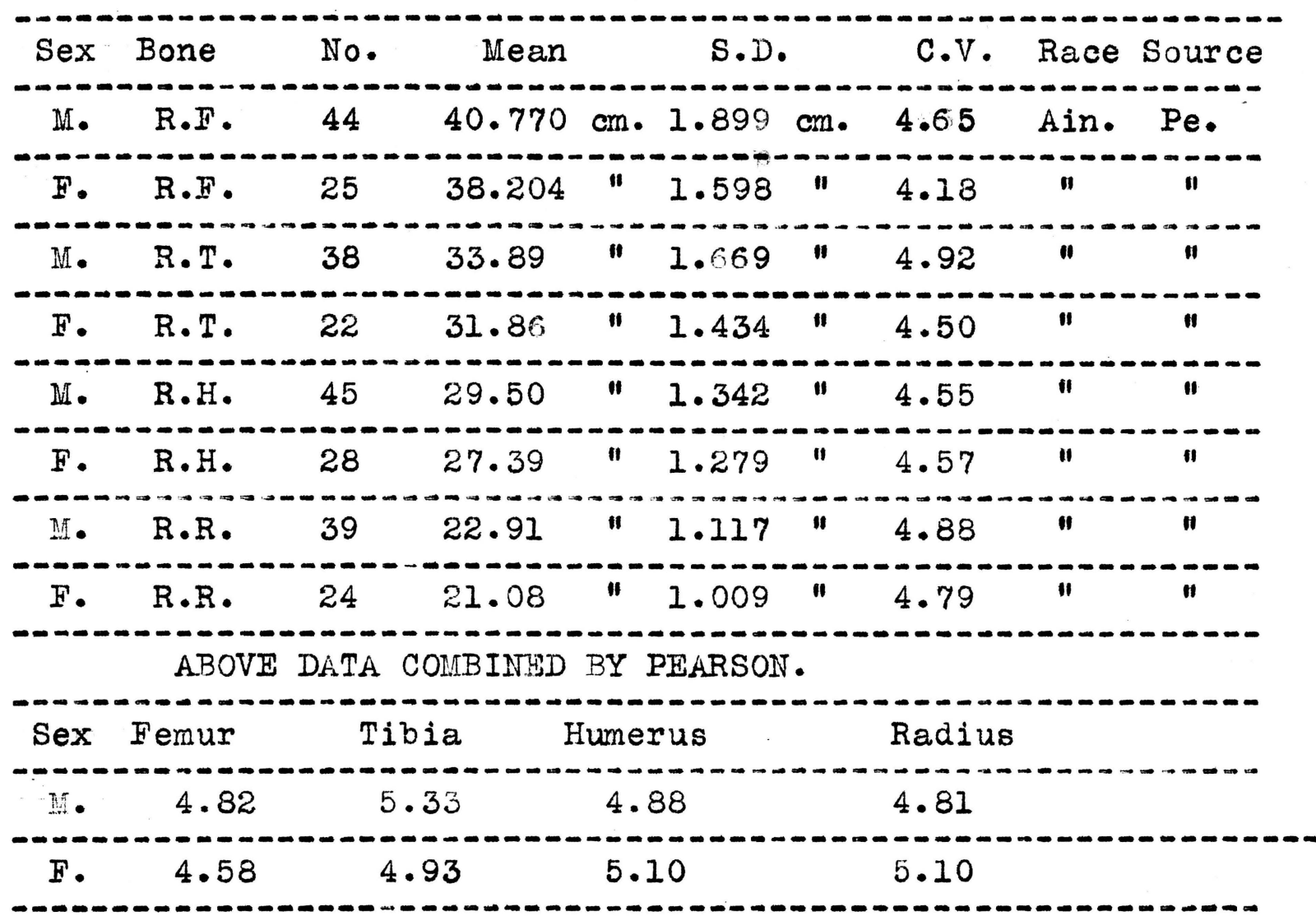

Professor Flinders Petrie took four hundred skeletons of the Libyan race, of $4000 \mathrm{~B}$. C. to England and Mr. E. Warren of University College, London, took a complete series of measurements of them. The latter permitted Karl Pearson to use the long-bone data in his essay on "Variation in Man and Woman".

The statistics for the femurs of Neolithic man and the inhabitants of the Canary Islands were obtained by Pearson from a paper by J. Rahon, "La taille prehistorique".

Dr. E. Rollet is responsible for the modern French measurements and the Japanese University of Tokio for those of the Aino race. Mr. Pearson has certainly gathered his material from sources far and near. His collection of Family 
Measurement Cards has furnished the English numbers.

In comparing all of these the femur measurements show greater variability for men in four cases, greater variability for women in one case and in the other, equal variability.

The radius and tibia statistics show the male more variable, and the humerus shows the preponderance on the side of the females. When the whole series is combined, we find greater male variability in the femur and tibia and greater female variability in the humerus and radius. In averaging the S. D.s of the four bone measurements the result for the male is 4.96 and that for the female 4.93. This indicates practically equal sex variability as far as these measurements are concerned. 


\section{WEIGHT.}

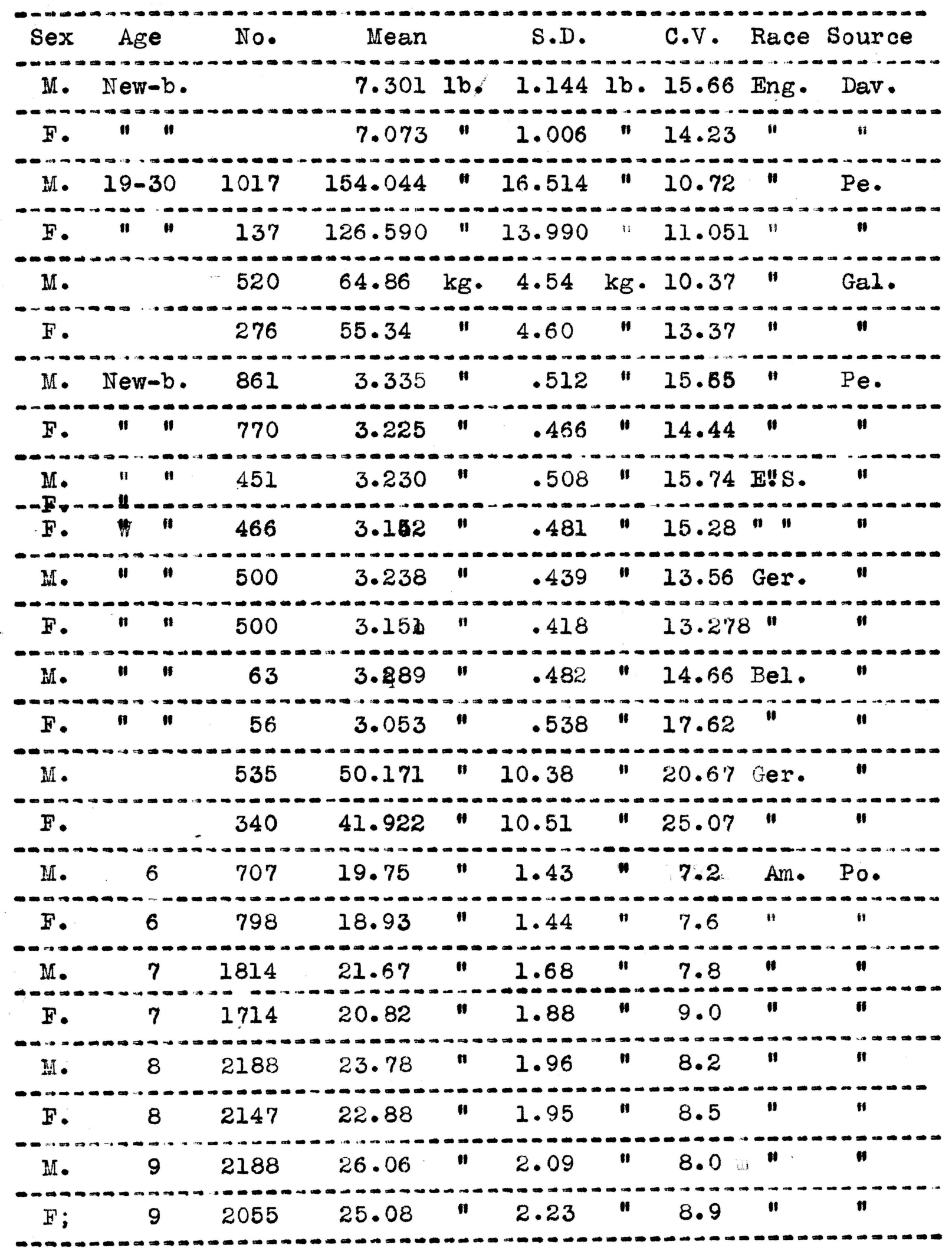


WEI GHT . Cont ' d.

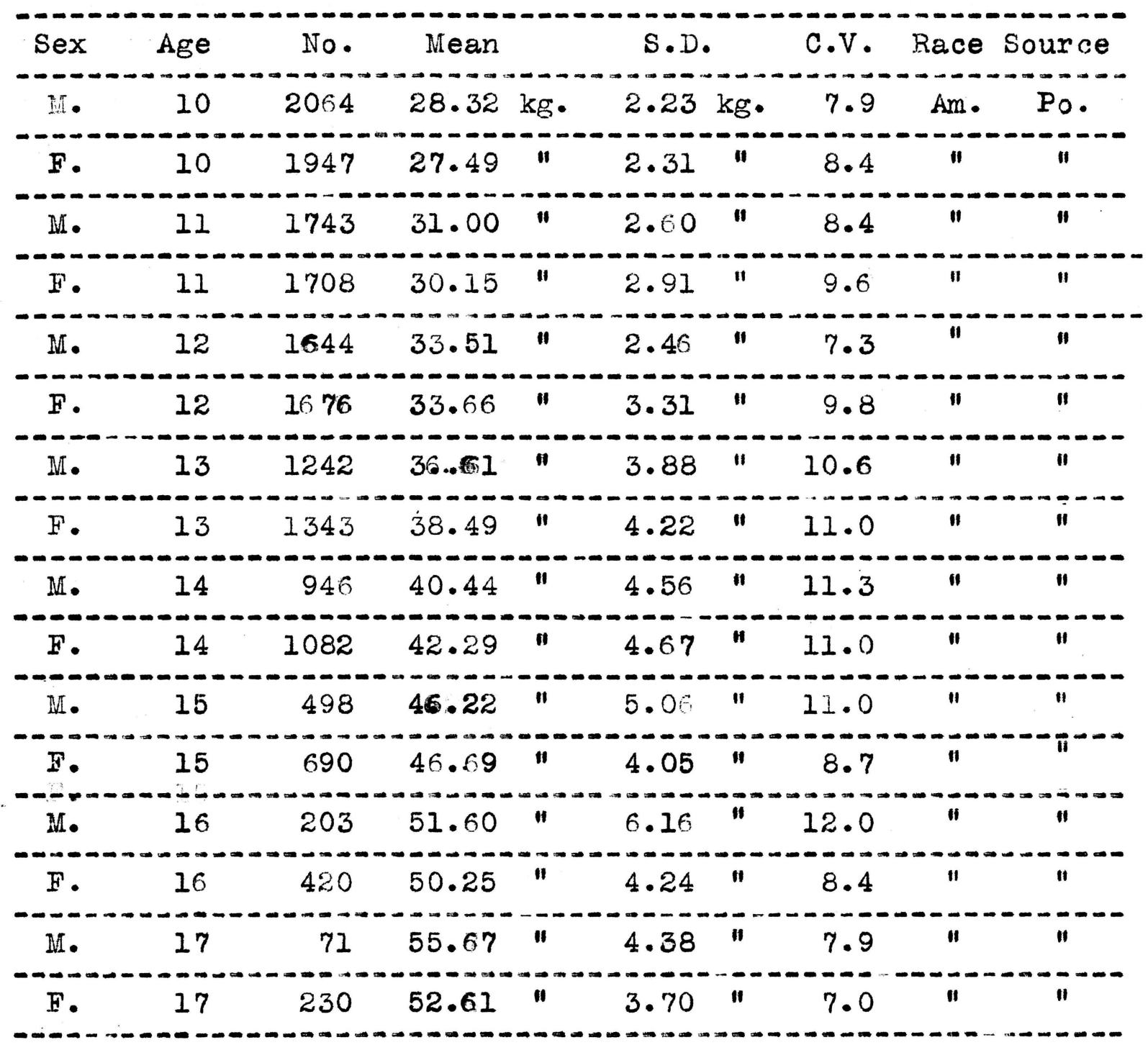

In weight we have four groups of data for new-born. The males are more variable in three out of the four groups. The conflicting group is so smell in comparison with the other three that it is not deserving of much consideration.

In averaging the $\mathrm{C} . \mathrm{V}$. of the various ages of American school children I find the girls more varisble by .02 of $1 \%$, but in considering the ages separately, I notice greater female variability in the eight earliest ages, equal variability at 15, and greater male variability in the next four ages. 
Summarizing weight statistics we find males more variable at birth; greater female variability from 6 to 14 years inclusive; preponderance for the males in ages 14 to 17 inclusive; and adult females more variable.

Therefore, we conclude that sex variability in weight is a matter of age, and no generalization can be made. 
IENGTH OF HEAD.

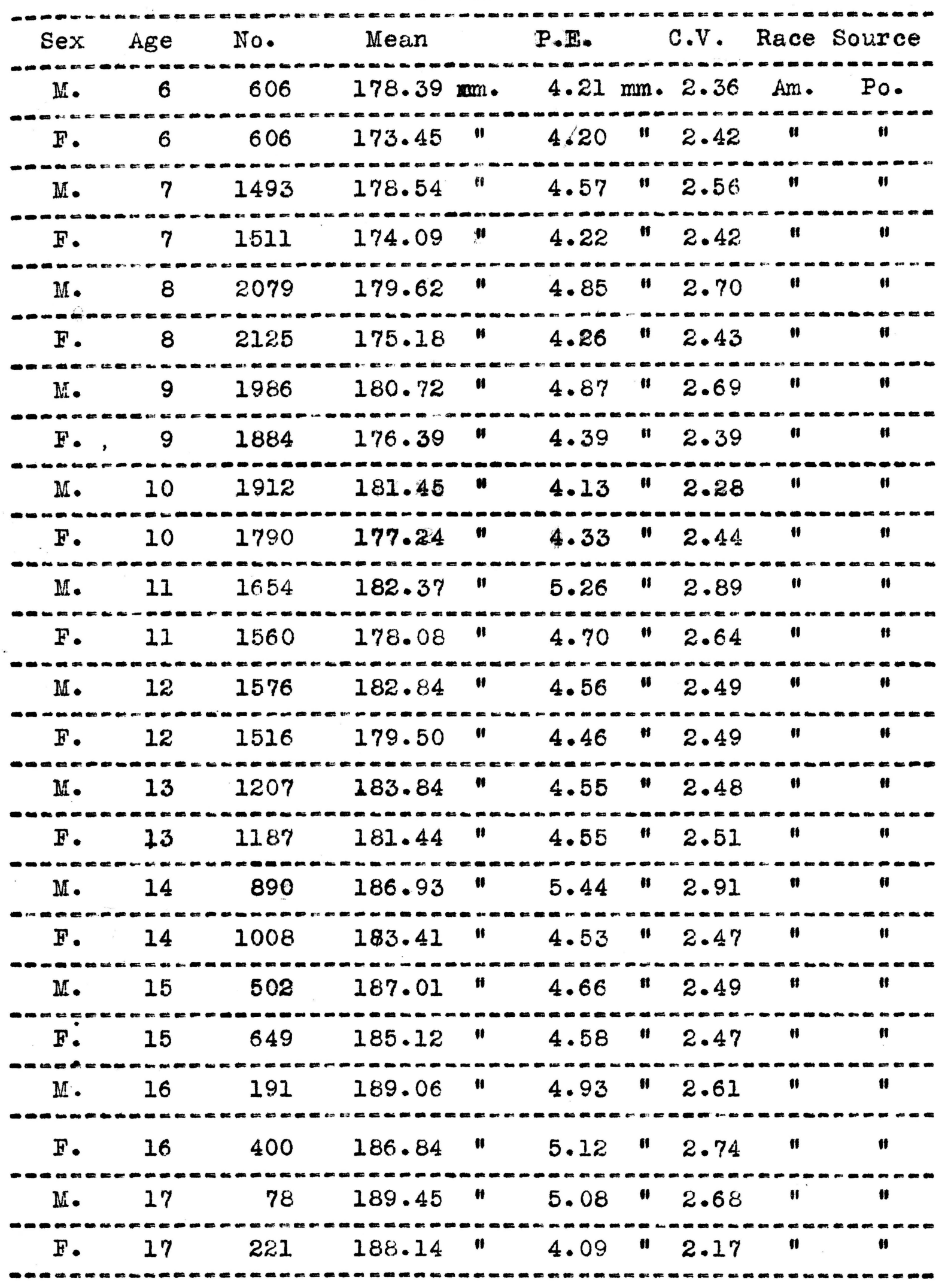


IWINGPH OF HEAD.Cont'd.

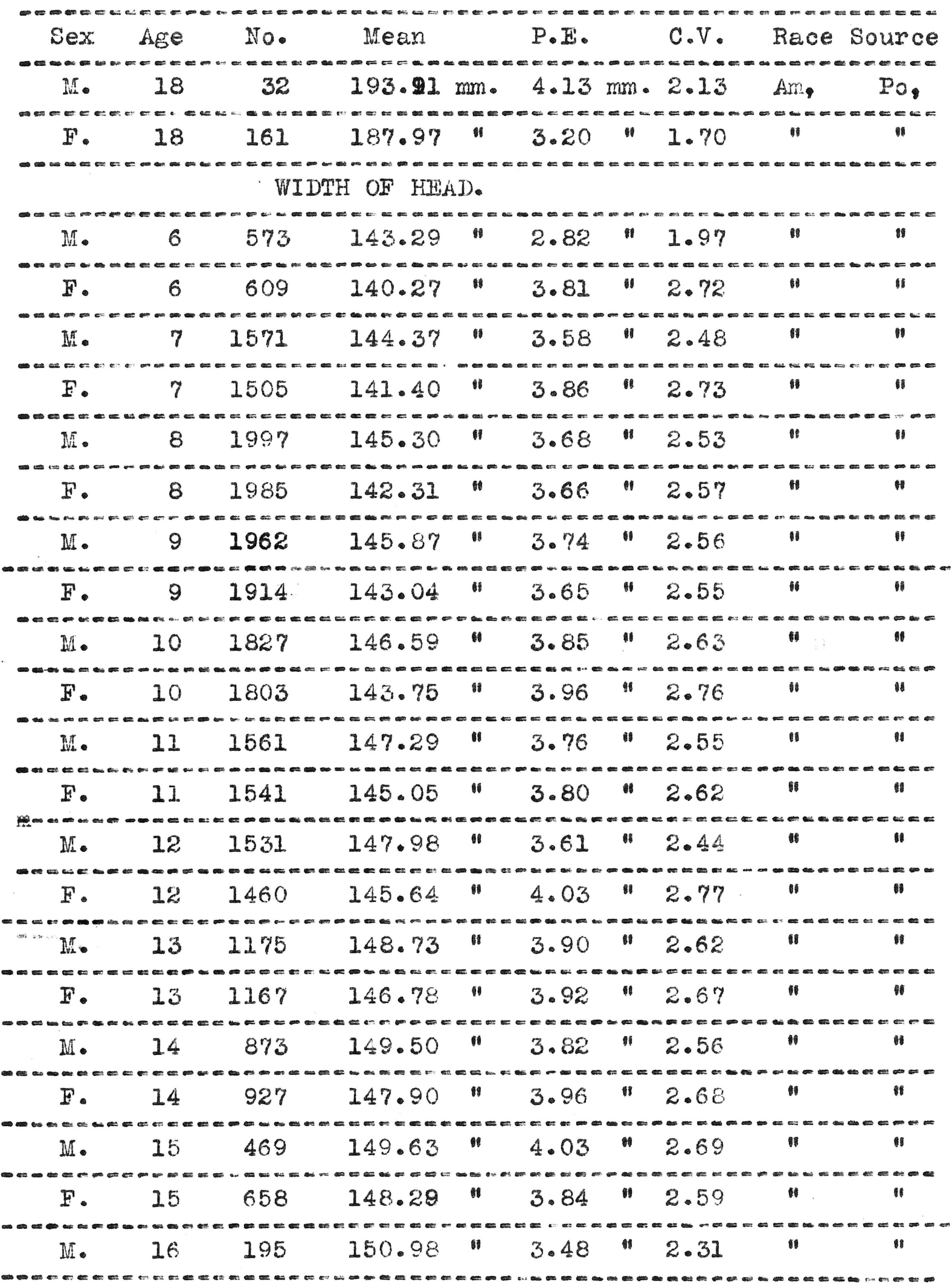


WIDTH OF HEAD. Cont'd.

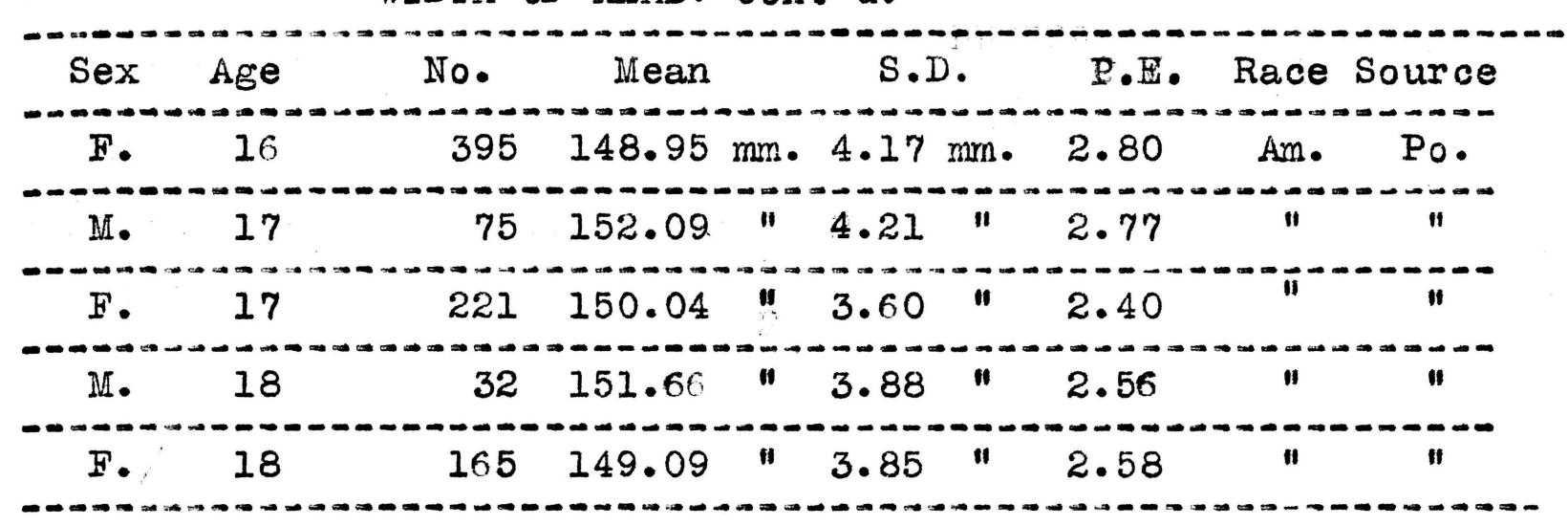

Porter, alone, has given us length and width measurements of the head, and here we find a peculiar condition.

In length of head the boys are noticeably more variable, their average being . 13 of $1 \%$ greater in both earlier and later ages. The opposite situation is found in wicth of head, the females being more variable by about .16 of $1 \%$. In considering these statistics age 18 was omitted in both measurements. 


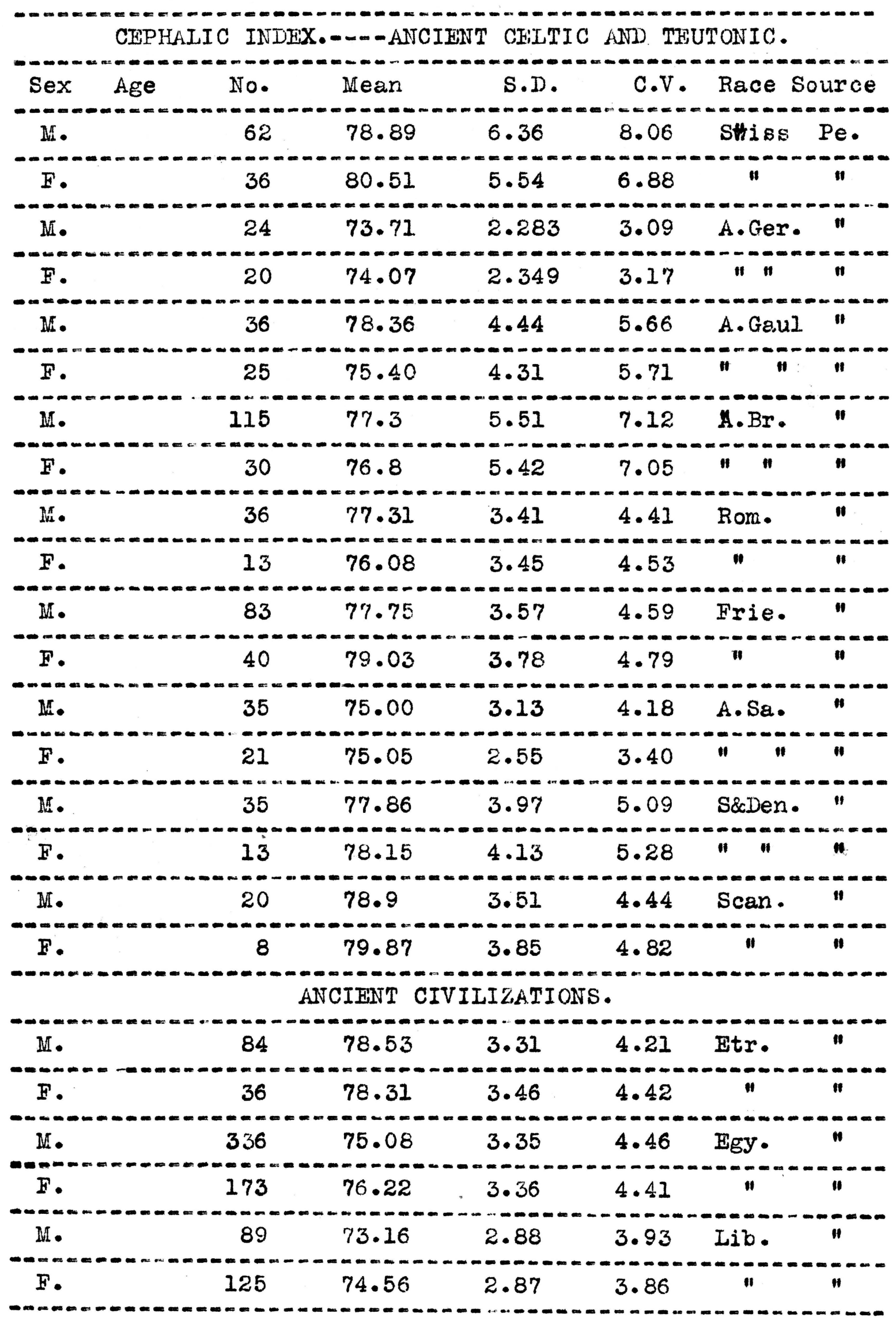


CEPHAIIC INDEX. ANCIENT CIVIIIZATIONS.COnt'd.

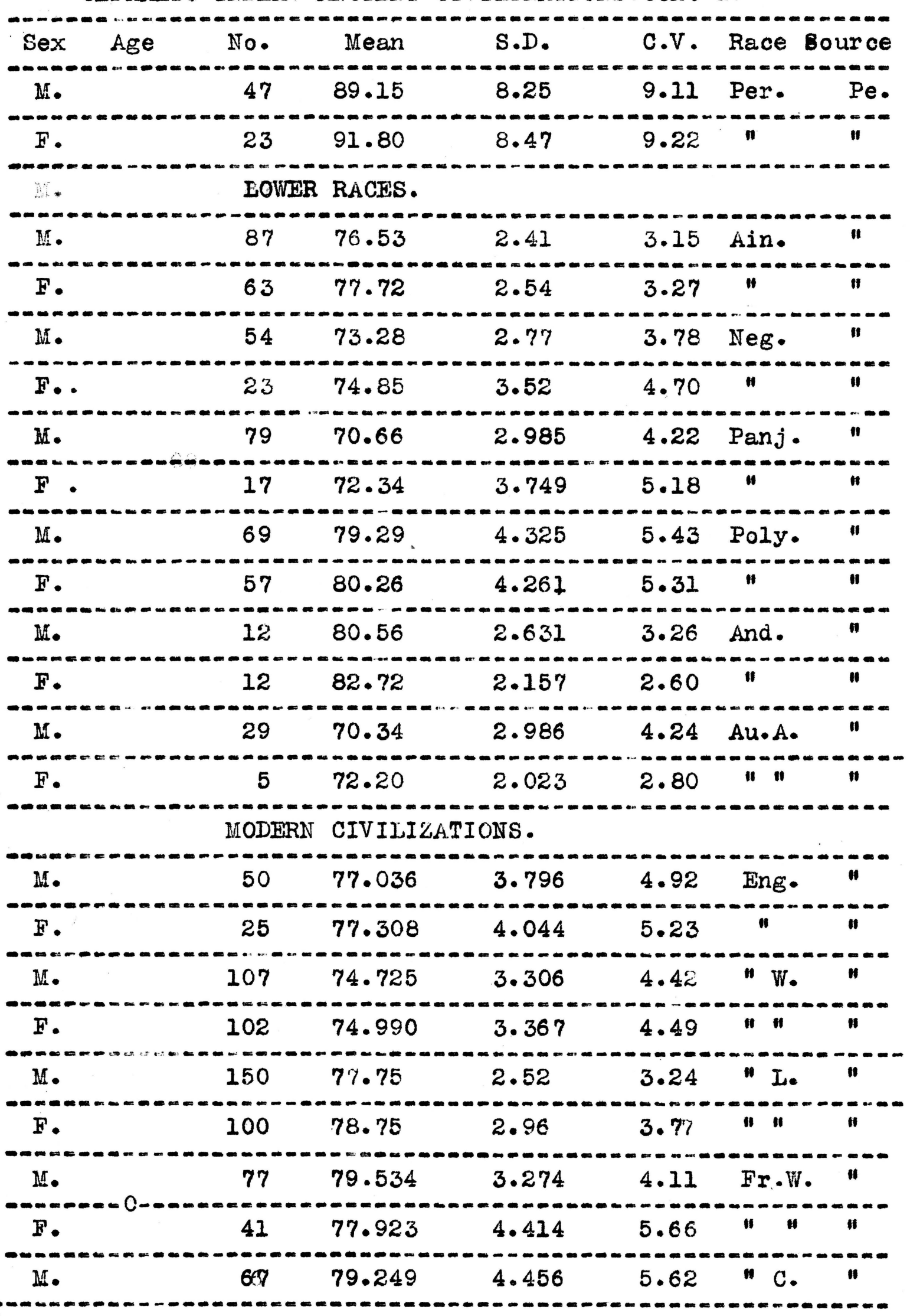




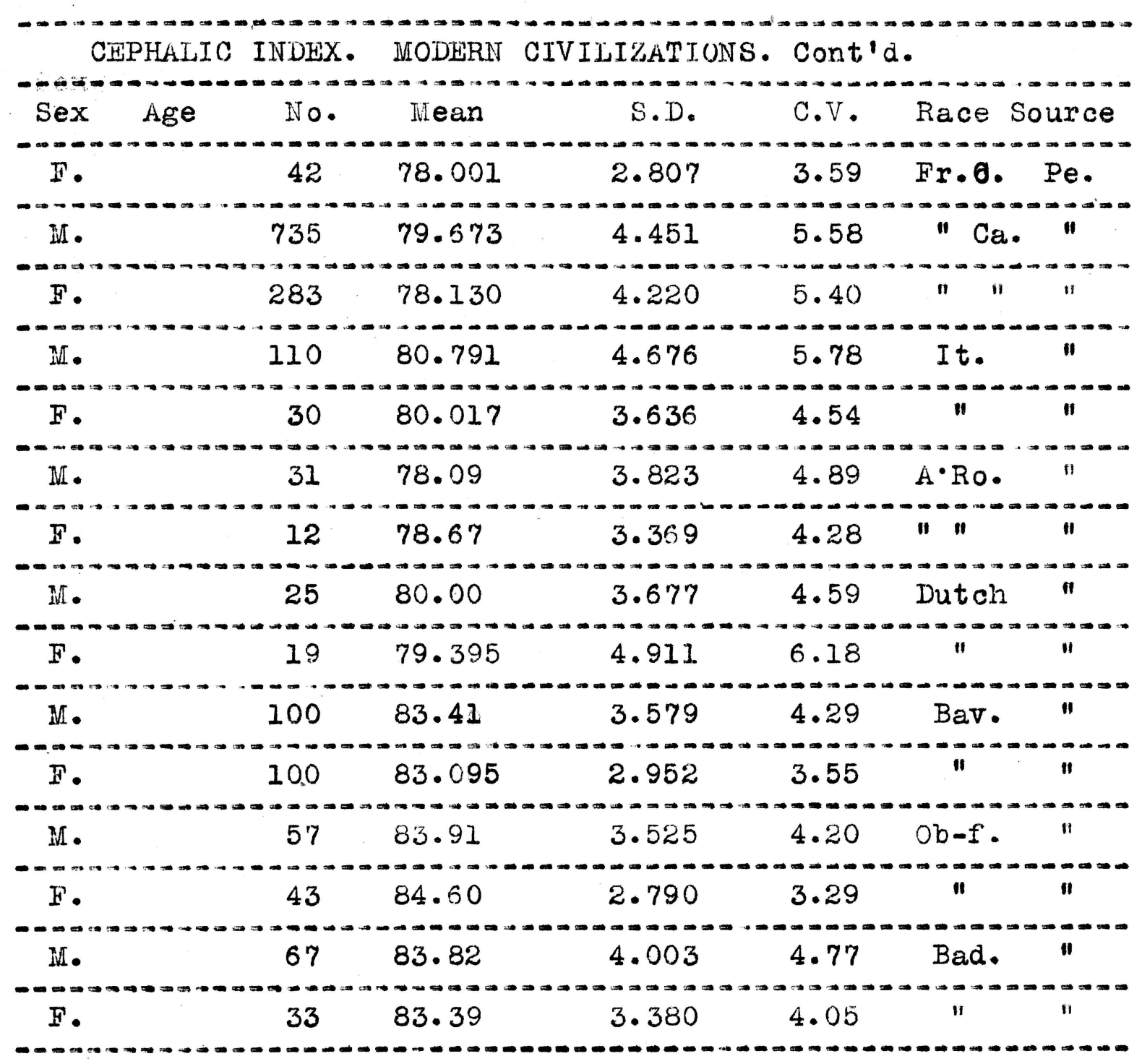

The great variety of sources from which the data on cephalic index were gathered makes it practically impossible to compare one race with another. Pearson divided it into four groups, namely: Ancient; Lower; Ancient Celtic and Teutonic; and Modern.

In the first, second, and third groups the number of races are divided about half and half as regards variability of the sexes. However, Pearson averaged the S. D.s for the various groups and found that of the female slightly greater than that of the male in all but the modern group. There the male was more variable. 
When the Engligh are considered separately the women are .33 of $1 \%$ more variable. The German series indicates greater male variability and the French does also.

Unfortunately Porter did not compute the cephalic index, in spite of the fact that he had the necessary head measurements, so we have no American data. Pearson worked out a formula by which he calculated this index from Porter's measures of mean length, mean width, and the probable deviations for boys and girls. He used only the ages $6,7,8,9$, and 10, and concluded that the girls were slightly more variable.

After surveying the complete table there seems no possible conclusion but the one of practically equal variability for the sexes if all series are given equal weight. 
SKULI CAPACITY.-.-. PRIVITIVE AND UNCIVIIIZED RACES.

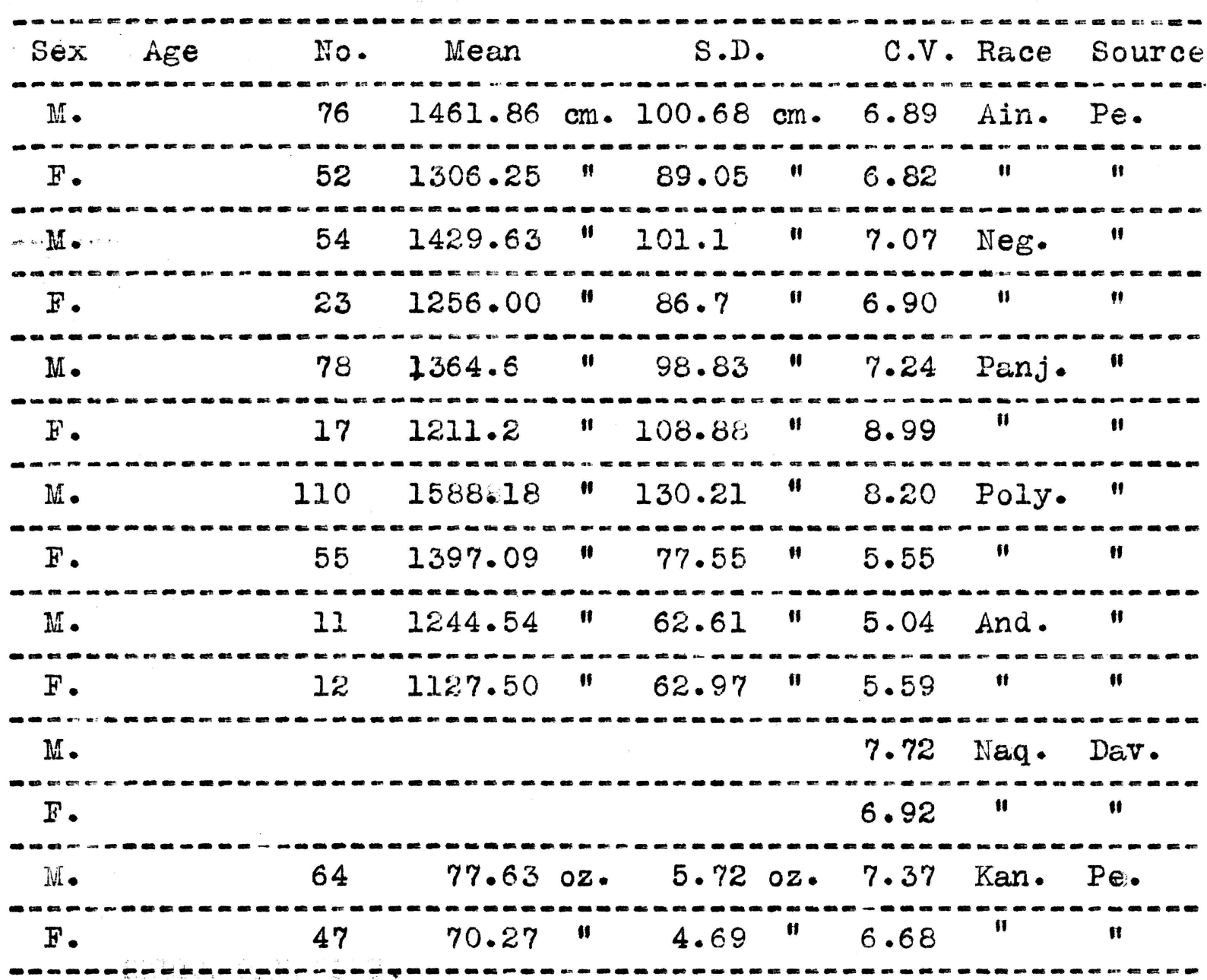

SKULI CAPACITY.--FOREATHERS OF ENG.,FR • AND GERMANS.

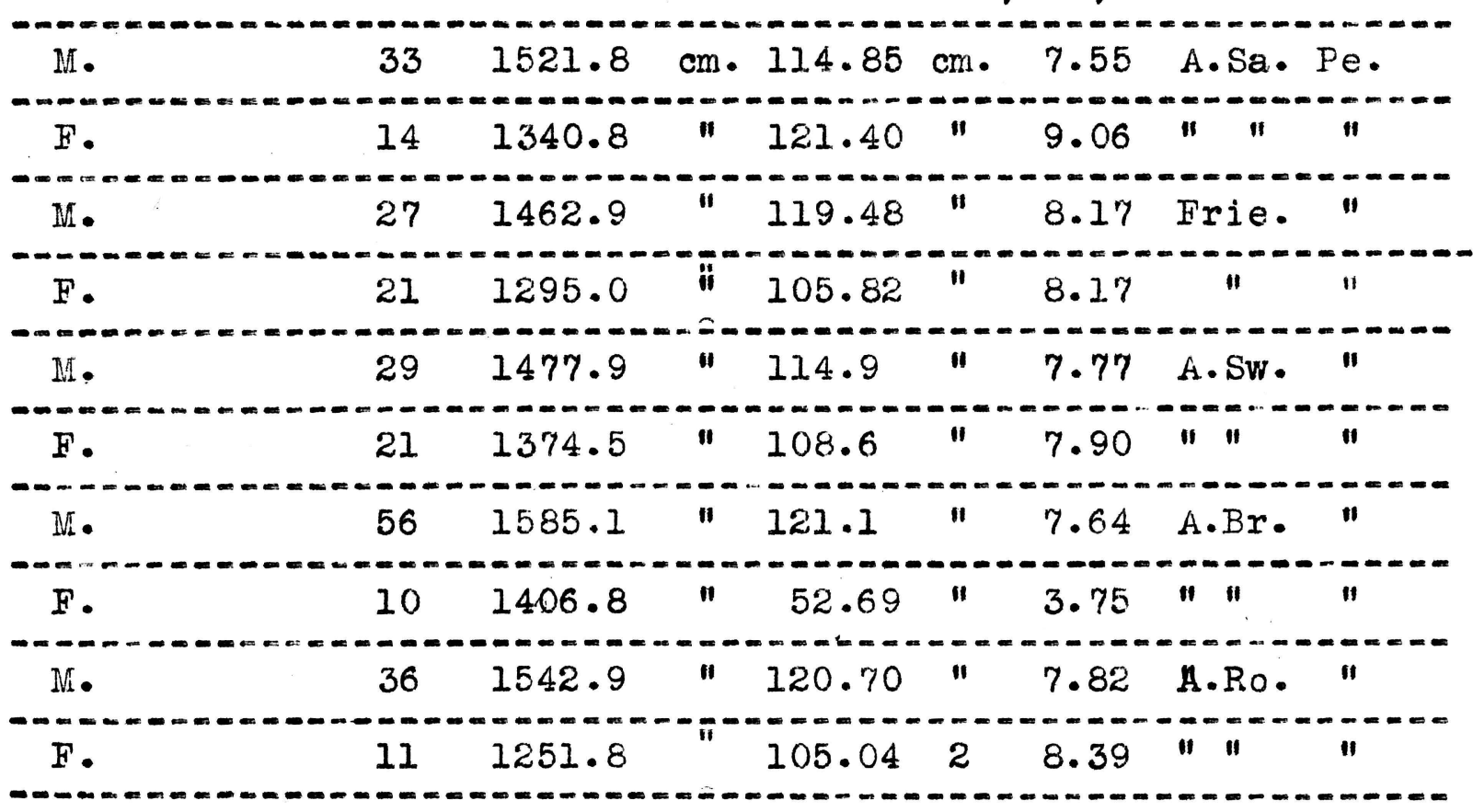




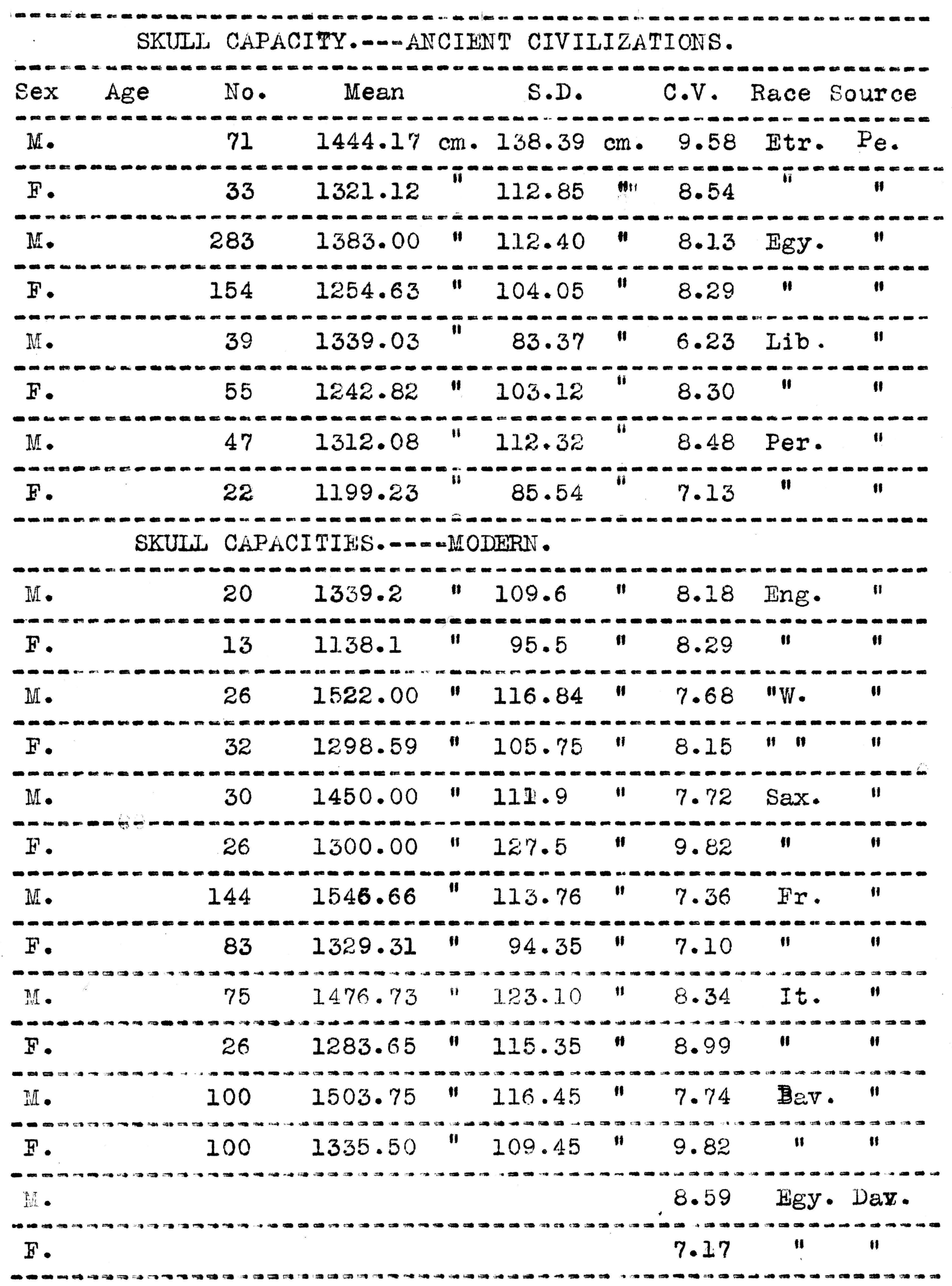


In skuld capacity, as in cephalic index, we have a wide ronge of sources from which the statistics were obtained. The races are divided into four groups:-Ancient; Primitive and Uncivilized; Forefathers of modern English, Germens and French; and Modern Civilizations.

In the Ancient group there are as many races showing greater male variability as female, but the series with the greatest number of subjects falls on the side of greater female veriability

The Primitive and Uncivilized group has six for and one against greater male variability. The Forefather group shows the contrary condition with all on the side of greater female $\operatorname{varicbility.~}$

Turning to the Modern group it is possible to combine several series because they are of the same race. The wornen are more variable in the English, German and Italian groups, while the men are more so in the French and nodern Egypticn groups.

No definite conclusion is possible with this mass of inextensive, unreliable and contredictory data, but I believe I may safely say that it points toward equal sex variability. 


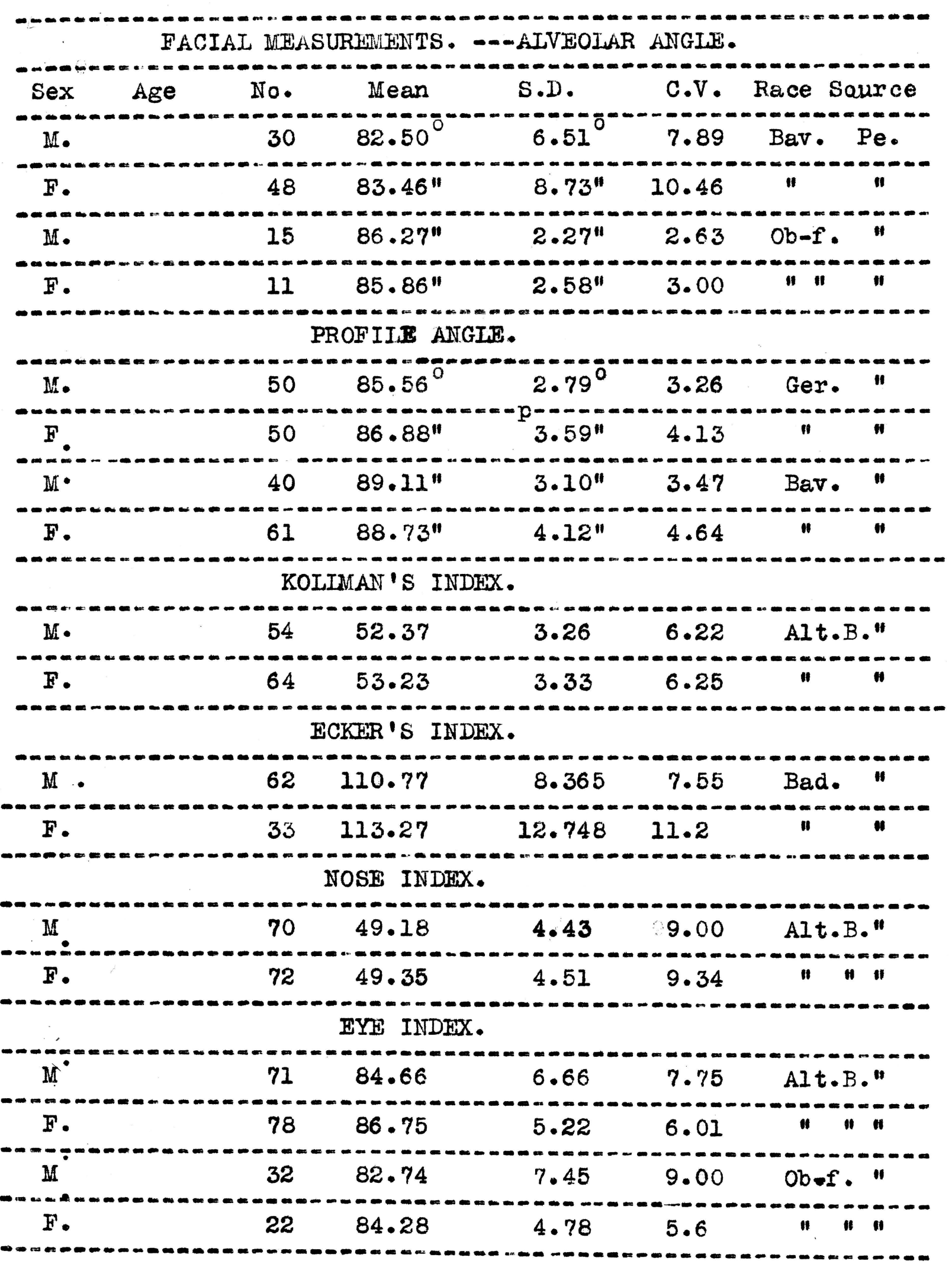


FACIAL MEASUREMENTS--EYE SOCKETS.

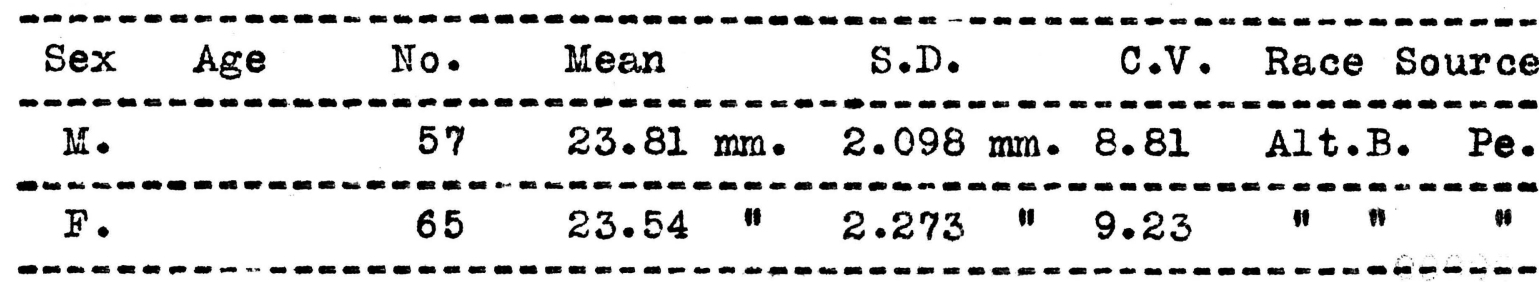
FOREHEAD-BREADTH INDEX.

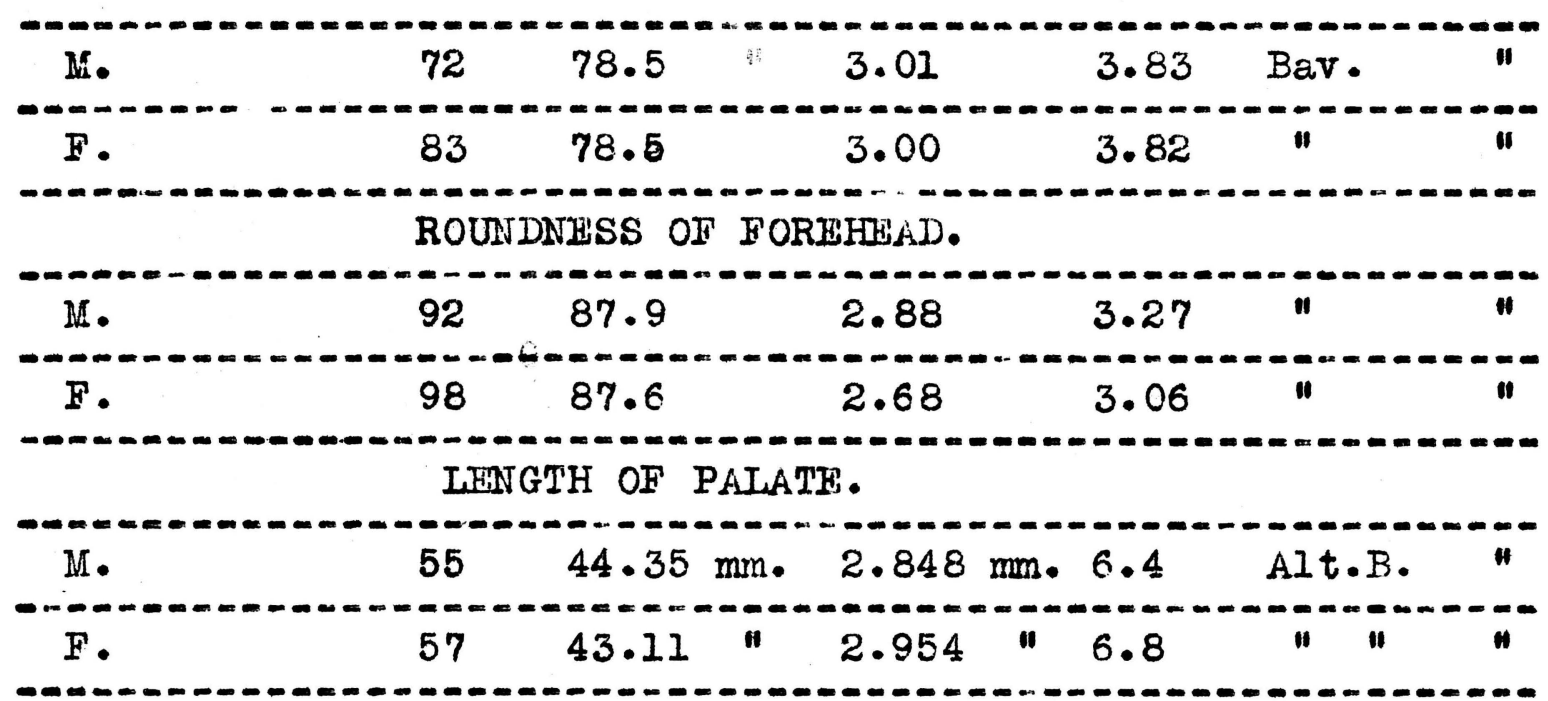
HEIGHT OF FACE FROM ROOT OF NOSE TO POINT OF CHIN.

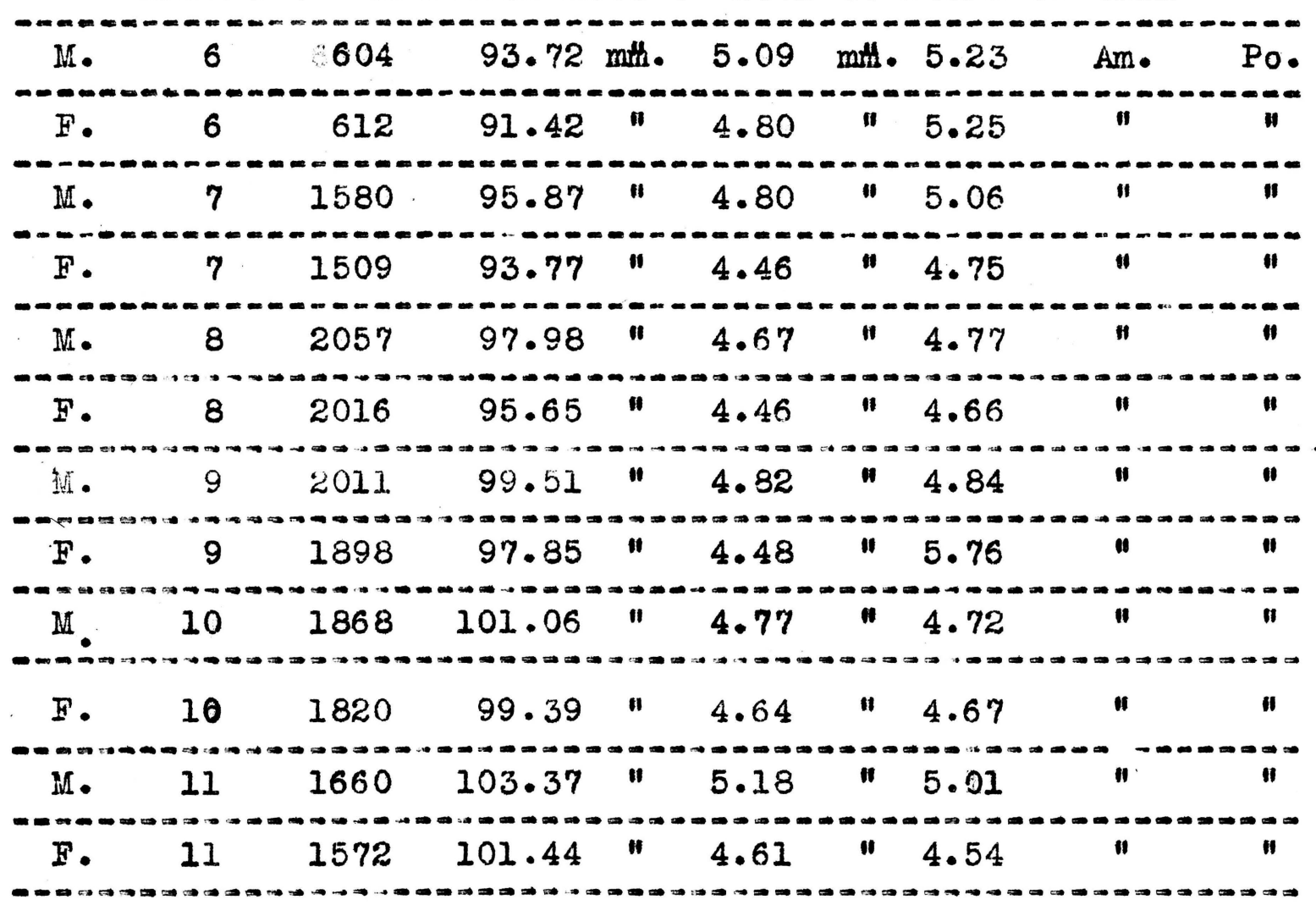


HEIGHT OF FACE EROM ROOT OF NOSE TO POIN OF CHIN. Cont'd.

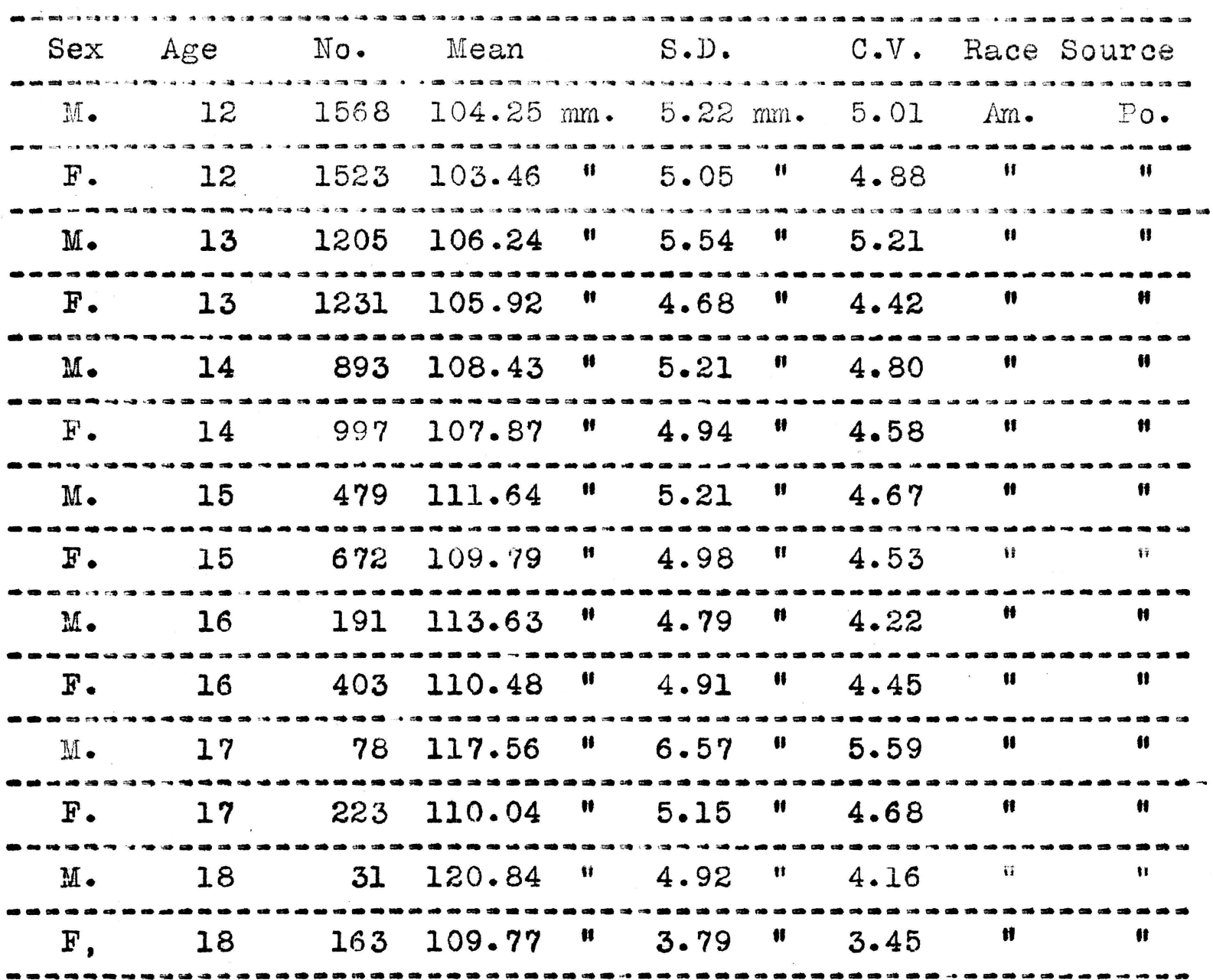

-. HEIGHT OF FACE FROM HAIR-IINE TO POINT OF CHIN.

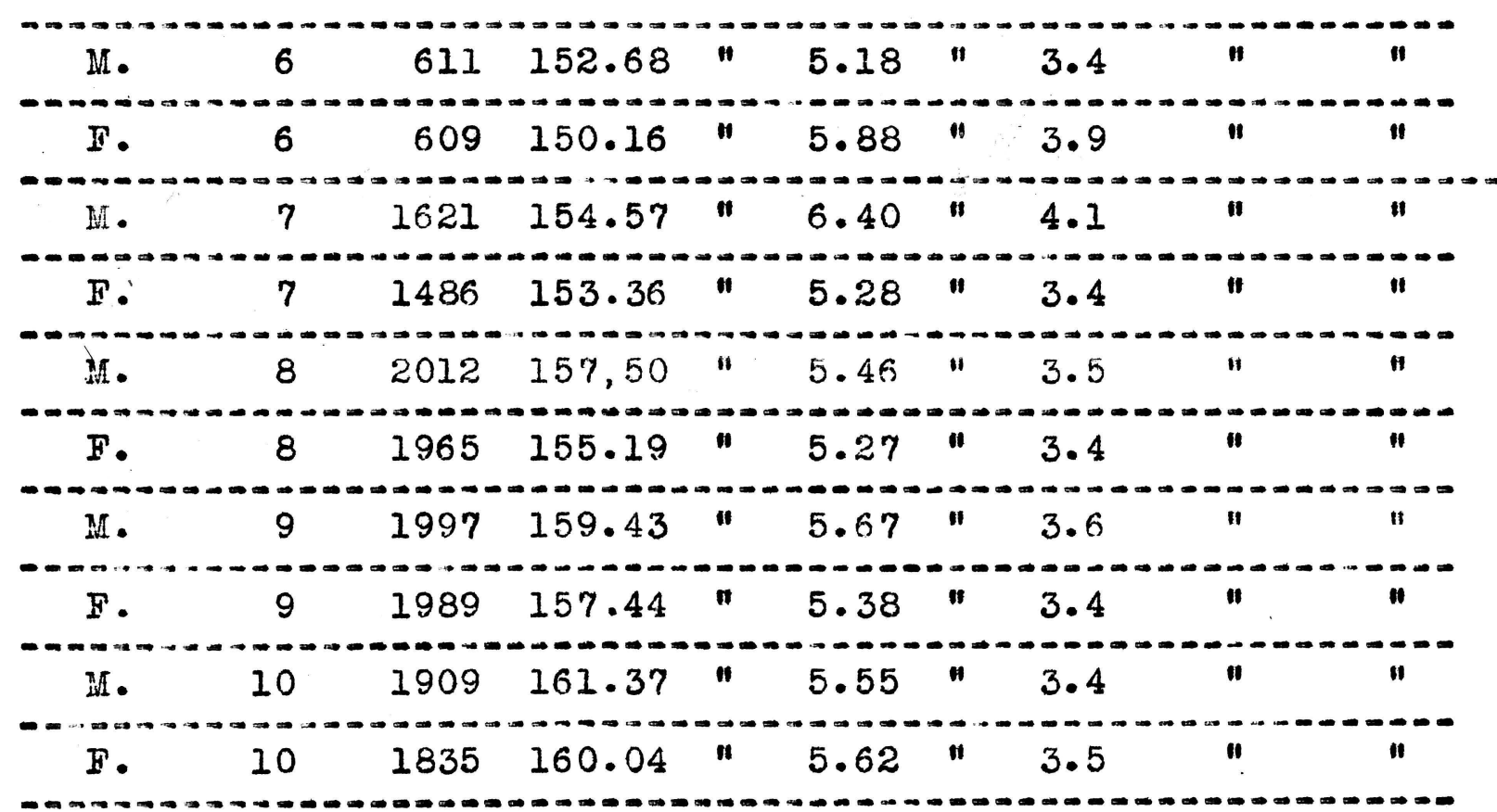


HIGHT OF FACE FROM HAIR-IINE TO POINT OF CHIN. COnt'd.

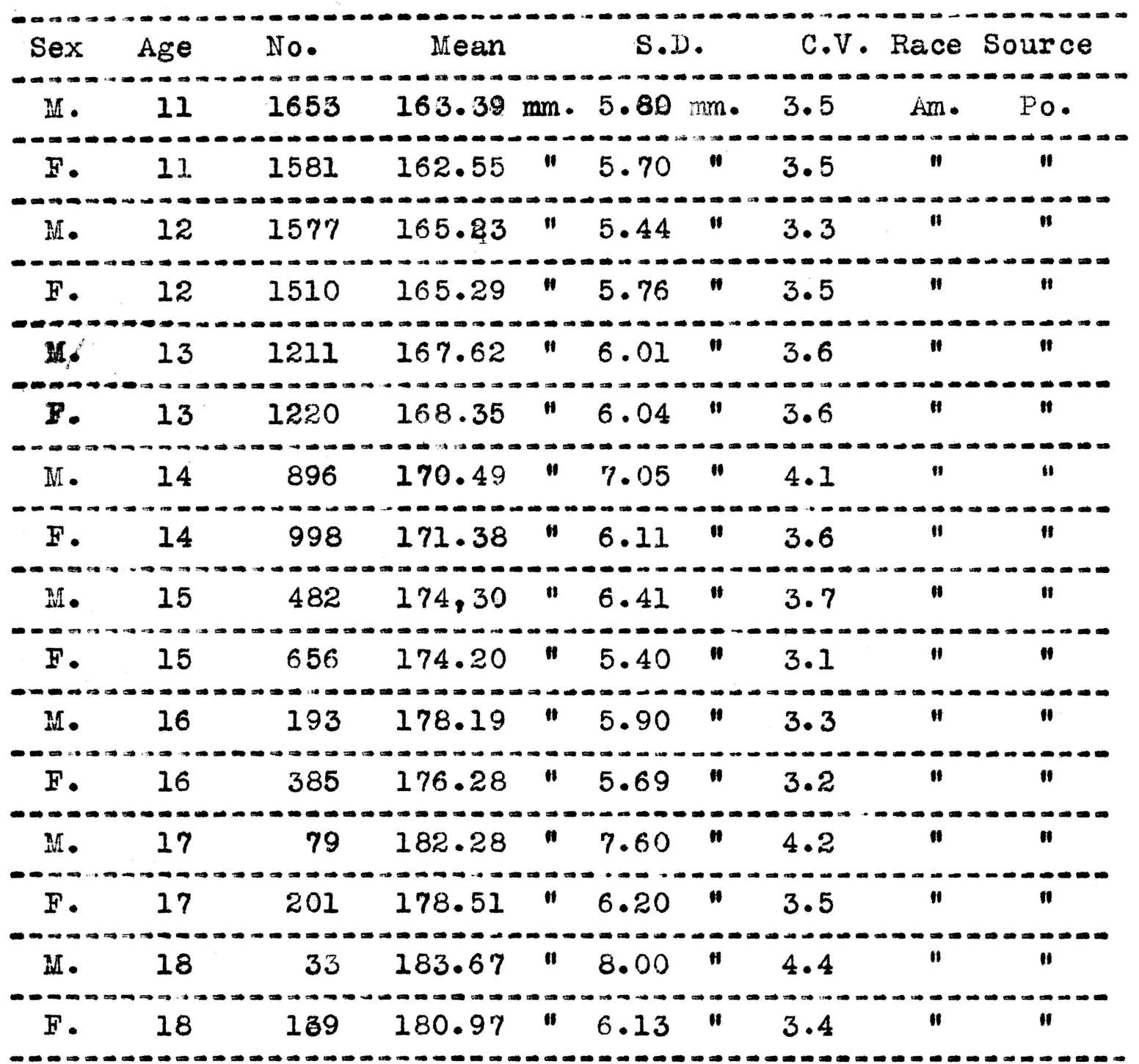

WIDTH OF FACE.

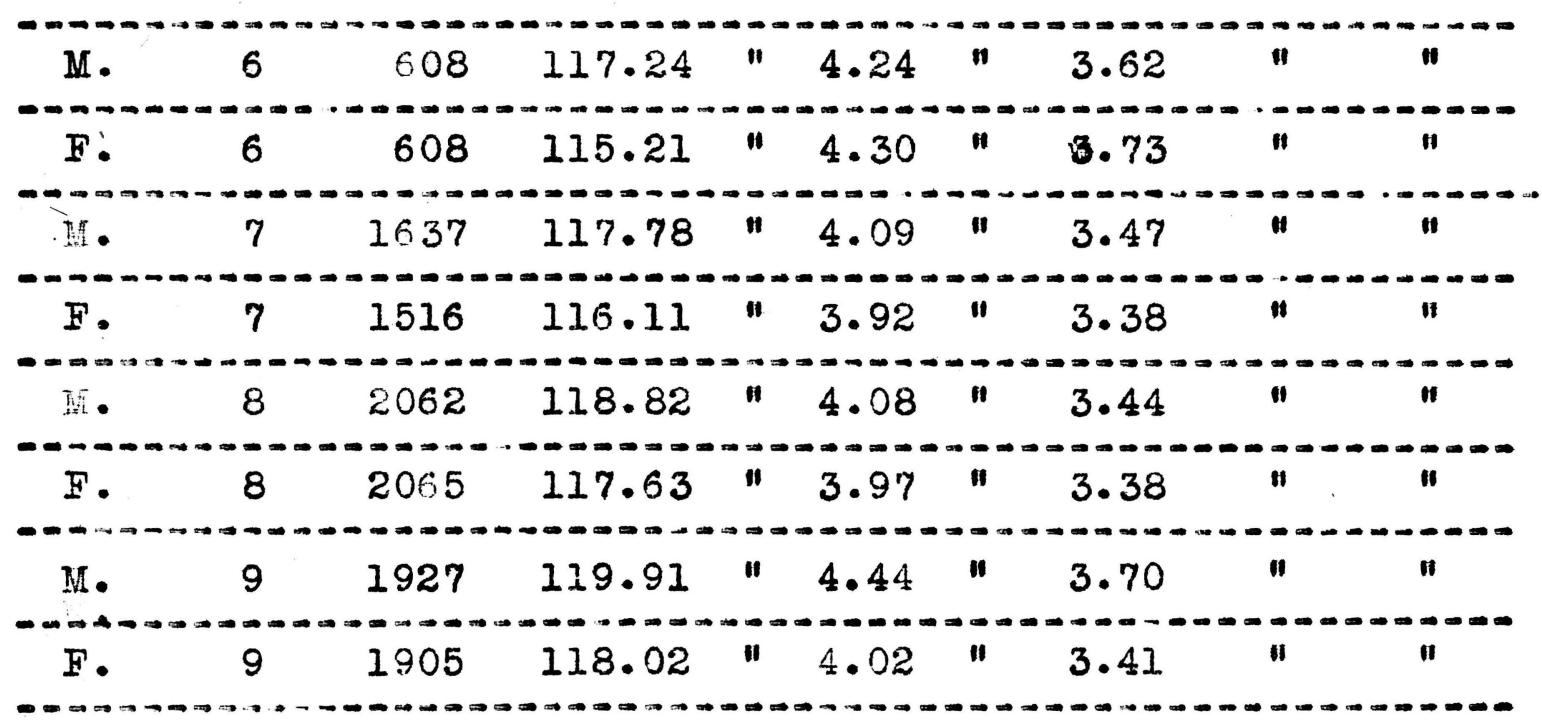




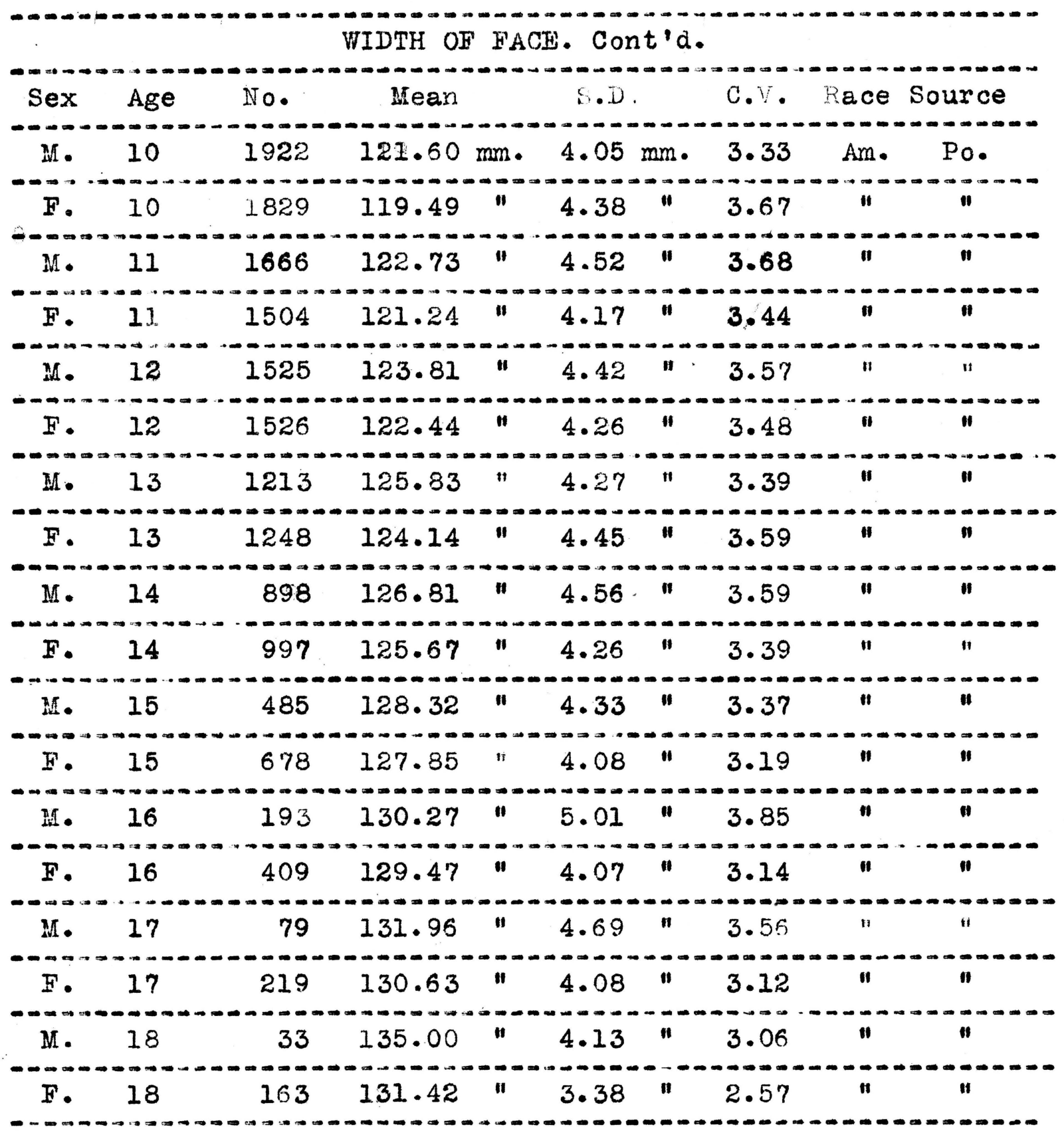

The table is the best sumnary here because of the many different measures discussed. In the snaller series the males show greater variability on only three out of the nine groups. In the more extensive studies on the height and width of the face by Porter, the nales show a significantly greater variability in all three series. 


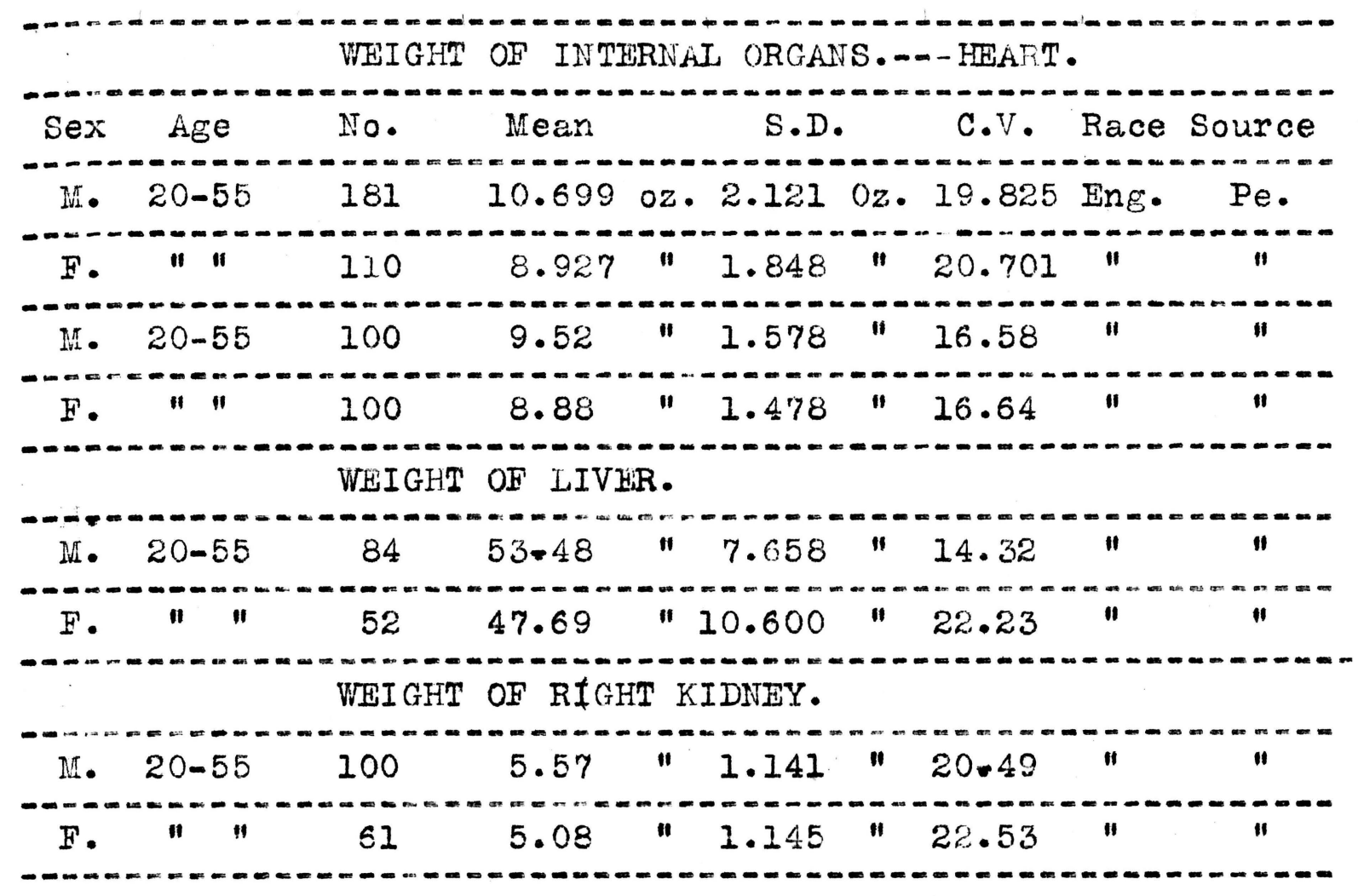

The above date were obtained by Pearson from the postmortem examinations conducted by Reid and Peacock.

The first heart series was formed by combining the measurements of Reid and Peacock and we find the women more variable in spite of the fact that the $S$. D. for the men is greater. The second series is that of Peacock in which a.II hearts weighing over 12 ozs. are considered unhealthy, and are therefore omitted. The preponderance of variability remains on the side of the women although the same relation exists in the S. D.

In the case of the liver and the right kidney the women are more variable, so there is a deciced contradiction to the theory of greater male variability in these three measurements. 


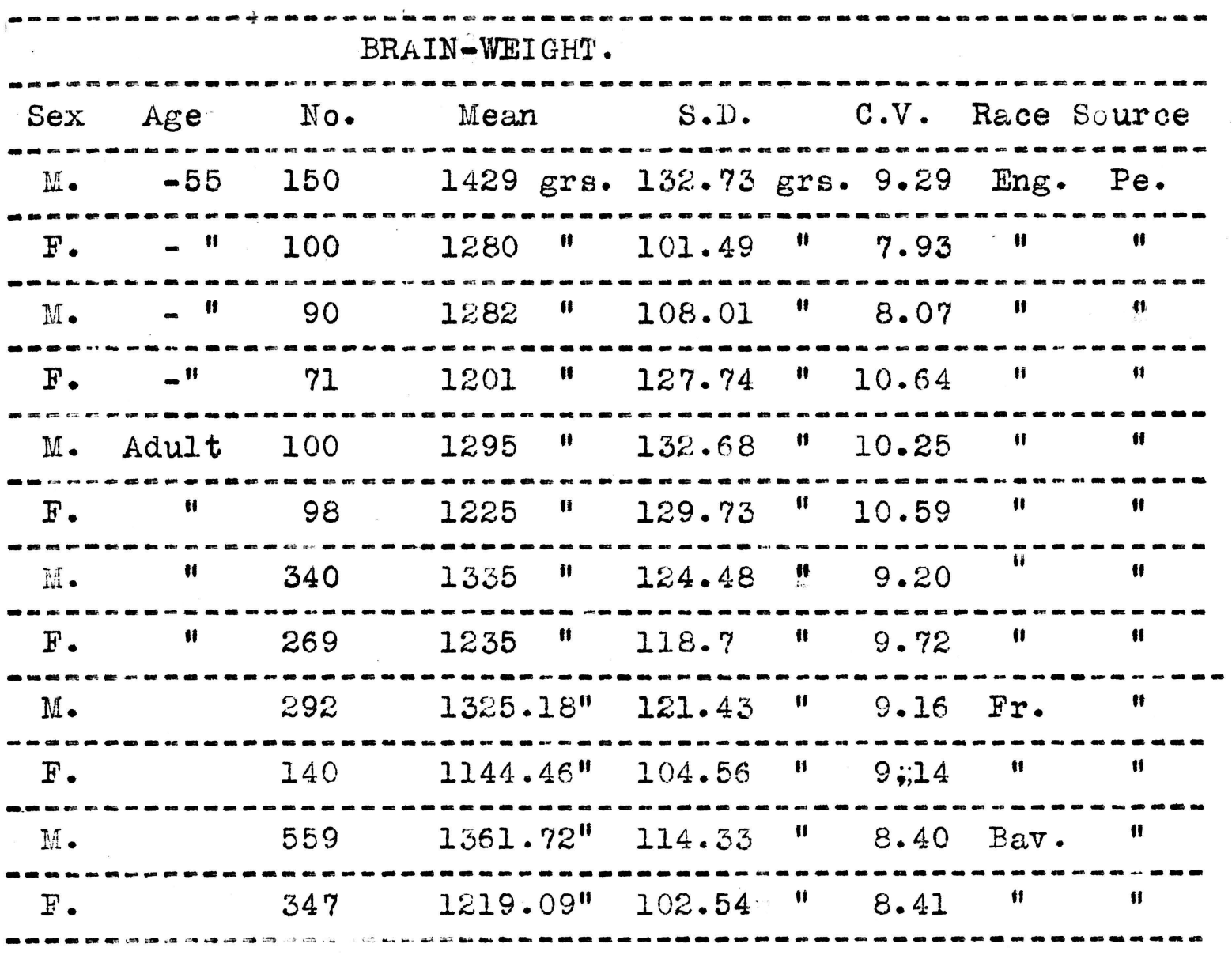

Very limitedtrustworthy data on the brain are avajlable, but Pearson has combined that of Reld and Peacock to make the first comparison, indicating that the male brain is more variable. When he considered clendinning's, he found the female more variable, so he turned to Sim's statistics to decide the matter. Here he found the females again showing greater variability and the same was true when he combined the three serieg. However the difference was not great.

In both the French and German data there was almost equal variability, and one may easily conclude with Pearson that Professor Marshall was mistaken when he determined that the male brain was the more variable. The latter draws his conclusions after studying Boyd's tables of brain measurements. 


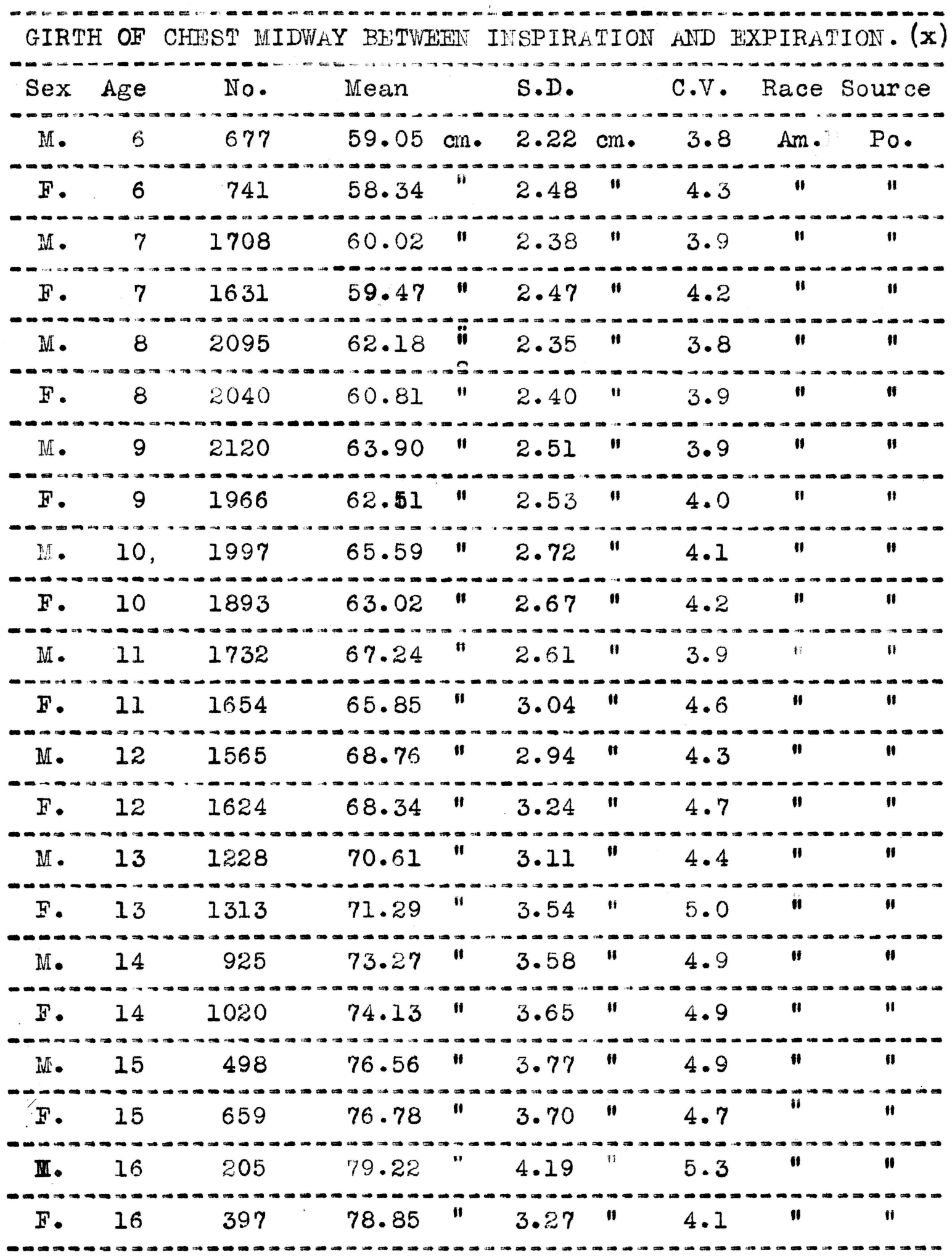

(x) Measurement of chest at full expiration added to measurement at $f \dot{m} l l$ inspiration and the result divided by tro. 
GIRTH OF CHEST. COnt'd.

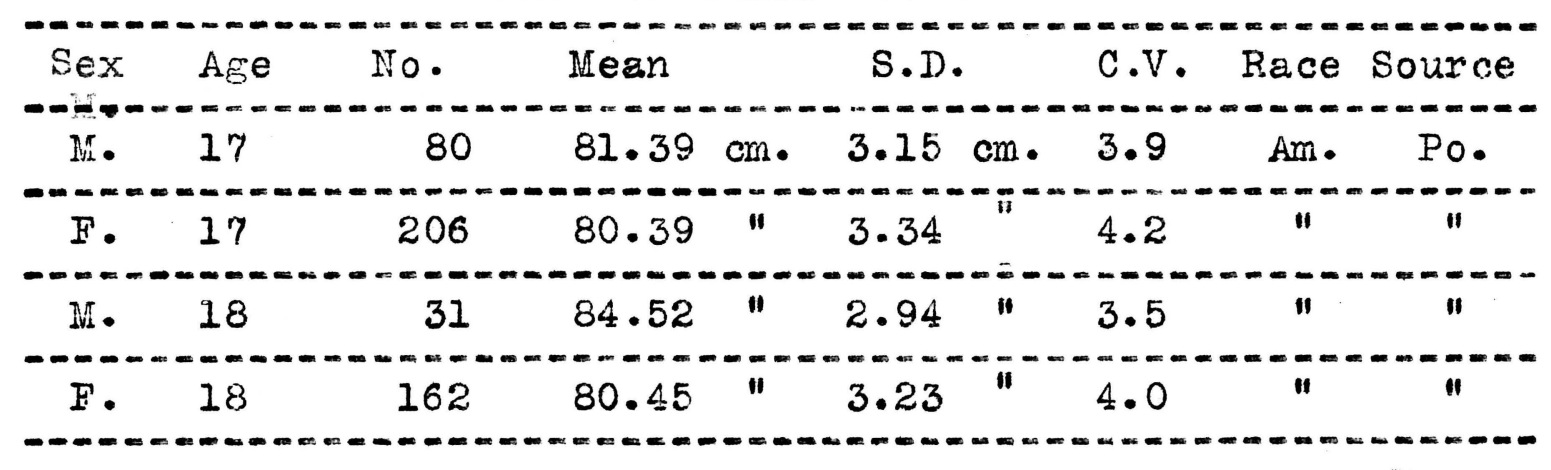

Again the only statistics we have for this measure are those of Porter and they indicate a slight preponderance of variability on the side of the girls both in the average of the C.V. s. for all ages and in the number of ages in which the girls are more variable, the ratio being 10 to 2 in favor of the girls with one case of equal variability.

Considering the ages separately the female is more variable in ages 6 to 13, there is equal variability at 14, and greater male variability at 15 and 16 . The females again are more variable at ages 17 and 18, but there are much fewer male measurements at these two last ages. 


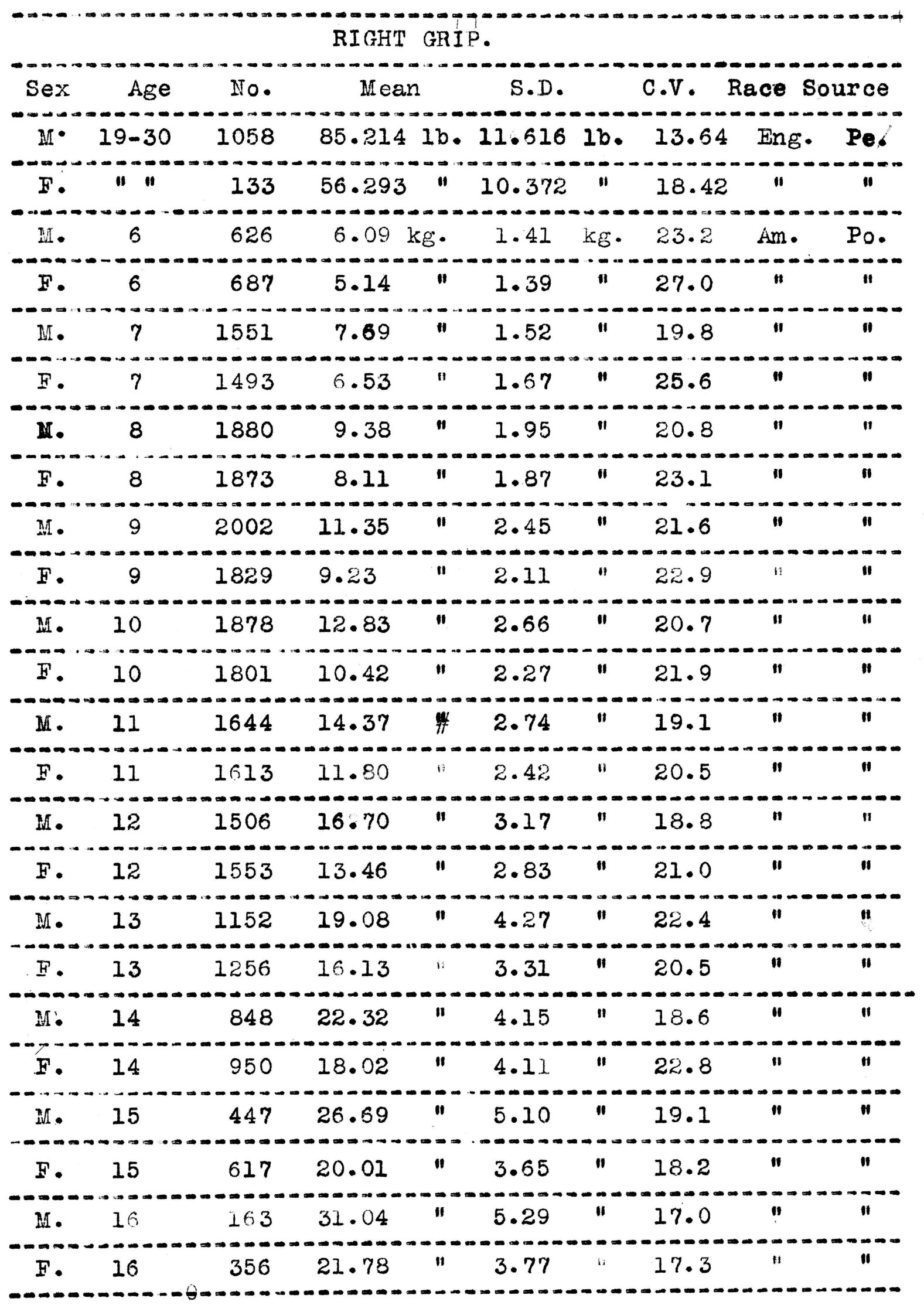


IEFT GRIP.

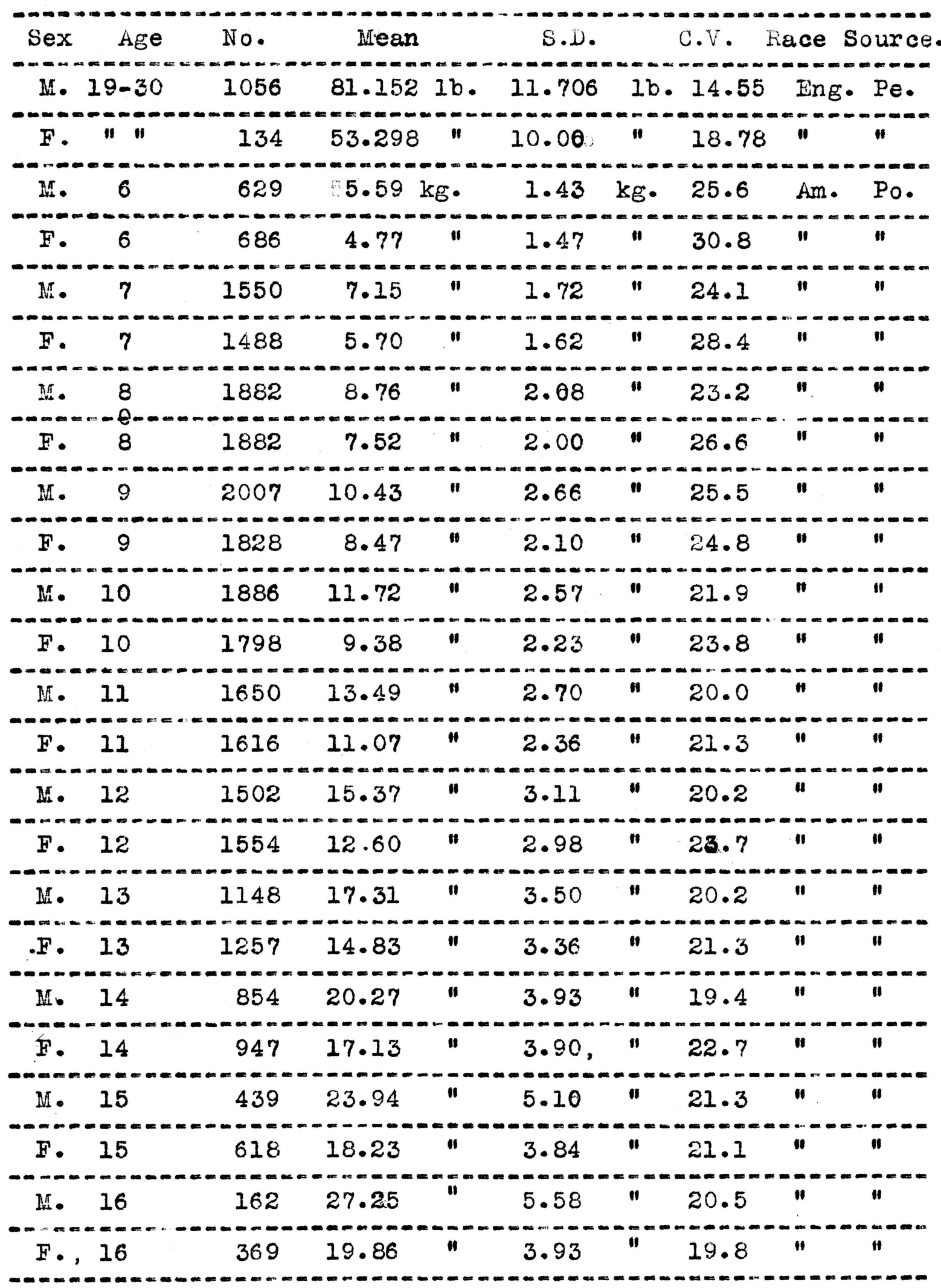




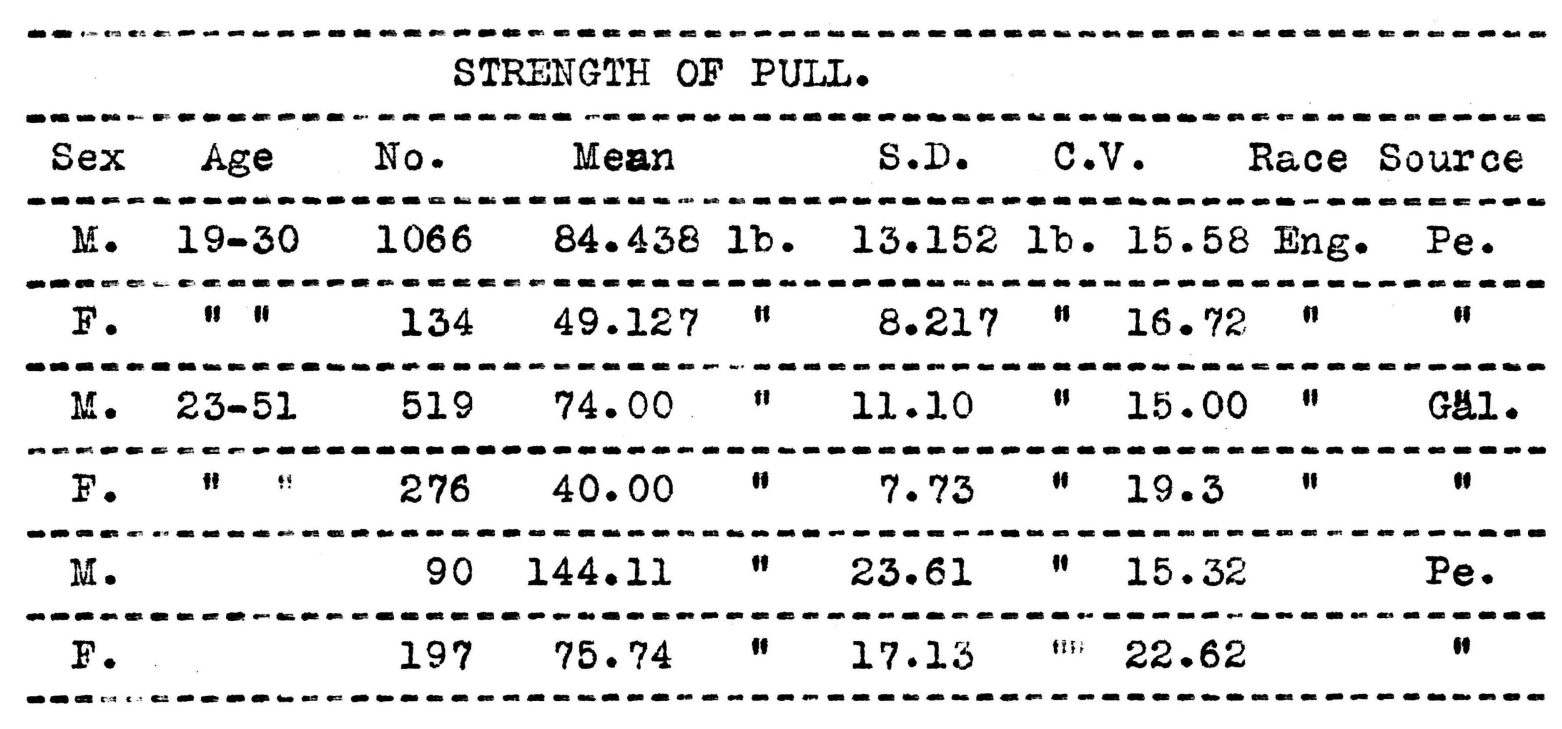

In both grip and strength of pull measurements the females are more variable and one may conclude that this is secondary sex characteristic in both chifdren and adults. 
CONCIUSION FOR PHYSICAI DATA

From the discussions following the various tables of physical data one can readily see that any generalization concerning sex variability in physical measurements as a whole is impossible. However, some indications of greater male variability are evident in certain measurements and at certiin ages, and greoter female variability in others--as follows:-

In width of head; arm bone length; weight of internal organs and brain; strength of pull; and adult weight; we find the females more varicible.

The males show greater variability in sitting height; length of head; facial measurements; leg bone length; and weight at birth.

Stature, span,weight, and chest girth statistics show a marked tendency toward greater female variability at the ages 6 to 13 years, and greater male variability at adolescence. Equal variability of the sexes is indicated in cephalic index and skull capacity.

Perhaps the next few years will make enough data available to definitely determine the question of sex variability. 
Turning from the physical to the mental data on variation, we find five comparatively recent investigations. They were made by Dr.W. H. Pyle, Professor of Educational Psychology at the University of Missouri, and three of his students.

Certain standardized tests originated or revised by Dr. Pyle were used. His investigations were made in the schools of Missouri, towns and cities, in 1913 and 1916. P. E. Collings, County Superintendent of McDonald County, Missouri, made a survey of the rural schools under his jurisdiction. Creighton's investigation was among the students in Chinese schools, and mine included the pupils in four grade schools and the High School of Joplin, Hissouri.

I shall not describe the material, procedure, or purpose of each test since that information is to be found in either of the manuals published by Dr. Pyle. $(x)(x)(x)$

In computing the C. V. from the data of the investigators I used the A. D. (average deviation) instead of the S. D. (standard deviation).

Since the material used and the methods of grading were practically the same, these five groups of statistics are in a condition to be compared one with the other.

The five sources are abbreviated as follows:-

1. Pyle 1913---.--Py. '13.

2. Fyle 1916-..-.-Py. '16.

3. Collings-...-.-Coll.

4. Creighton--.---Cre.

$(x)(x)\left(\begin{array}{l}5 \\ x\end{array}\right)$ Summerfield--.-sum.

1. "Examination of School Children". W.H.Pyle. Macmillan 1913.

2. "Manual for the Mental and Physical Examination of School Children". W.H.Pyle. University of Missouri Bulletin. 


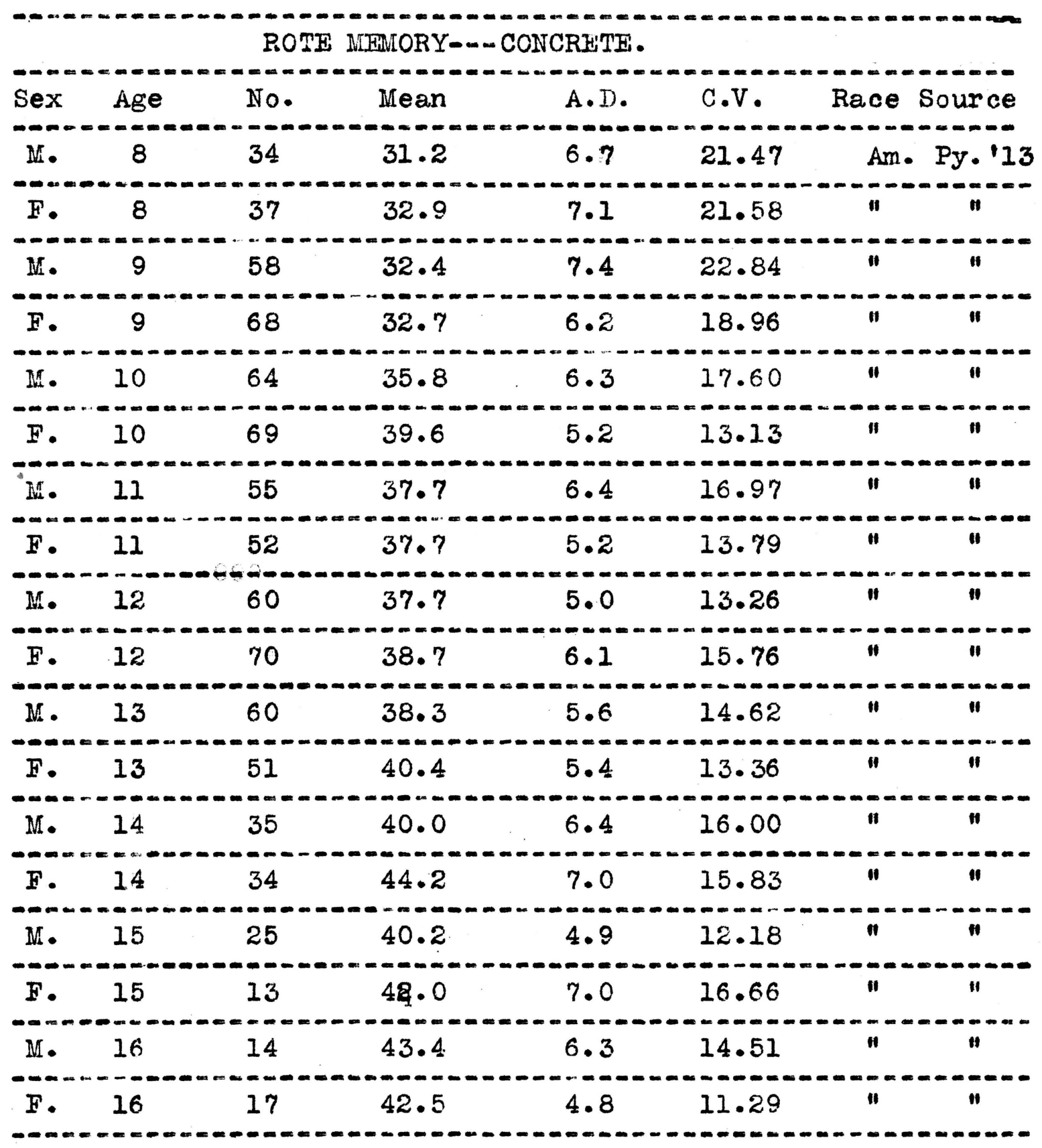


ROTE MEMORY---CONCRETE Cont'd.

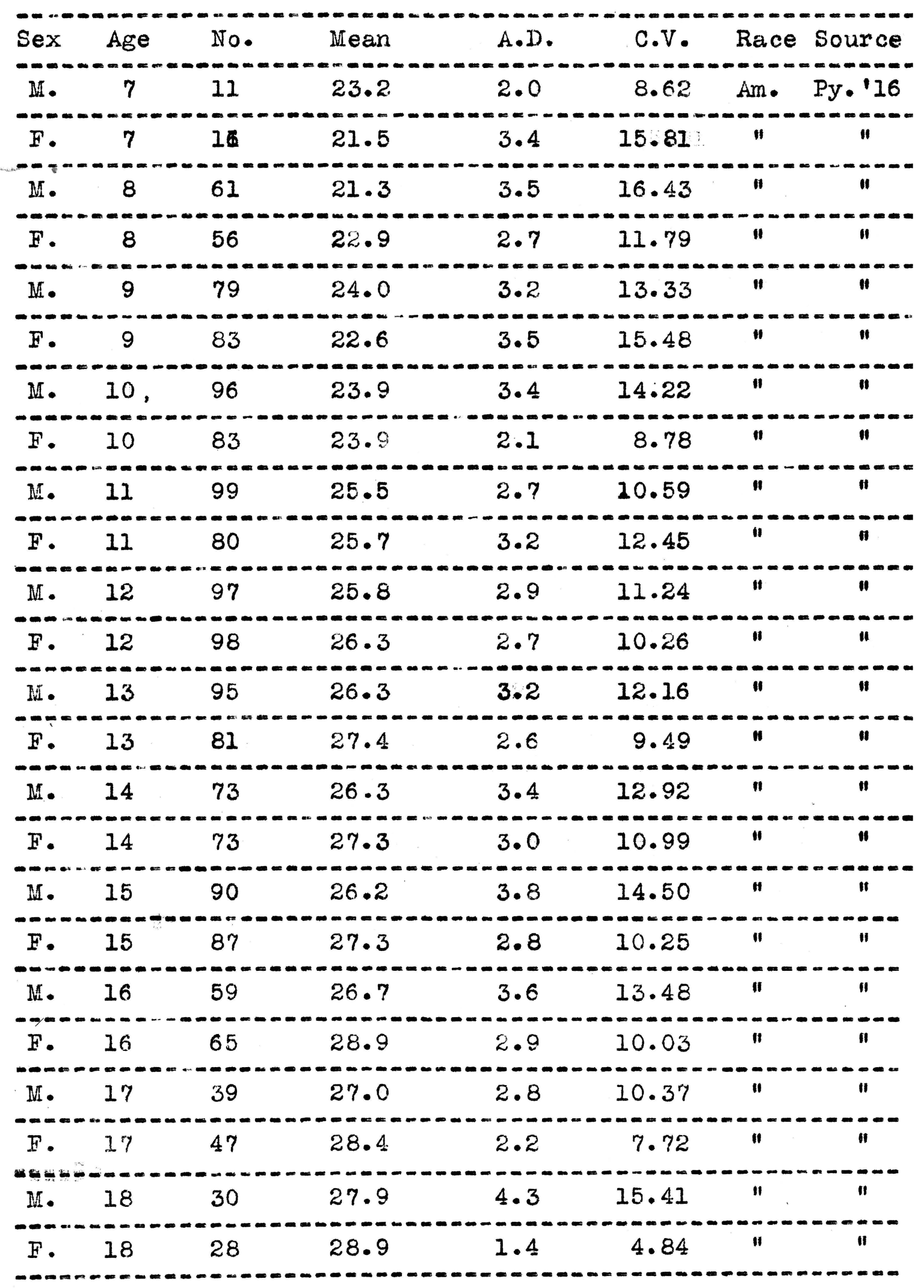


ROTE MEMORY-.-CONCRETE.COnt'd.

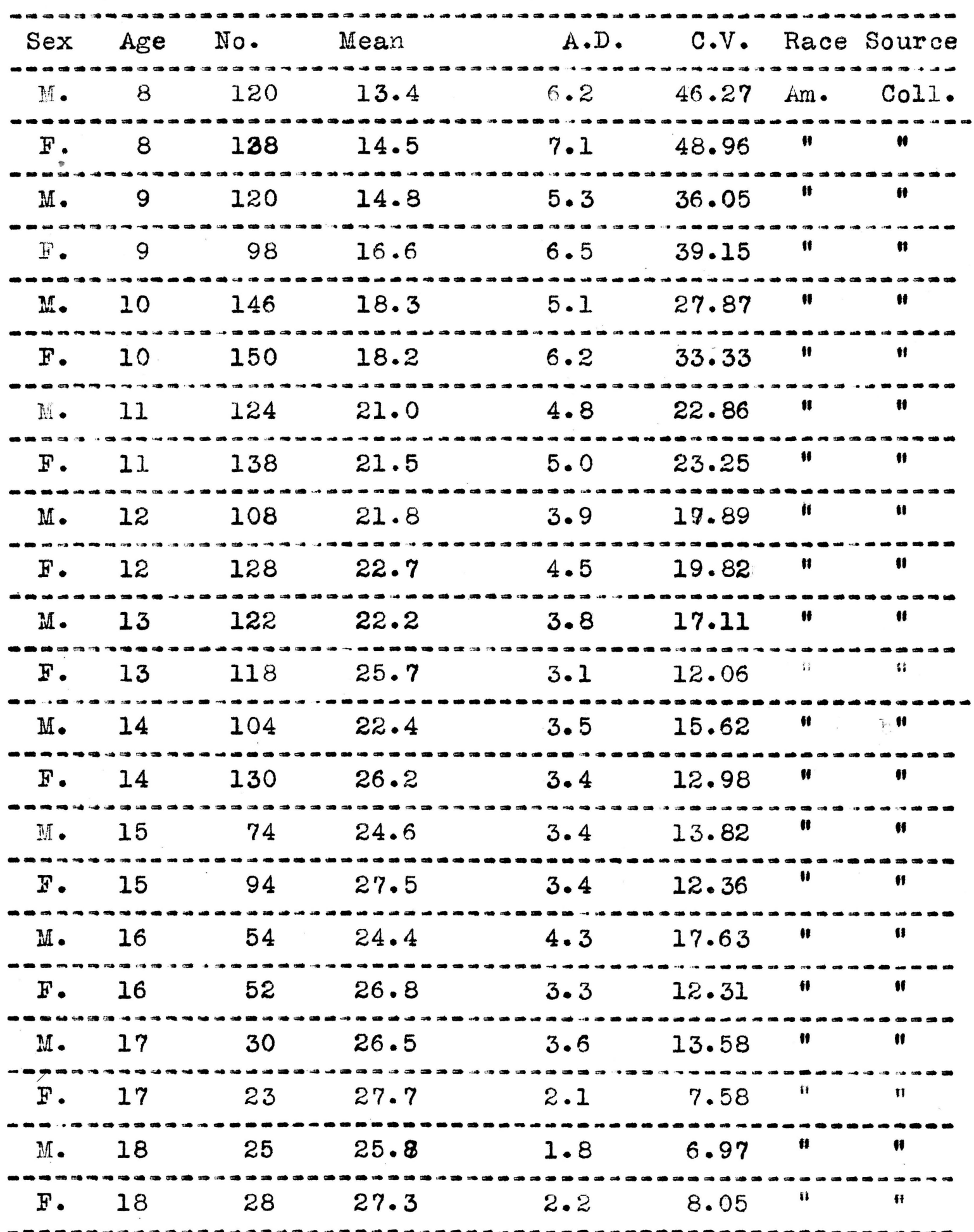




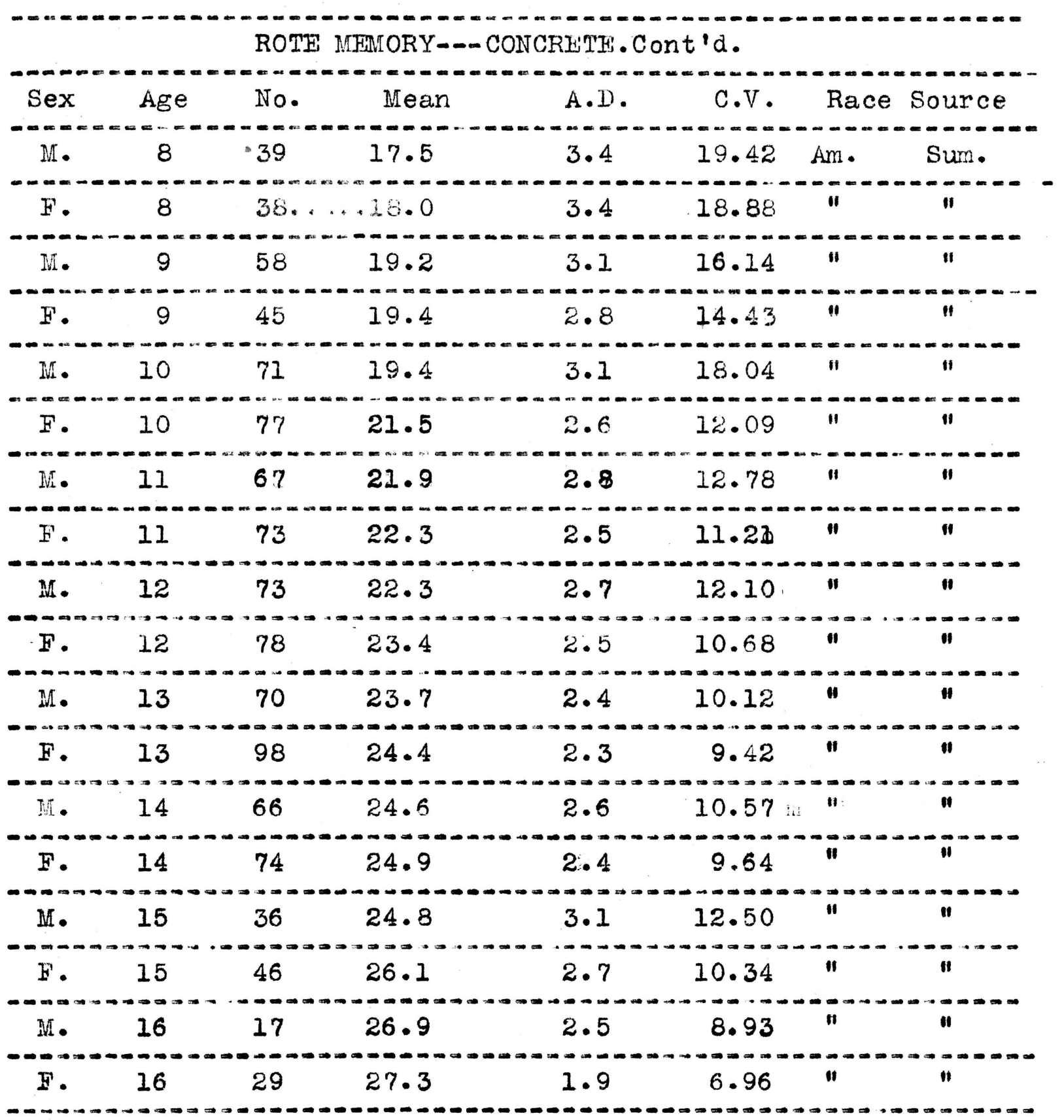


ROTE MEMORY --CONCRETE. Cont' $d$.

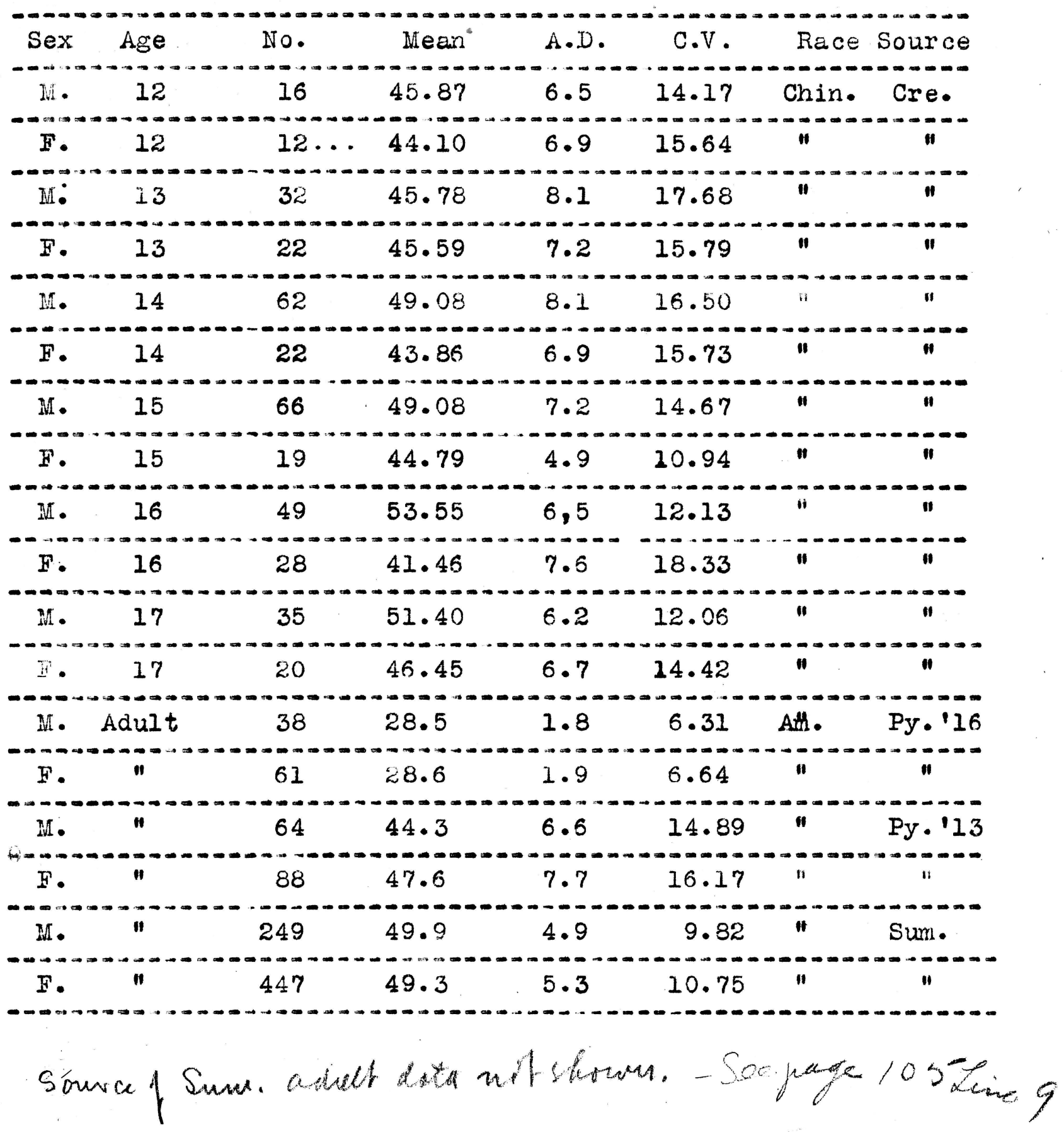


Considering concrete rote memory first, we find the following:-

1. Pyle '13 shows girls more varicble at ages 8, 12, and 15, while the boys are more variable at all the other ages. The difference in the average C. V. is 1.02 with the preponderance on the side of the boys.

2. Pyle 16 shows females more variable at ages 7, 9, 11, and 18, the males more variable at $8,10,12,13,14$, 15, 16, and 17 years. The average is again on the male side, being 2.96 greater than that of the female.

3. Colling's data indicates greater female variability at $8,9,10,11,12$, and 18 years, and greater male variability at $13,14,15,16$, and 17 years. The average is .53 of $1 \%$ greater for the males.

4. My data shows males more variable at every age, the difference in the average C. V. being $2.99 \%$ in favor of the males.

5. The Chinese statistics give only the measures for the ages 12 to 17 inclusive, and the girls are more variable in the first three and the boys in the last three. Here for the first time the average $C . V$. of the females exceeds that of the males, and to the extent of .6 of $1 \%$.

\%. 6. Adult data--The three groups agree in greater female varicility, ranging from .33 of $1 \%$ to $1.28 \%$ When all ages (not including adults) are averaged, greater male variability is indicated in the four American series, but in considering the ages separately, two series 
show the girls more variable at 8,9 , and 11 , while three show them more variable at 12. The Chinese girls vere more variable when dill ages were averaged. This leads me to believe that if there is greater female variability in concrete rote memory, it is to be found in the earlier ages, and among adults. (page 59.) 
ROTE MEMORY-- ABSTRACT.

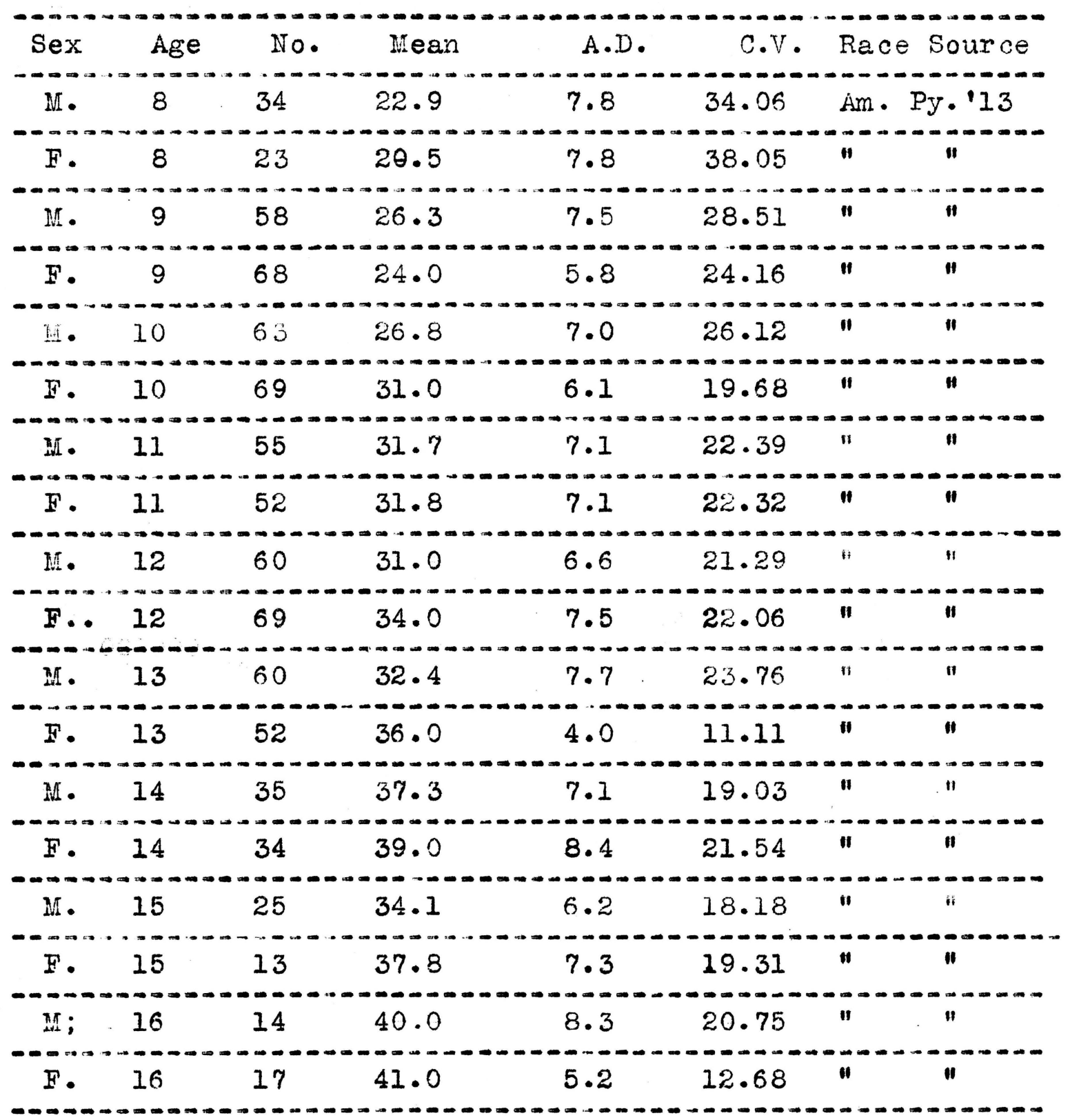


ROTE MEMORY---ABSTRACT. Cont'd.

\begin{tabular}{|c|c|c|c|c|c|c|c|}
\hline Sex & Age & No. & Mean & $A \cdot D$. & C.V. & Race & Source \\
\hline & 7 & 11 & 21.0 & 2.5 & 11.90 & Am. & Py.'16 \\
\hline & 7 & 16 & 19.5 & 3.4 & 17.42 & $"$ & $"$ \\
\hline & 8 & 60 & 18.2 & 3.5 & 19.80 & $"$ & $"$ \\
\hline & 8 & 56 & 21.0 & 2.6 & 12.38 & $"$ & " \\
\hline 10 & 9 & 85 & 21.3 & 2.7 & 12.67 & " & ii \\
\hline$\approx$ & 9 & 82 & 21.9 & 3.0 & 13.70 & " & " \\
\hline & 10 & 97 & 22.2 & 3.4 & 15.31 & " & \\
\hline & 10 & 83 & 21.9 & $3 . \theta$ & 13.70 & " & 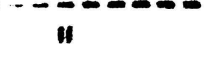 \\
\hline & 11 & 98 & 23.4 & 3.9 & 16.66 & $"$ & 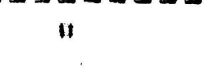 \\
\hline & 11 & 80 & 24.2 & 3.1 & 12.81 & " & in \\
\hline & 12 & 96 & 24.0 & 3.1 & 12.91 & $"$ & "i \\
\hline & 12 & 100 & 25.2 & 3.3 & 13.09 & - & \\
\hline II & 13 & 95 & 24.3 & 3.3 & 13.58 & & $"$ \\
\hline F & 13 & 82 & 26.1 & 3.0 & 11.49 & $"$ & $"$ \\
\hline ini & 14 & 73 & 24.7 & 3.1 & 12.14 & $"$ & $"$ \\
\hline 5 & 14 & 72 & 26.2 & 2.8 & 10.68 & "i" & 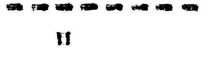 \\
\hline IN) & 15 & 92 & 25.3 & 3.7 & 14.62 & $"$ & " \\
\hline$F$ & 15 & 86 & 25.8 & 3.0 & 11.62 & $"$ & i" \\
\hline in & 16 & 59 & 25.7 & 3.2 & 12.45 & " & $"$ \\
\hline F. & 16 & 63 & 27.9 & 3.5 & 12.54 & 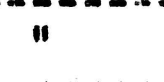 & $"$ \\
\hline $\mathbb{M}$. & 17 & 40 & 27.2 & 3.1 & 11.50 & $"$ & " \\
\hline - $\therefore$. & 17 & 47 & $2 ?: 1$ & 3.0 & 11:0? & & \\
\hline if & 18 & 30 & 27.6 & 3.3 & 11.95 & $"$ & $"$ \\
\hline F. & 18 & 28 & 28.9 & 3.0 & 10.38 & $"$ & 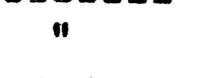 \\
\hline
\end{tabular}


ROTE MEMORY -...ABSTRACT. Cont' '

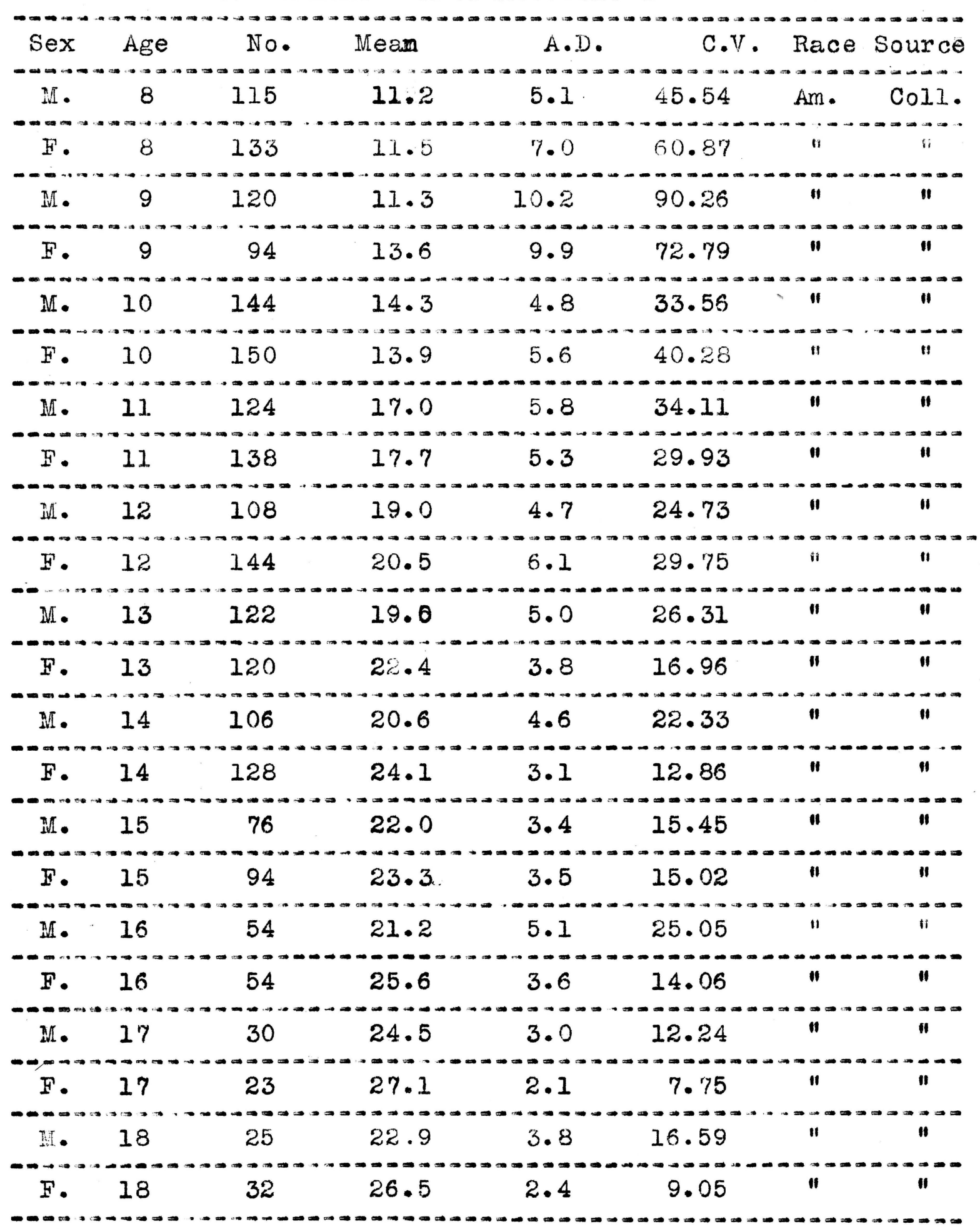


ROTE MEMORY---ABSTRACT'Cont'd.

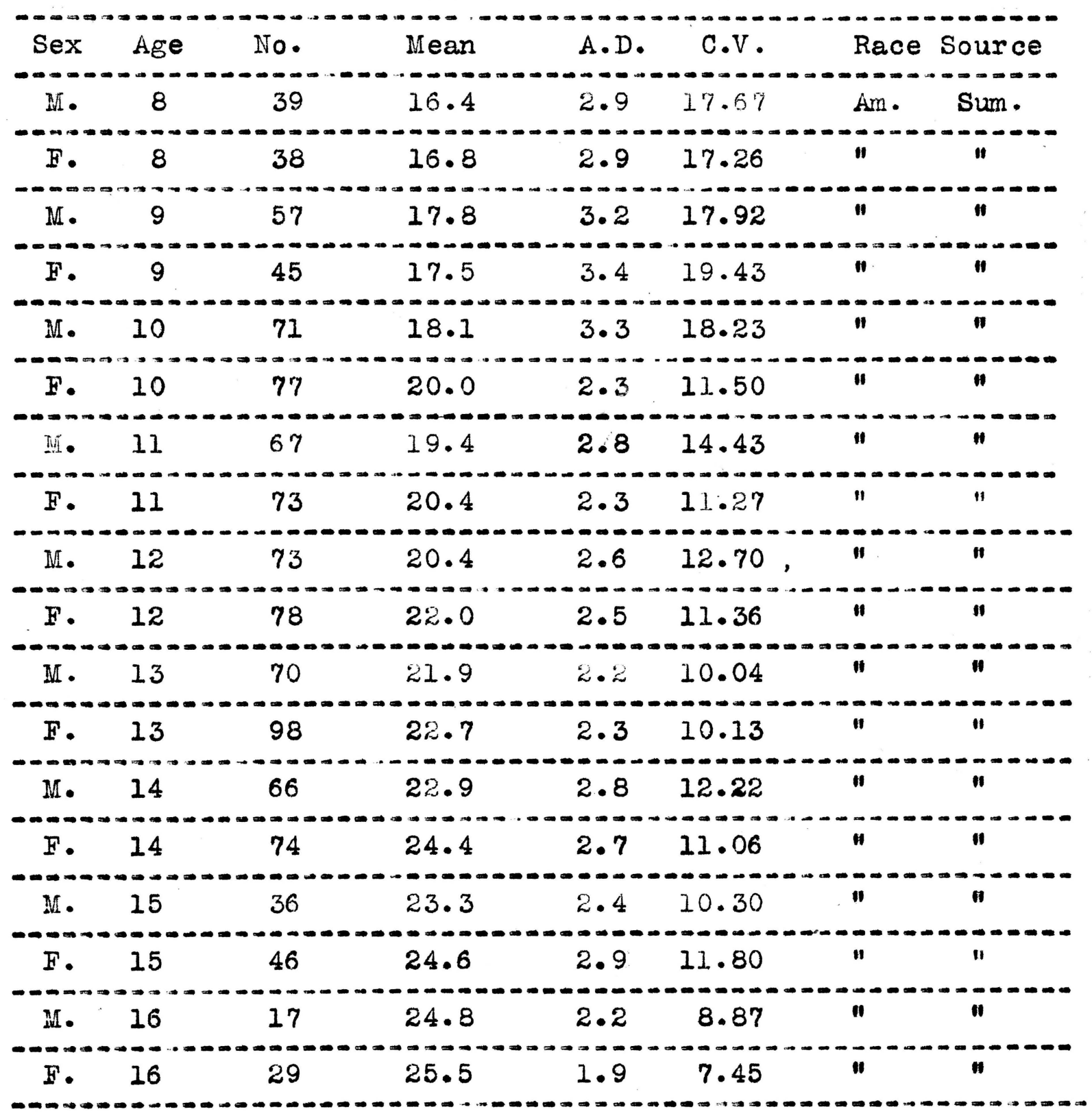


ROTE MEMORY - - ABSTRACI, Cont' $d$.

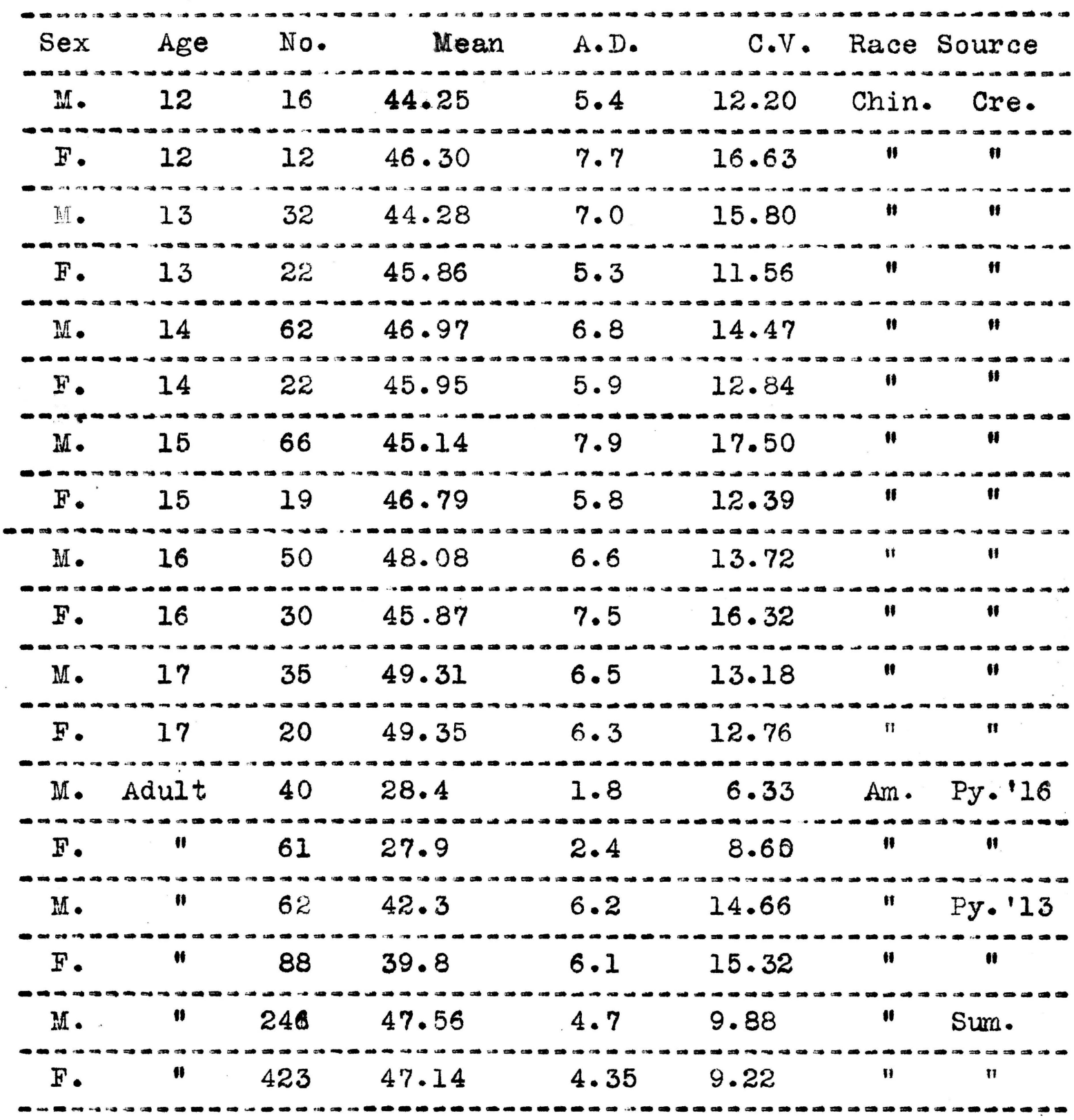


Abstract rote memory varies slightly as to results, so must be considered separately. Summized, they are:-

1. Pyle 113.

Girls more variable at ages 8, 12, 14, and 15.

Boys more variable at ages $9,10,11,13$, and 16. Average--2.58\% greater for males.

2. Pyle 1 16 .

Females more variable at ages 9,12 , and 16 . Meles more variable at ages 8, 10, 11, 13, 14, 15, 17, Average--1.82\% greater for temales.

3. Collings.

Girls more variable at 8,10 , and 12 years. Boys more veriable at 9, 11, 13, 14, 15, 16, 17 and 18. Average--5.07\% greater for boys.

4. Summerfield.

Girls more variable at 9,13 , and 15 years. Boys more variable at $8,10,11,12,14$ and 16 . Average--1.23\% greater for boys.

5. Chinese.

Females more variable at 12 and 16 years. Males more variable at 13, 14, 15, and 17 years. Average--Ifales more variable by .73 of $1 \%$

6. Adult.-.-University of hissouri students. Page 59. Pyle 113 and Pyle 116 show girls more variable by .66 of $1 \%$ and $2.27 \%$ respectively. Summerfield shows males more variable by .66 of $1 \%$. 
In abstract rote memory we find the males more varieble, especially at the ages 10, 11, 13, and 14, and the f'emales more variable at 12 years and when adults. When all ages are averaged, however, greater male variability predominates. 
LOGICAI HIRMORY - WILIIE JONES.

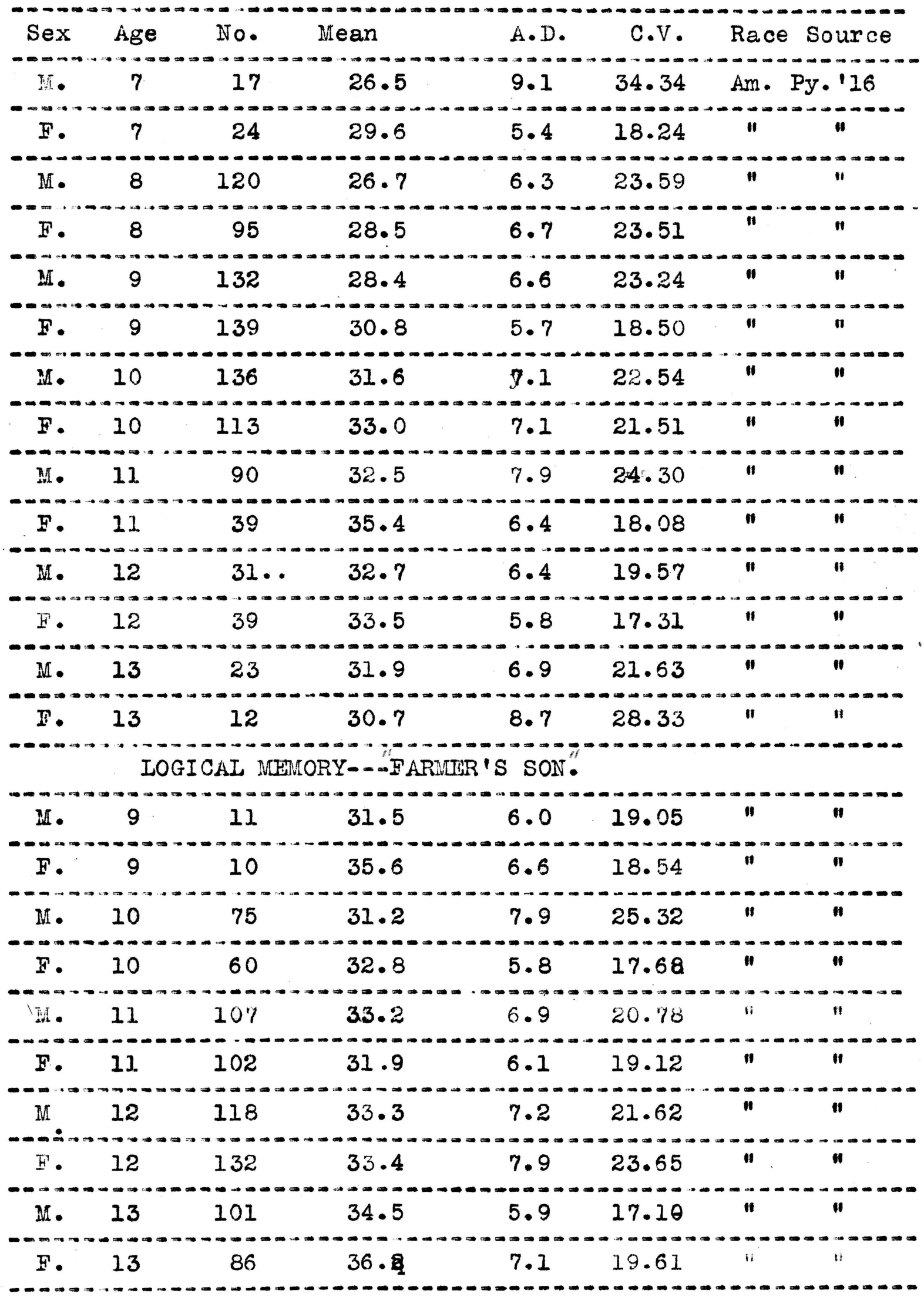


LOGICAL MLIMORY - - EARMER'S SON'Cont'd.

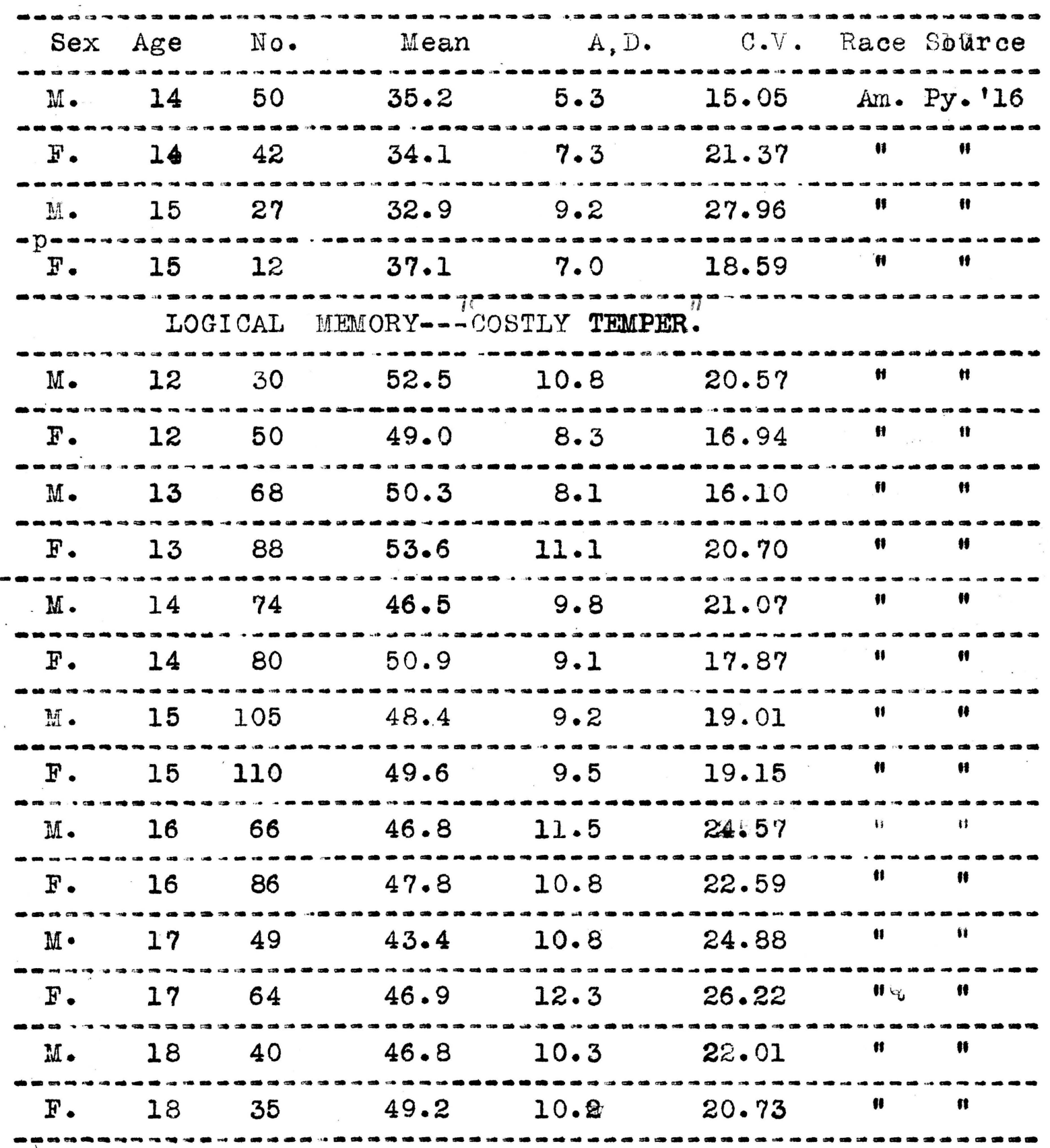


IOGI CAI MEMORY--MARBIE STATUE.Cont'd.

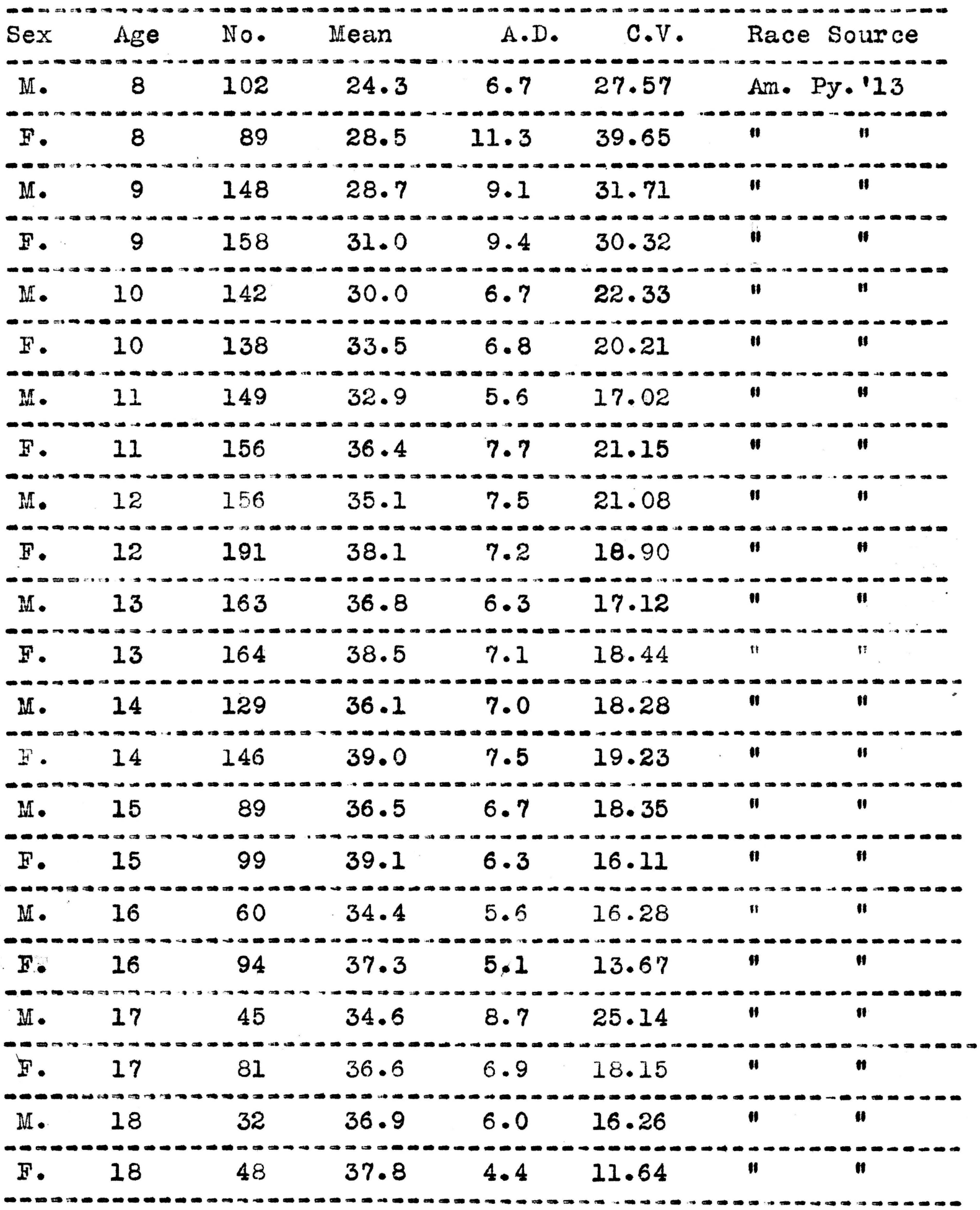


IOGICAL MENORY-D-IARBLE STAPUL.

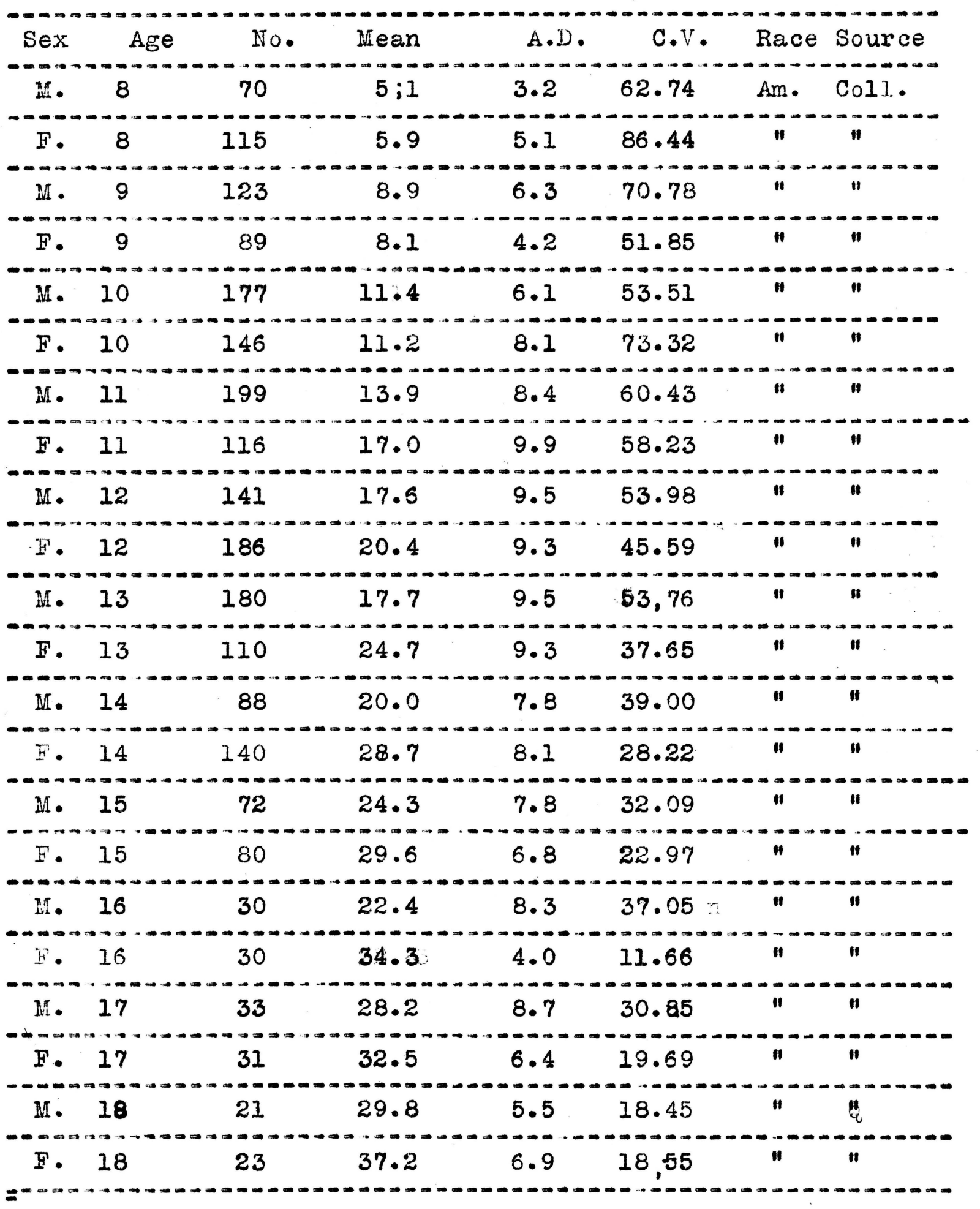


LOGICAI MEMORY--MARBIF STATUE. Cont'd.

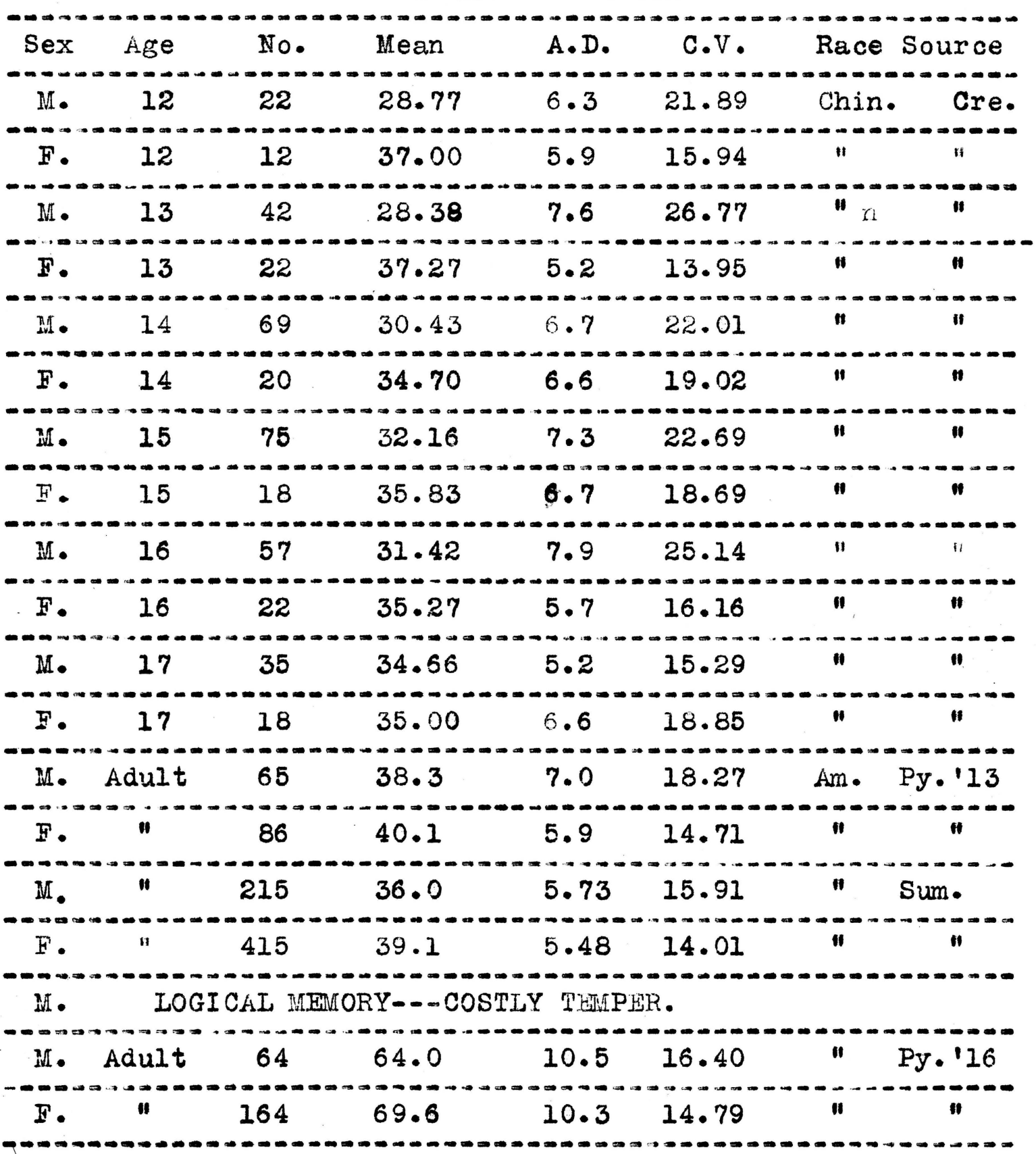


Logical memory or the reproduction of idecs gives the following results:-

1. "Willie Jones"--given by Pyle 'l6--shows the females more variable at 13 , and the males more so at $7,8,9,10,11$, and 12. The average C. V. is $3.1 \%$ greater for the males.

2. "Farmer's Son"--Pyle 16--shows the females more variable at 12, 13, and 14; while the males are more variable at $9,10,11$, and 15. The average C. V. being $1.19 \%$ greater for the males.

3. "Costly Temper"--Pyle 16--indicates greater female variability at 13, 15, and 17; and greater male variability at 12, 14, 16, and 18. The boys have a larger average $\mathrm{C} . \mathrm{V}$. to the extent of $1.17 \%$, while the average C. V. for males is $1.9 \%$ greater than that for females when all ages are combined.

4. "Marble Statue" is the most extensively usea story, and four groups of data are available, with these results:-

Collings finds the fernales more variable at 8,10 , and 18; males more varicble at the remaining eight ages; and the average C. V. $5.41 \%$ greater $f$ or the males.

Pyle 'I3 finds the females more variable at 8, 11, 13, and 14; the males more variable at $9,10,12,15,16,17$, and 18; and the difference in average C.V.s .32 of $1 \%$ in favor of the males.

Chinese females are more variable at 17 , while the males are more so at ages 12, 13, 14, 15, and 16. The average C. V. being $5.19 \%$ greater for the males. 
The fourth group, in which only adult measurements are considered, consists of two series. Pyle 13 indicates greater male variability to the extent of $3.56 \%$ while my data shows the males more varicble by $1.9 \%$.

Averaging all ages in each of the seven series, the boys are found to be more variable in every one. Therefore, the general conclusion is thet the males are more variable in logical memory. 
FREE ASSOCIATIUA.

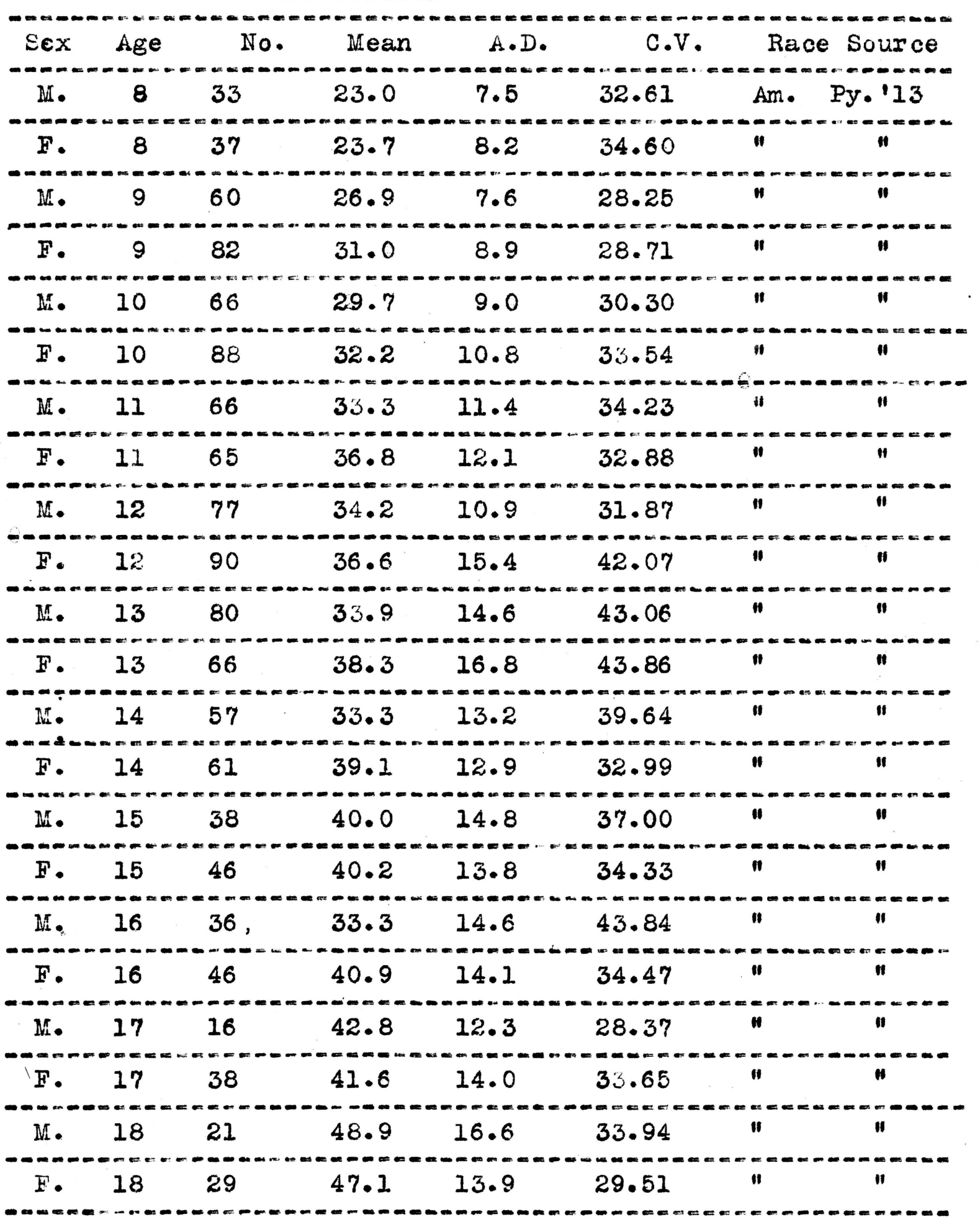


FREE ASSOCIATION . Cont 'd.

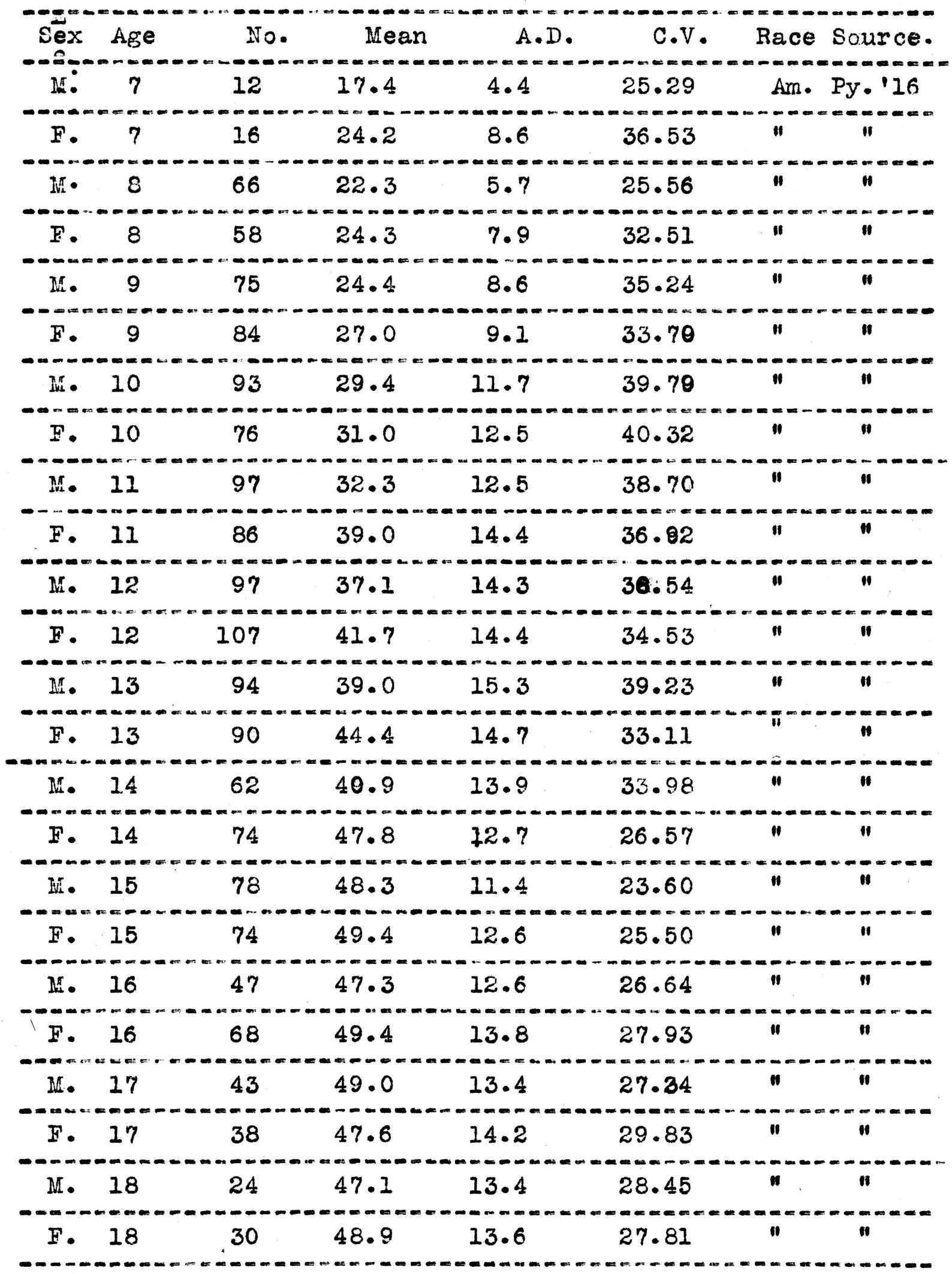


FREE ASSOCIATION.

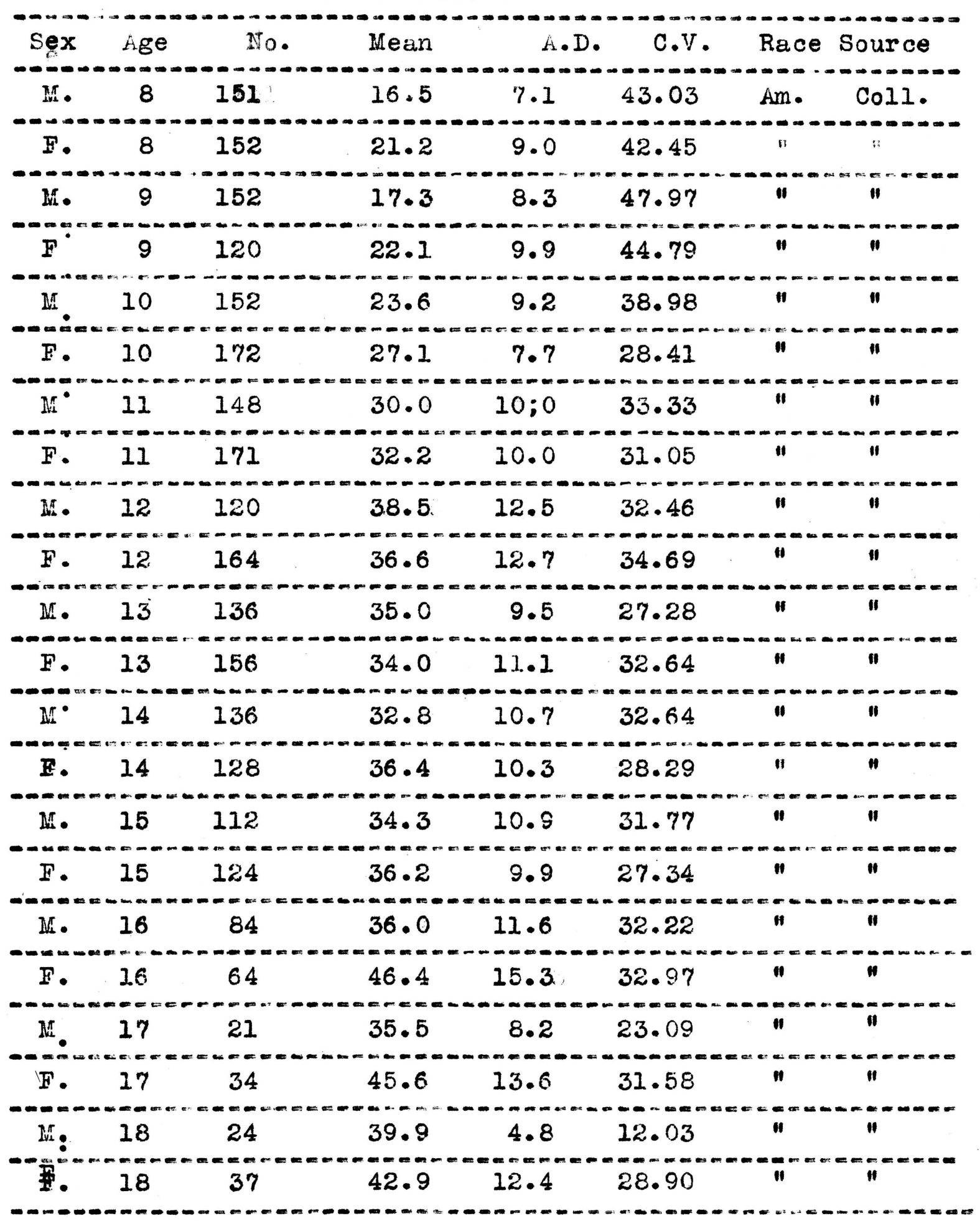


FREP ASSOCIATION - Cont'd.

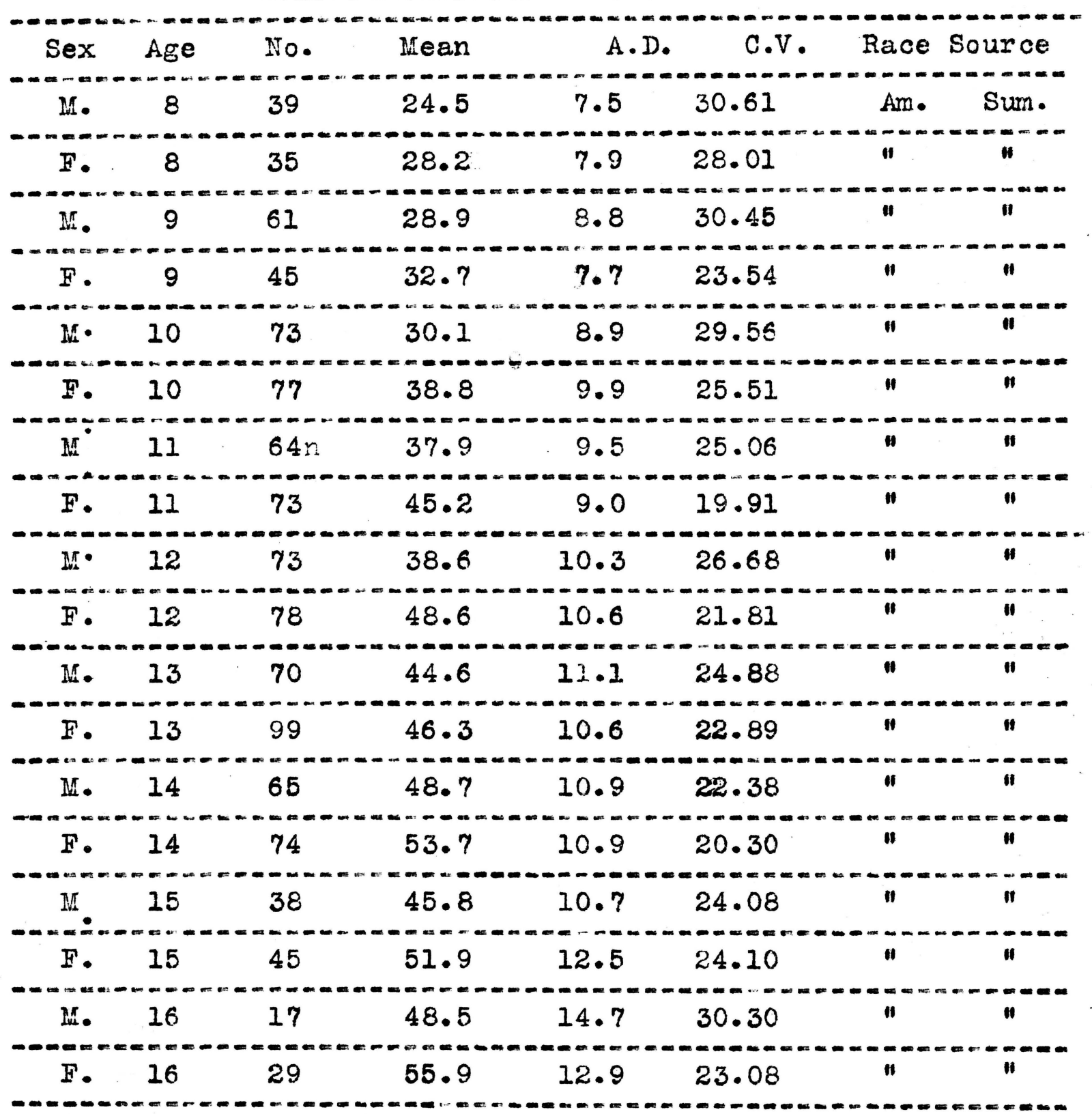




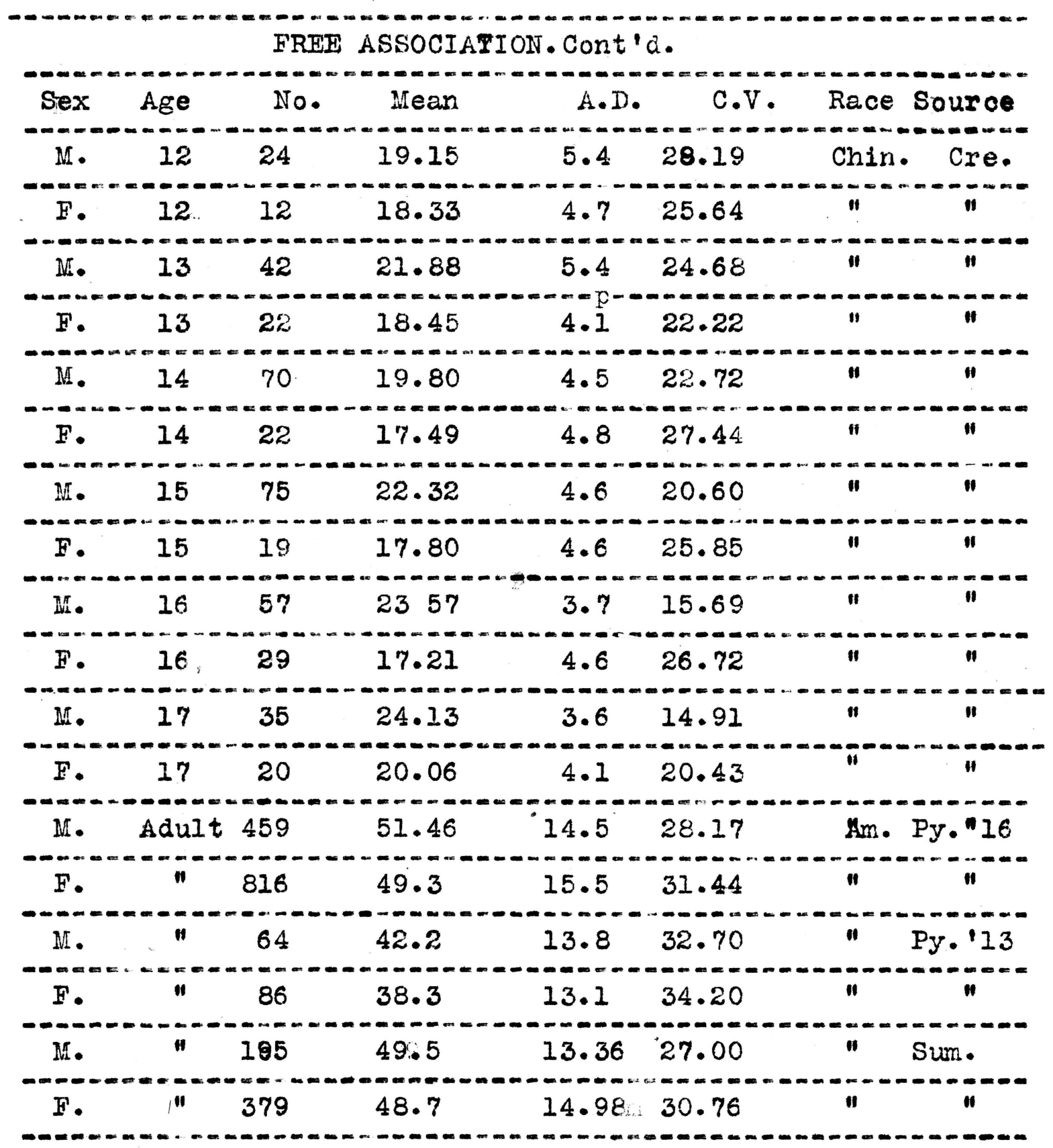


There are six series of data in the Free Association group--as follows:-

1. Pyle 113 indicates greater female variability at the ages 8, 9, 12, 13, and 17; greater male variability at 10, 11, 14, 15, 16, and 18; and when all ages are averaged the males are found to be more variable by .26 of $1 \%$.

2. Pyle 116 shows females more variable at $7,8,10$, 15, 16, and 17; the males more variable at 9, 11, 12, 13, 14, and 18; and the preponderance in favor of the meles .76 of $1 \%$.

3. Colling's series have the girls more variable at 8 , 9, 10, 11, 14, and 15; the boys more so at 12, 13, 16, 17, and 18; and contrary to the above series, he finds the females more variable by . 76 of $1 \%$ when all ages are averaged.

4. My data indicate greater male variability at all ages except 15, and then the females are only .02 of $1 \%$ more variable. The average $C . V$. in this series is $3.87 \%$ greater for the males.

5. The Chinese group indicates greater femile variability to almost the same extent as mine did for the males. The average C. V. is $3.58 \%$ greater for the female and they are more variable at four out of the six ages given.

The adult data, in three series, agree that girls are more variable to the extent of $3.27 \%, 1.5 \%$, and $3.76 \%$ respectively.

In the four groups of tests made on American chilaren, three show greater male variability. The Chinese girls were more variable in Free Association. 
CONTROLLED ASSOCIATION_-...OPPOSITAS.

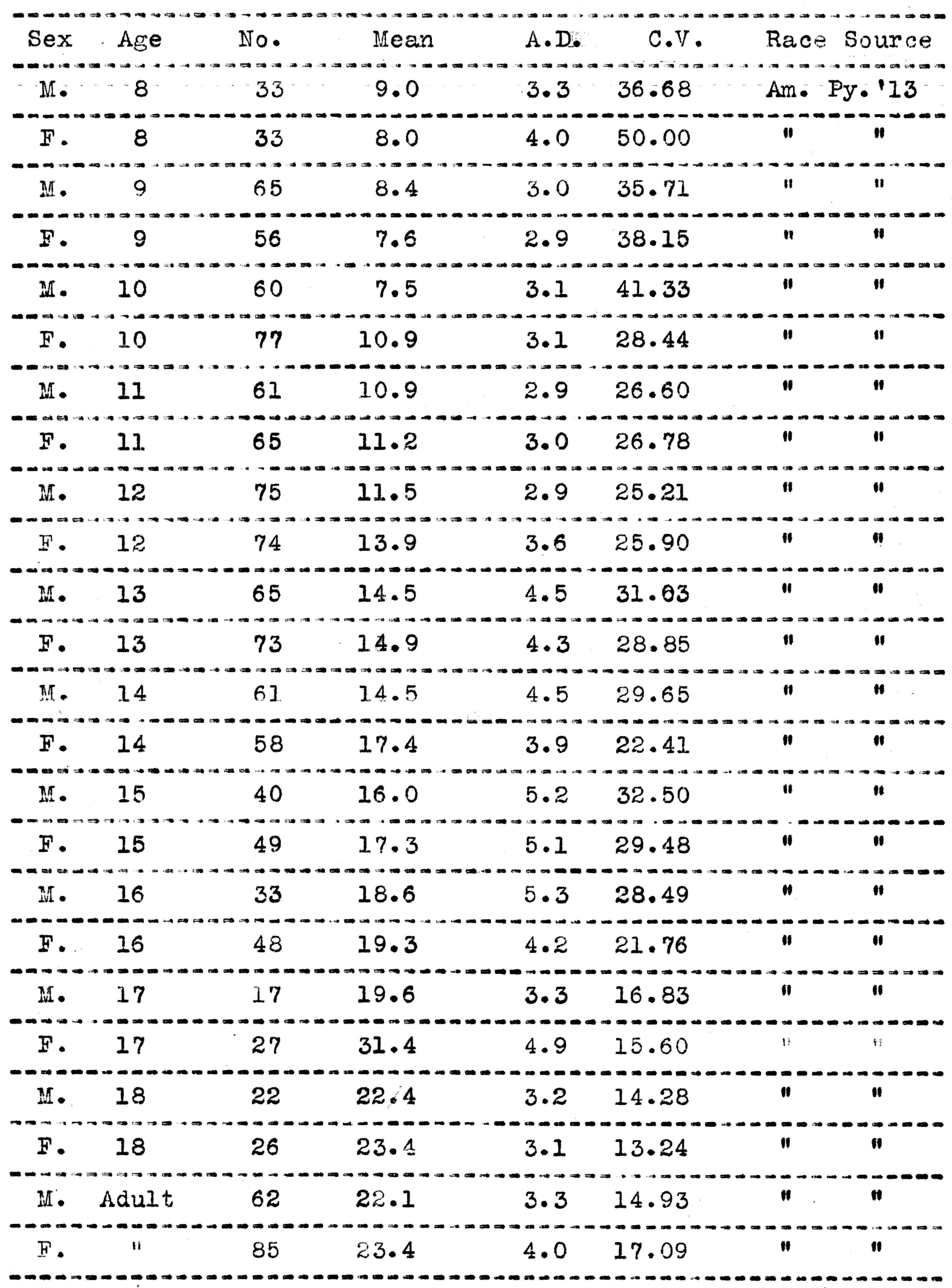


CONTROIIED ASSOCIATION-_..CPFOSITIS I.

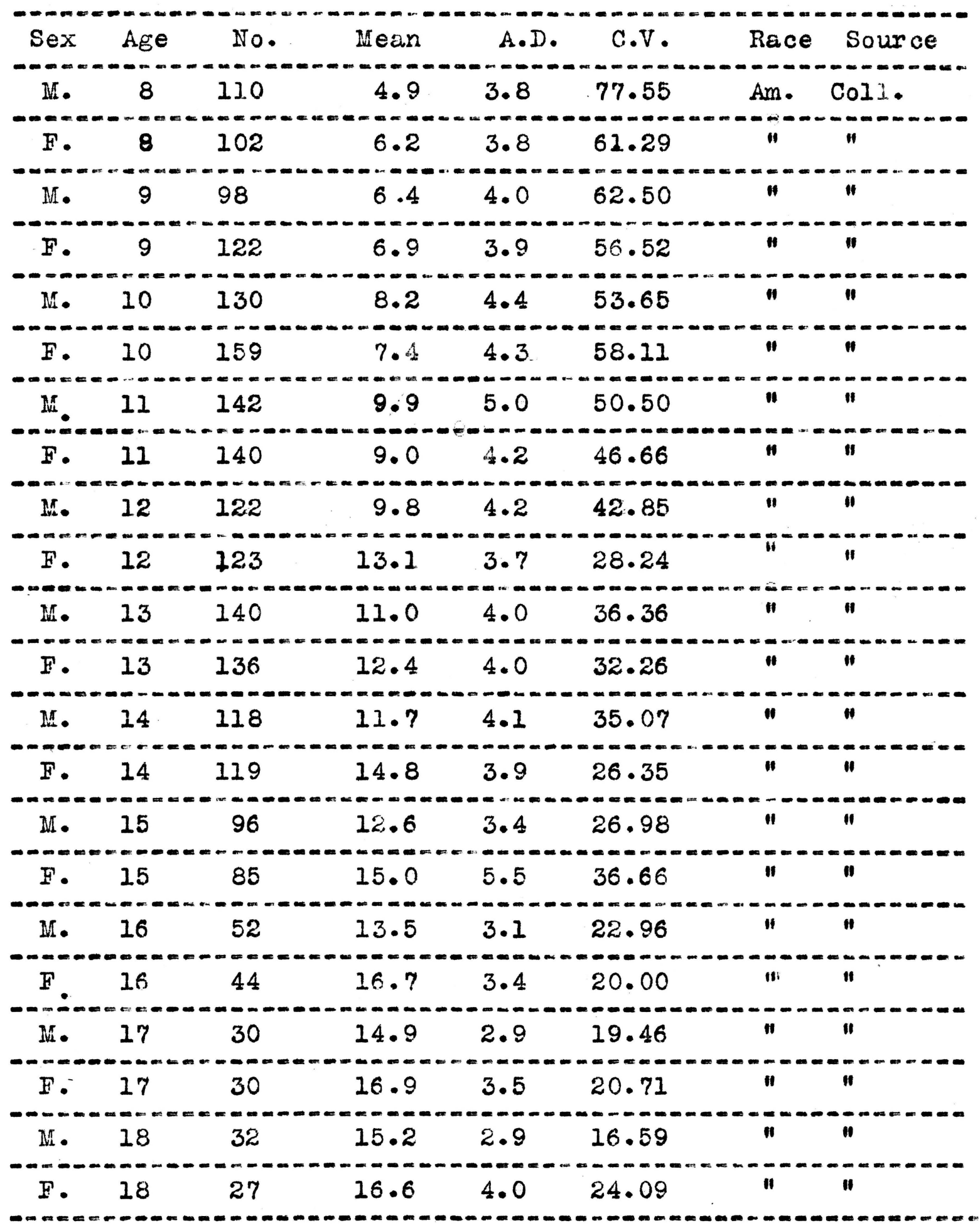


CONTRCIIED ASSOCIATION---OPPOSITES I.COnt'd.

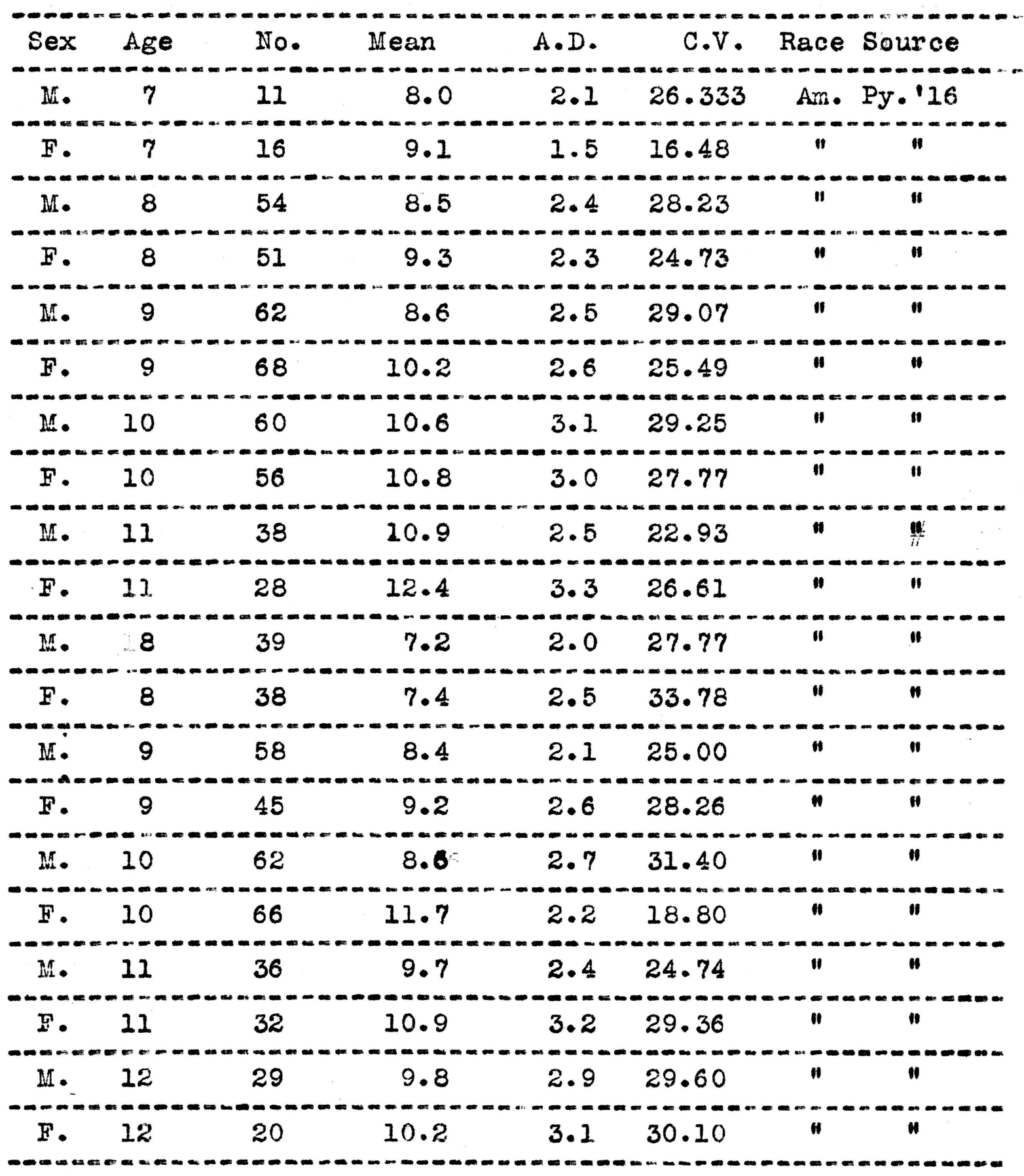


CONTROILED ASSOCIATION---OPPOSITES II.

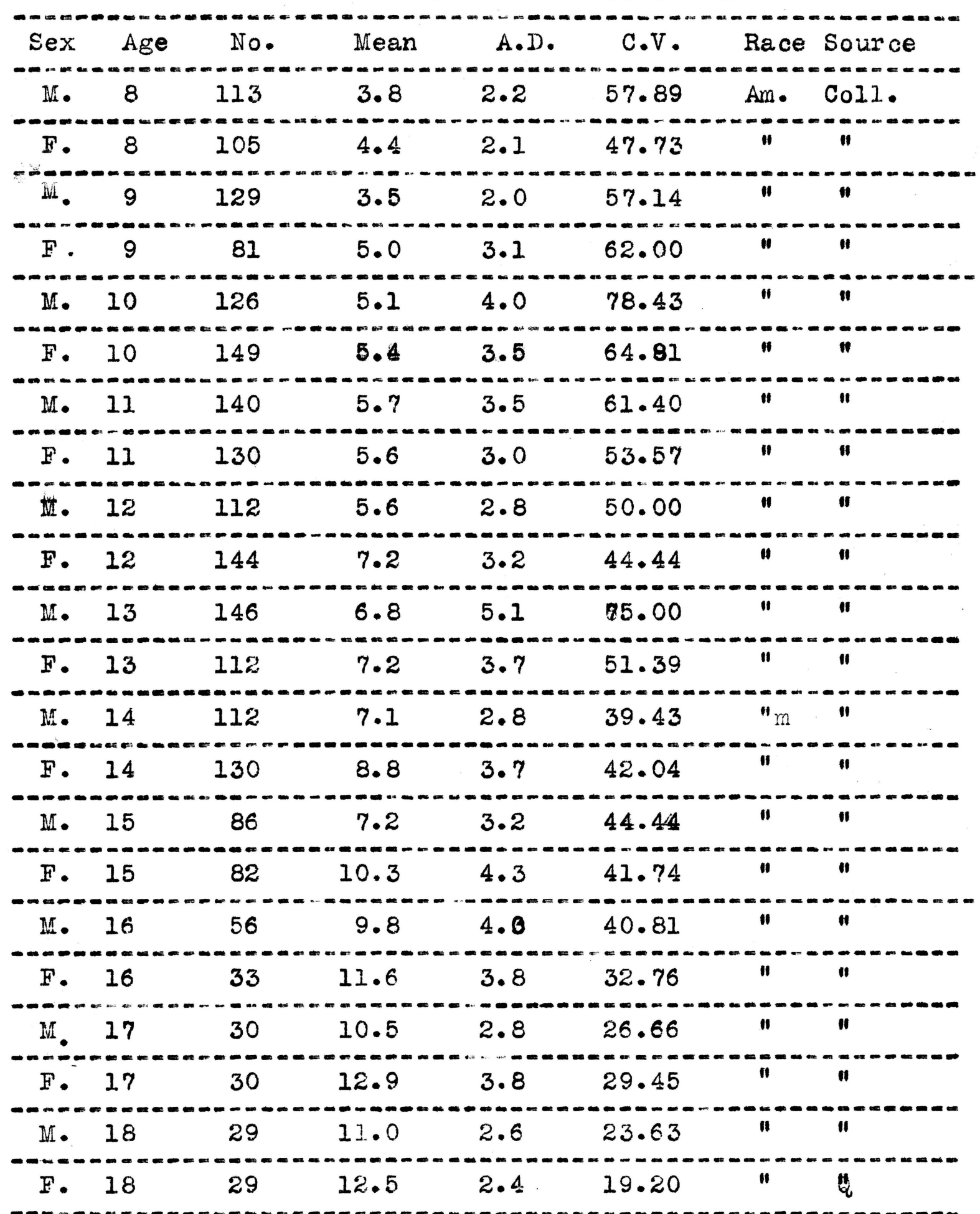


CONTROLIE] ASSOCIATION-_.OPPOSITESII . Cont'd.

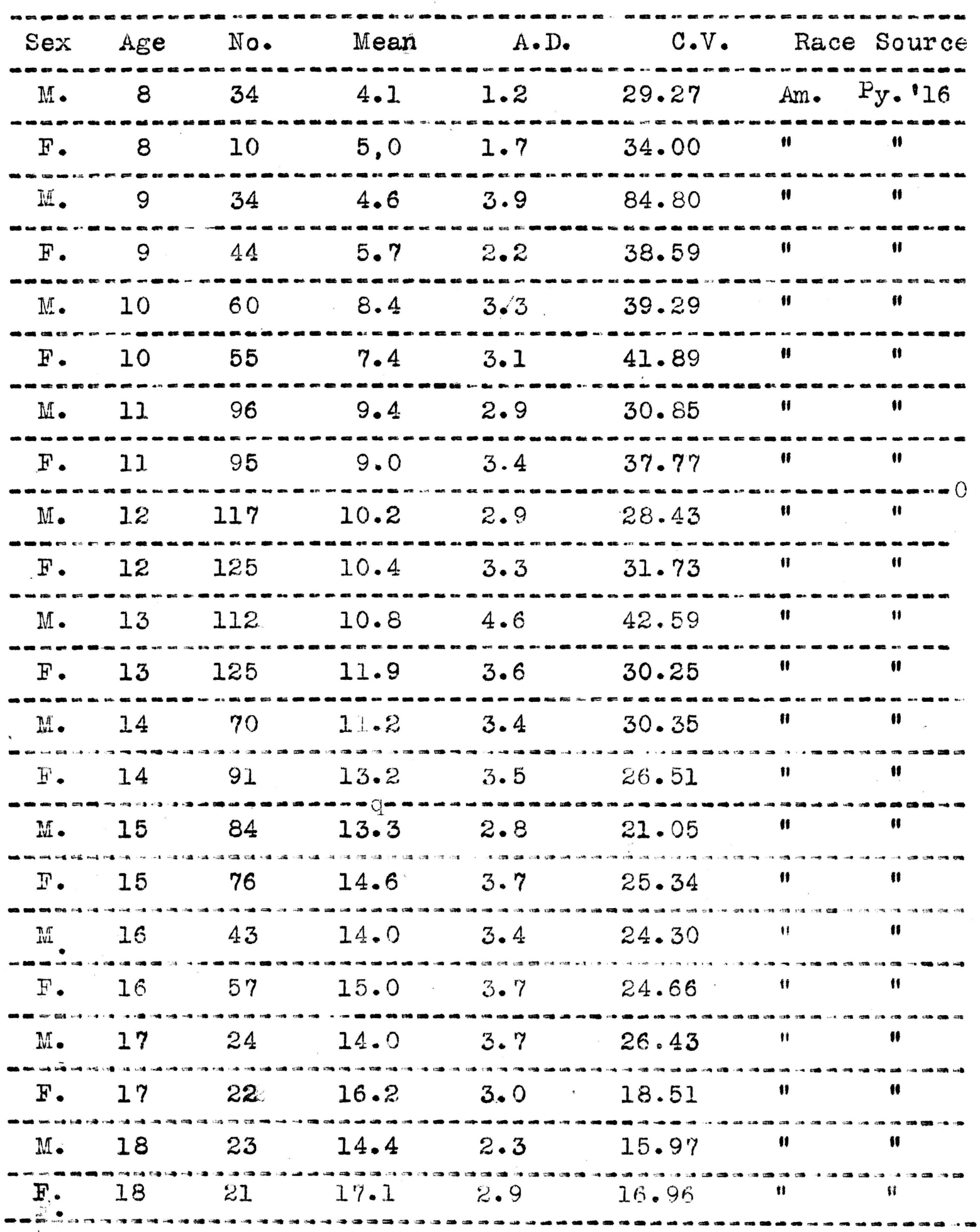


CONTROLLED ASSOCIATION---OPPOSITES II.

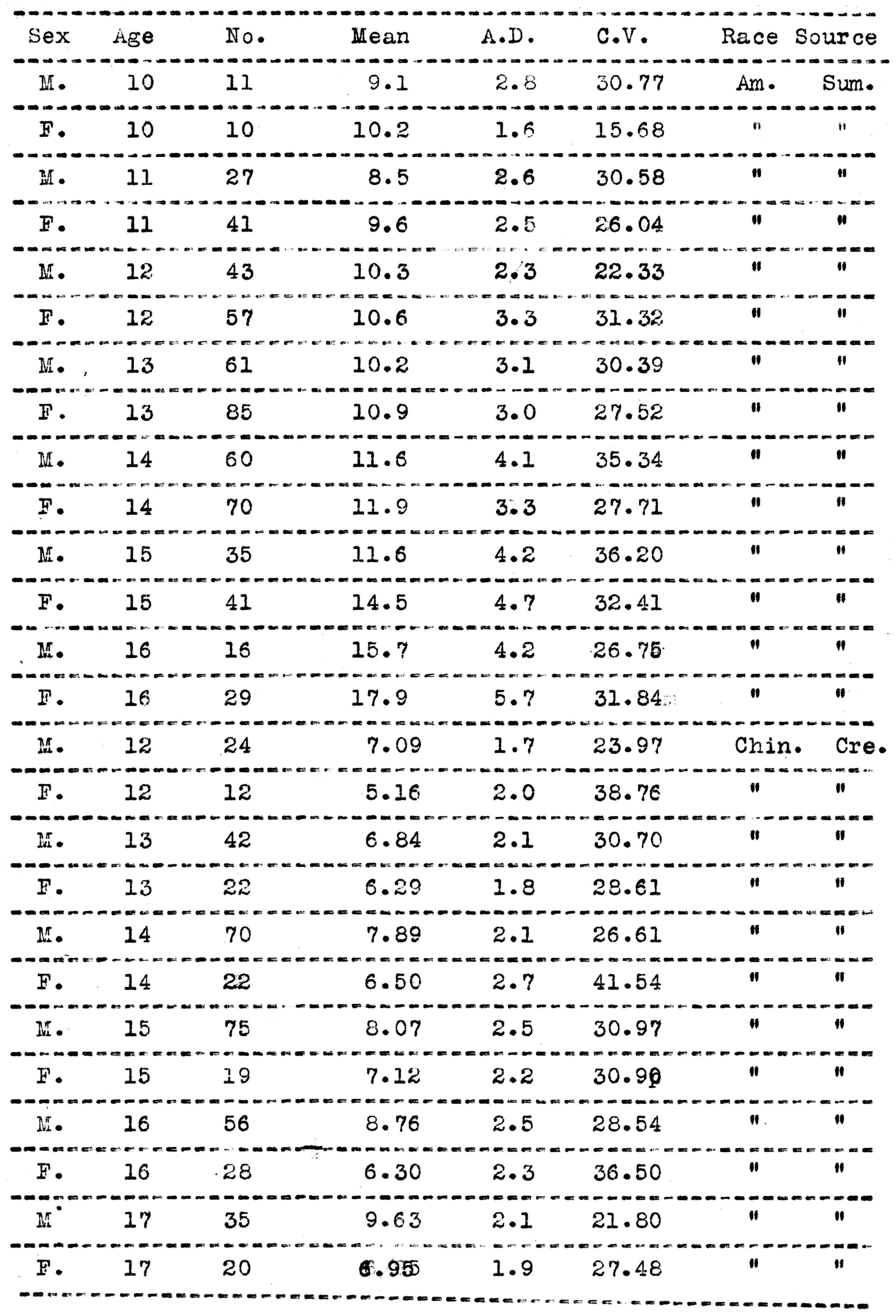


CONTROIIED ASSOCIATION-D-OPPOSITHS III.

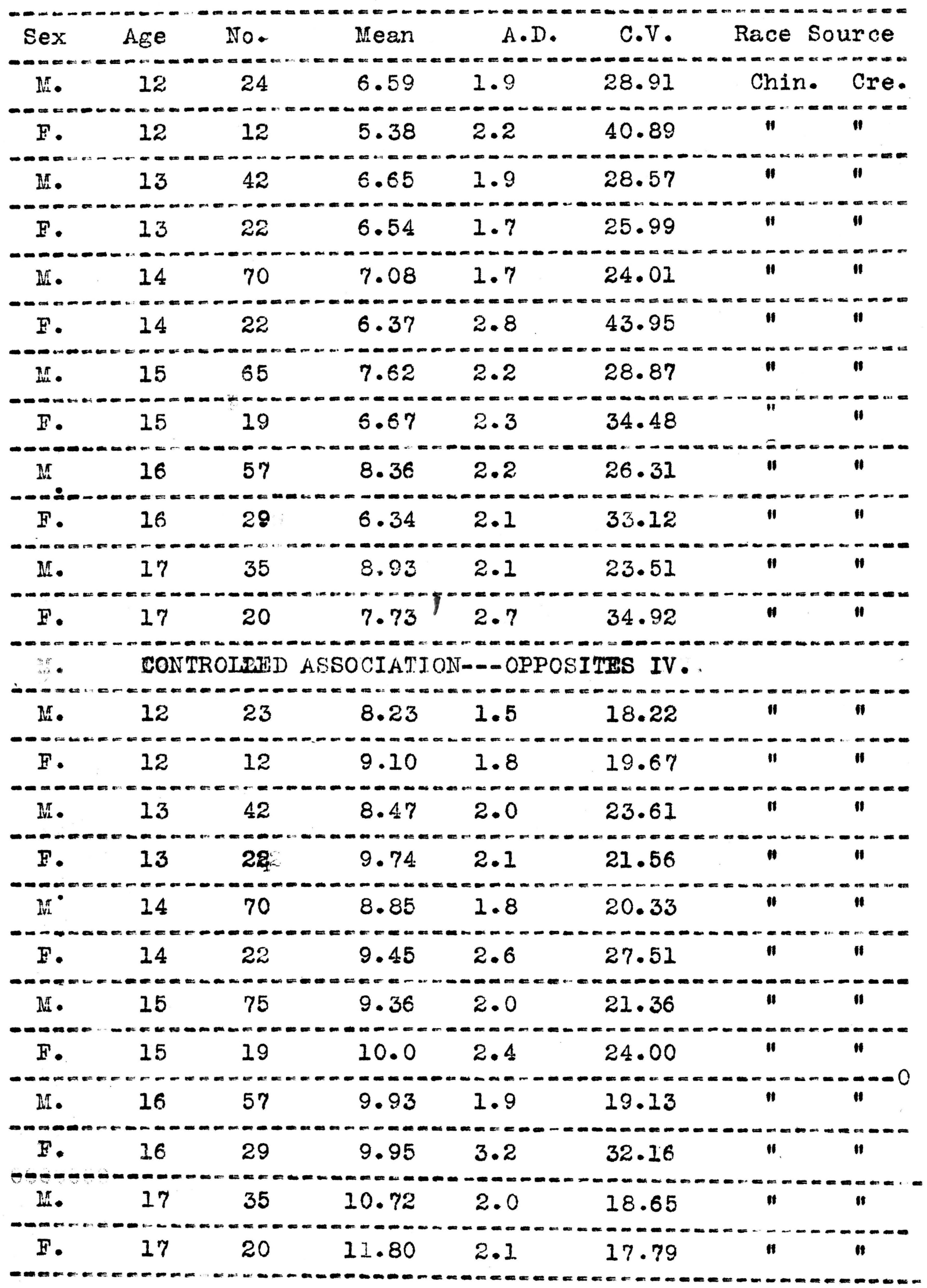




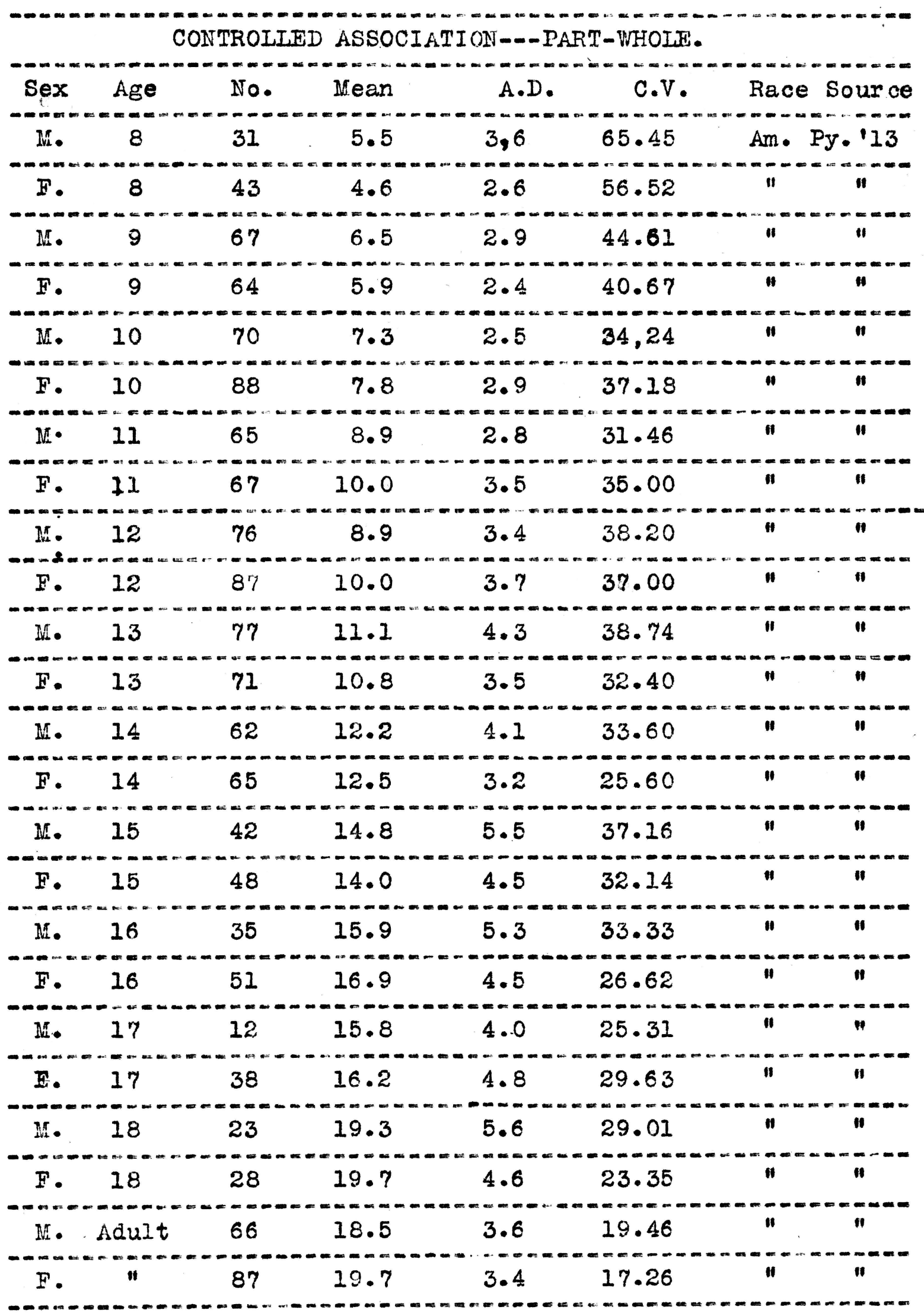


CONTROLIED ASSOCIATION-- - GTYUS-SPECIES.

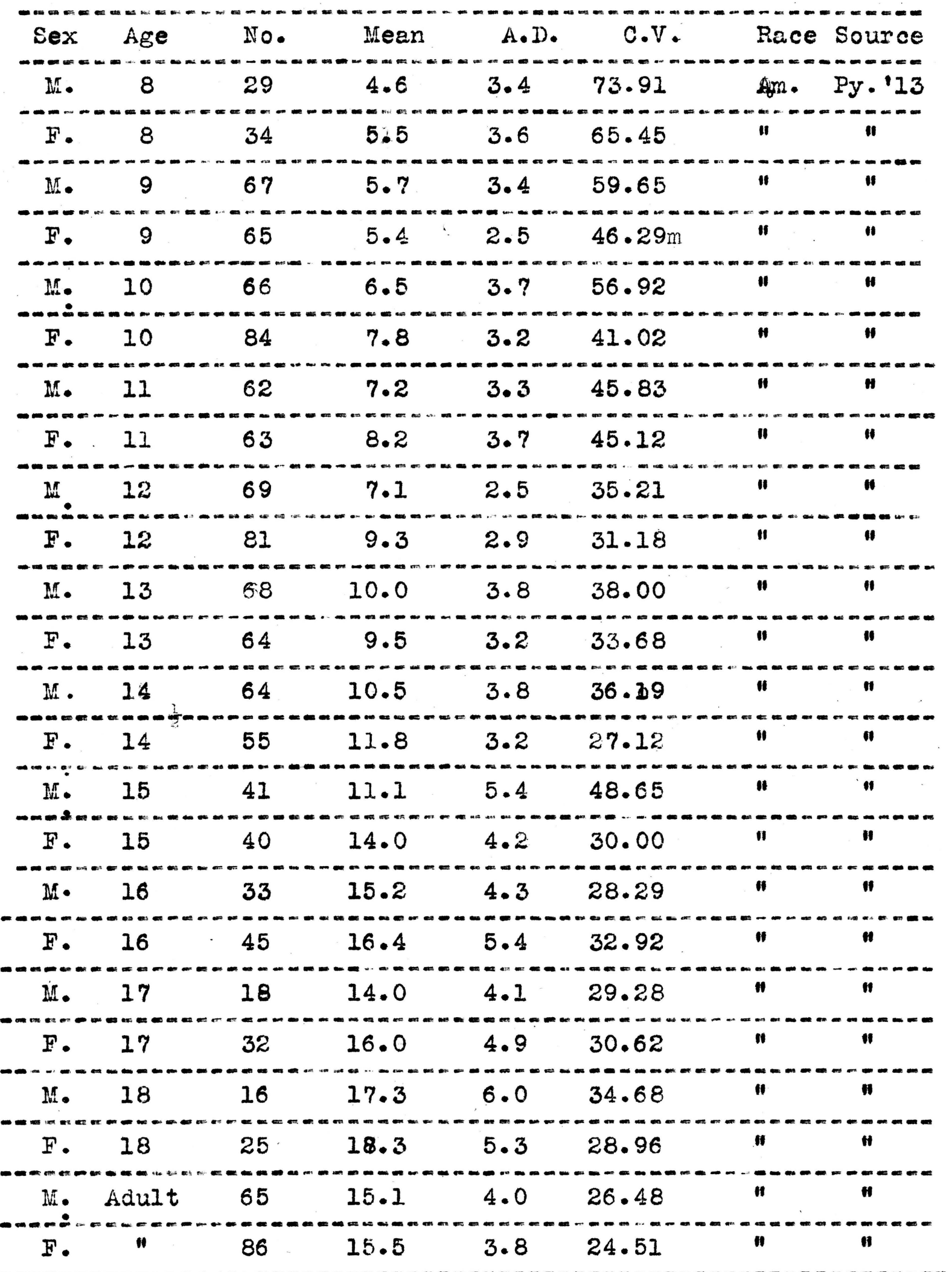


Controlled Association as tested by Various Iists of opposites, genus, species, and part-vhole series, has the following results:-

1. Pyle 113 series show the females more variable at ages 8, 9, 11, 12, cha adults; the males more variable at the remaining ages; and the average C. V. $1.61 \%$ greater for the males.

2. Opposites I, given in the lower grades by Dr. Pyle and me, and in all grades by Collings, show these results:-

a). Pyle 116--ltales more variable at ages 7, 8, 9, and 10; females more so at 11; and the average C. V. $1.22 \%$ greater for males.

b). Collings finds the f'emales more viriable at 10, 15, 17, and 18; the mailes at 8, 9, 11, 13, 14, and 16; cind the averige $3.05 \%$ greater for the males.

c). My results, the only ones of this group to have a larger average $C$. V. for the girls--it is .36 of $1 \%$ greater. I find the females more variable at $8,9,11$, and 12, and the boys more so at 10 .

3. Opposites II has four groups of data:-

a) Collings found the males more variable at all ages except 9, 14, and 17; and the averege in their favor by $9.61 \%$

b). Pyle 16 found the females more variable at all ages except $9,13,14$, and 17; but the avercige C. V. was $5.19 \%$ greater for the males. 
c). The Chinese series also indicated greater female variability, their average being $6.87 \%$ greater than that of the males; and considering the ages separately, they were more variable at $12,14,16$, and 17 , while the males vere more so at 13 and 15 years.

d). My data indicates greater male variability at 10, 11, 13, 14, and 15; greater female variability at 12 and 16 ; and the average C. V. $2.84 \%$ greater for the males.

4. Opposites III and IV given only to Chinese show the females more variable to the extent of $8.87 \%$ and $3.57 \%$ respectively.

5. The part-vhole and genus species series both show greater male variability.

In the American series the males are shown to be more variable, but the Chinese girls were more variable. 


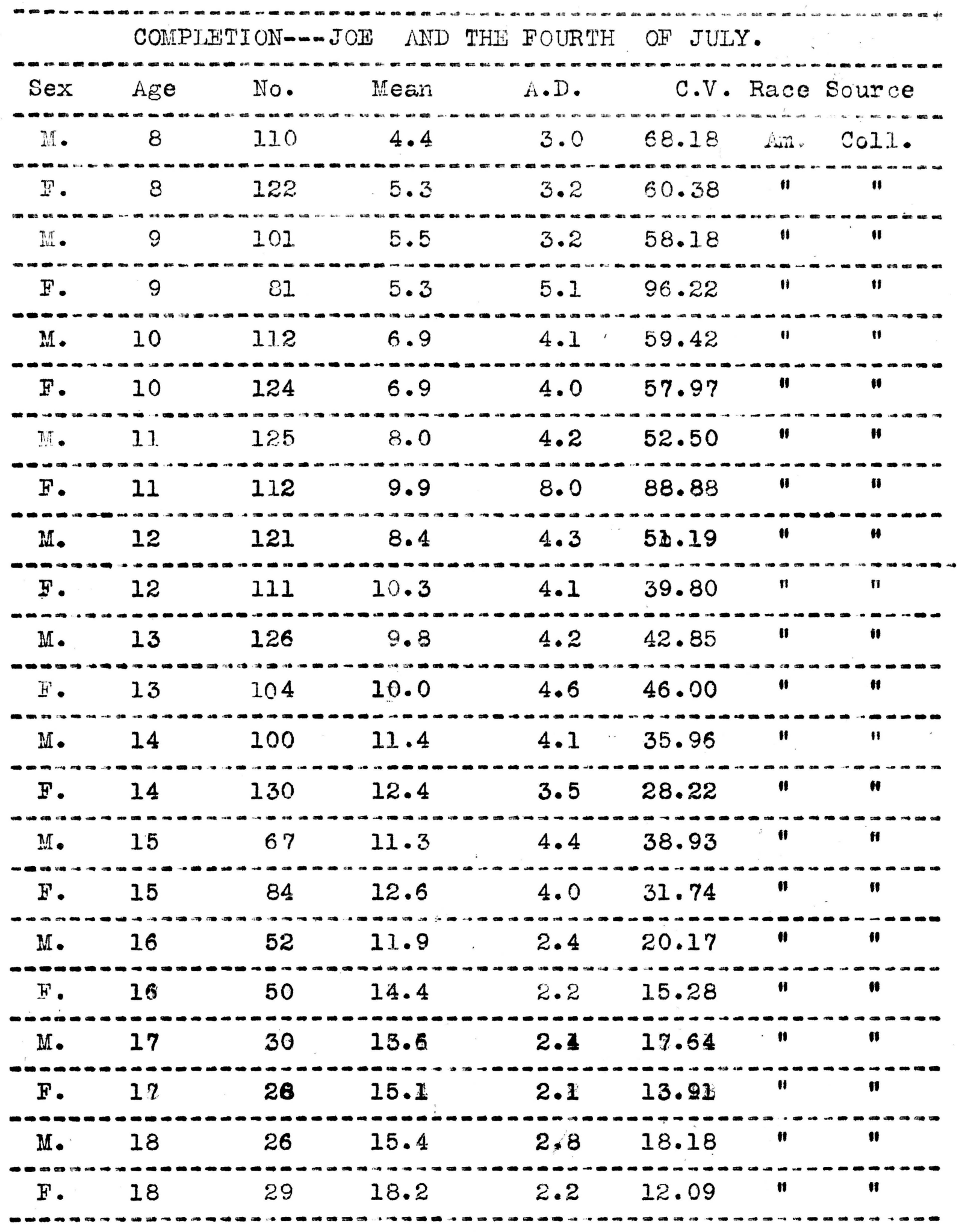




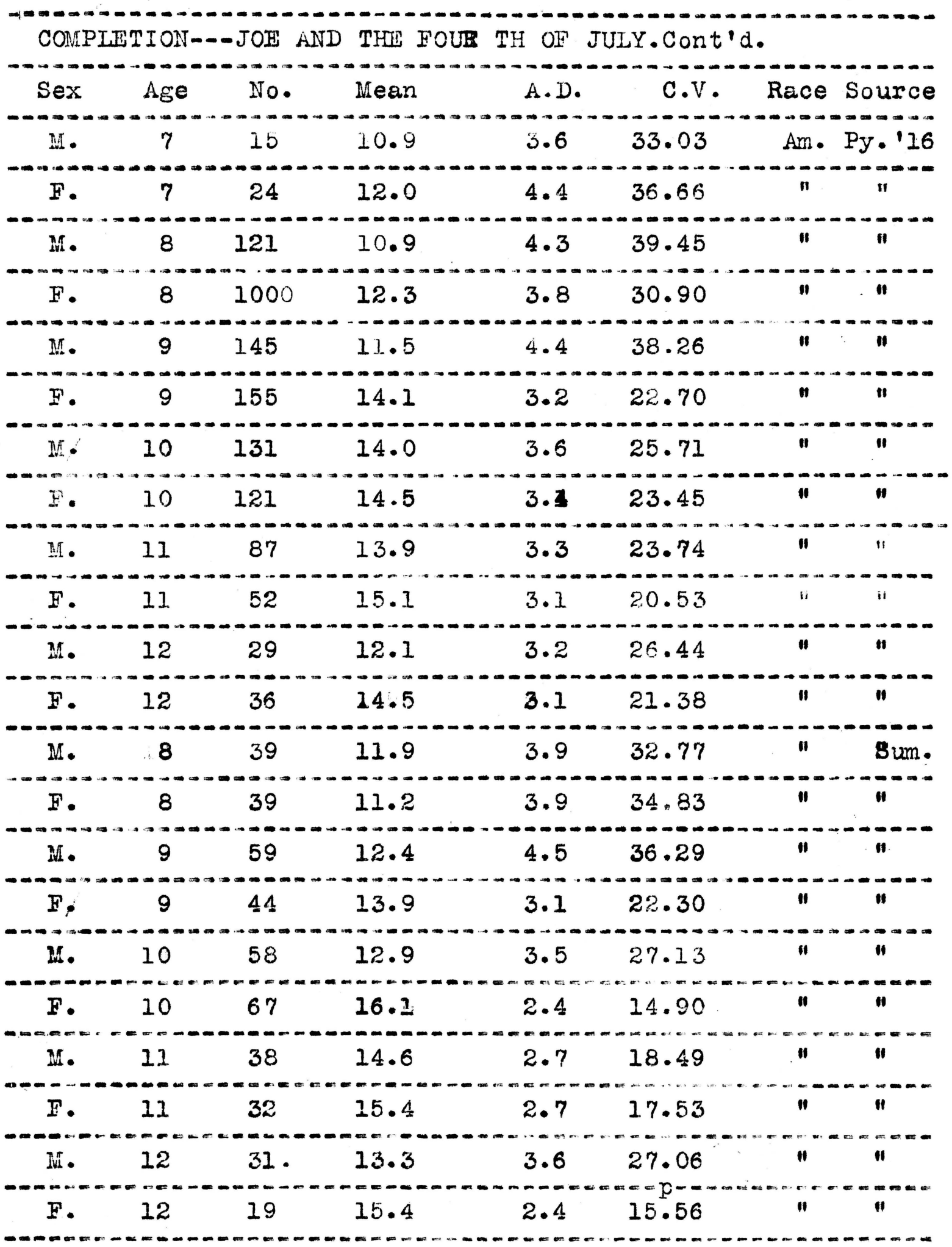


COMPINIIOAT-.. - TROUT.

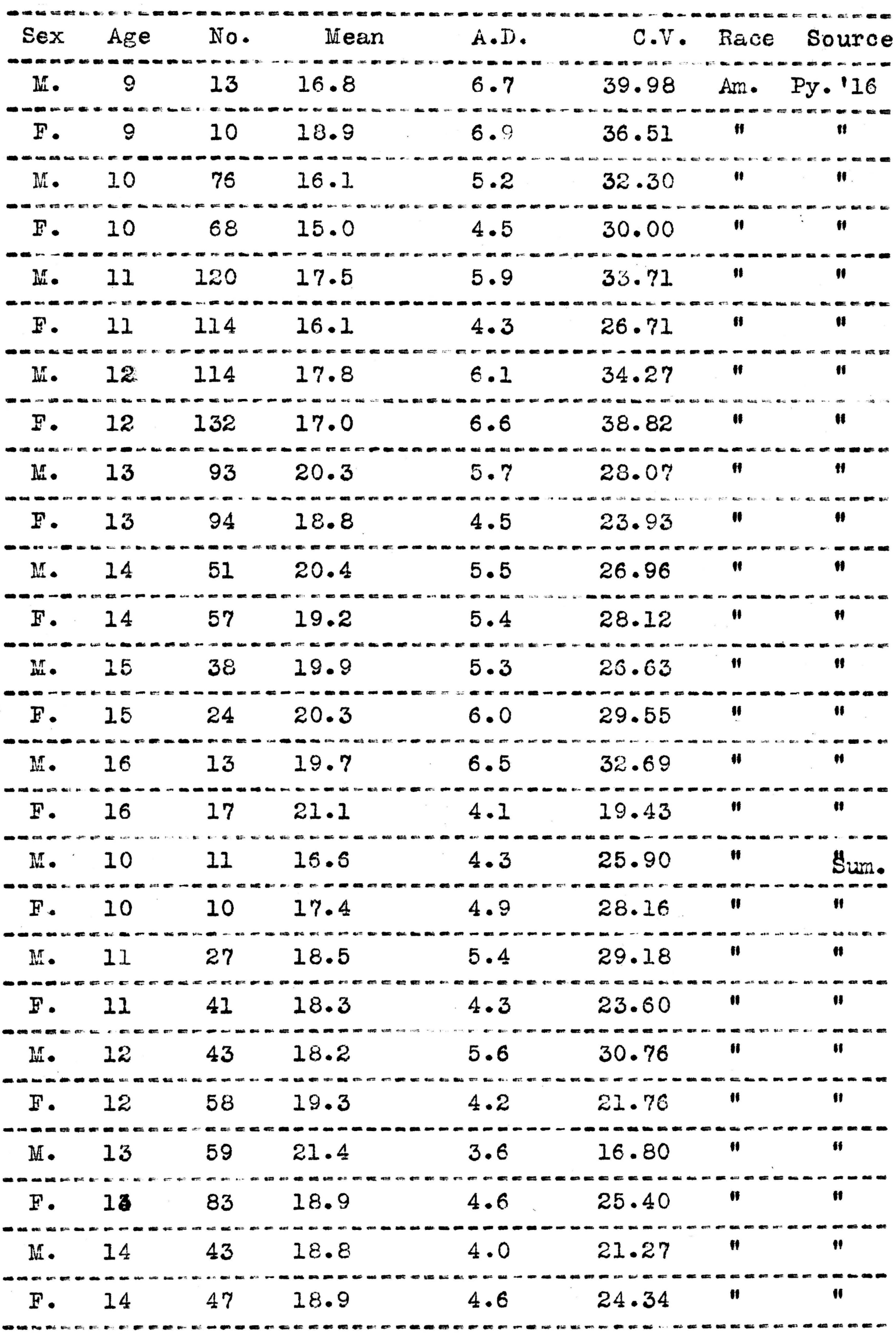


COMPIJTION- - DR. GOIDSMITH.

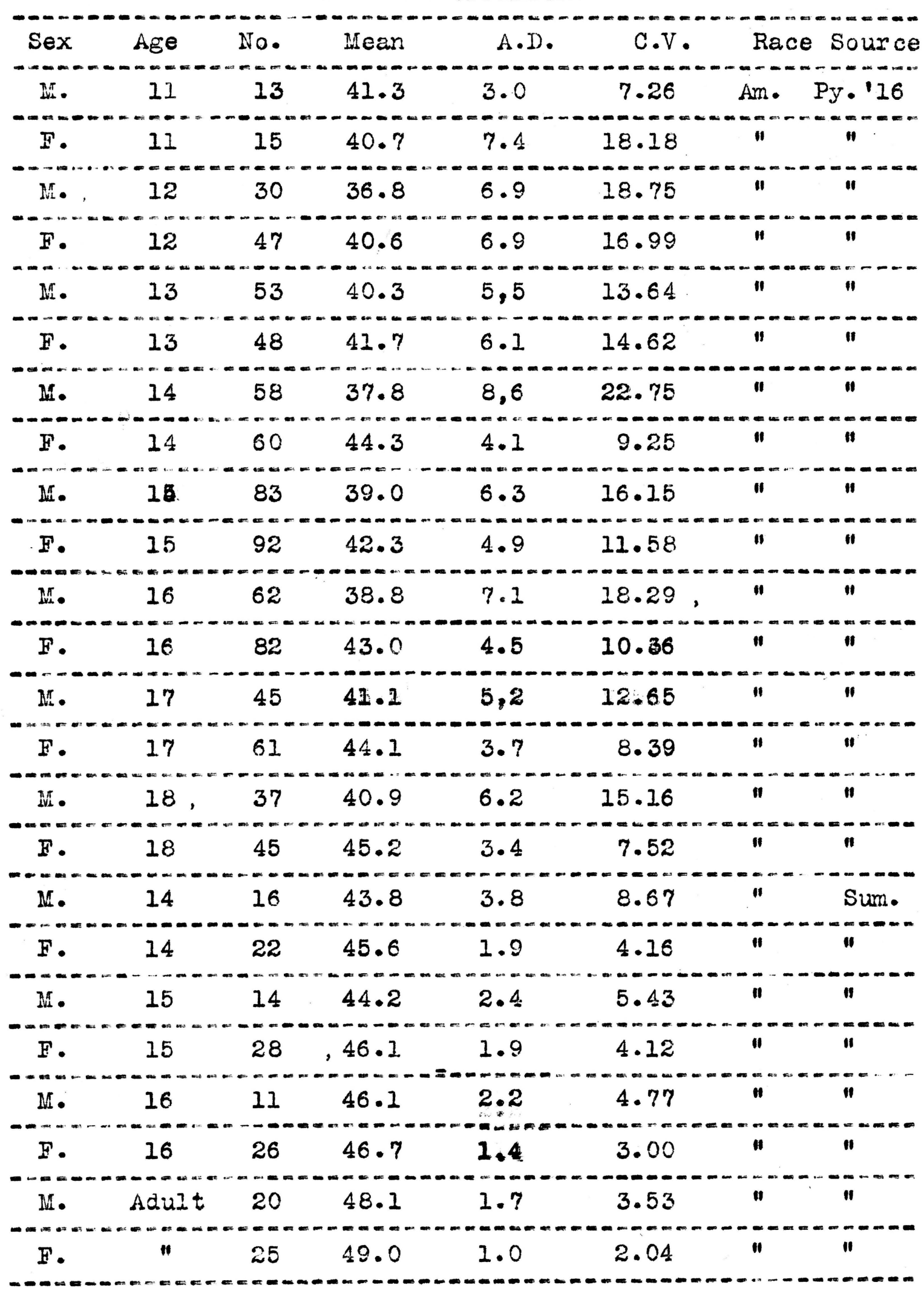


The Completion Tests--three in number--have the following results:-

1. "Joe and the Fourth of July"

a). Colling's series show the males more variable at eight of the seven ages, and their average C. V. $2.48 \%$ greater than the females.

b). Pyle 16 finds the males more variable at 8,9 , 10, 11 , and 12 as compored with the females being more variable at 7 ; and the average C. V. $6.93 \%$ greater for the males.

c). My data shows the males more variable at 9, 10, 11, and 12; the females more so at 8; and the average $7.33 \%$ greater for the males.

2. "The Trout"

a). Pyle 116 finds the females more variable at 12 , 14, and 15; the males more variable at $9,10,11$, 13, and 16 ; and the average $2.18 \%$ greater for the males.

b). My data shows the average C. V. .07 of $1 \%$ greater for the males in spite of the fact that the females are more variable at four of the six ages tested.

3. "Dr. Goldsmith"--in two series--shows greater male variability, the difference in the series being $3.46 \%$ and $2.53 \%$ respectively.

The Completion pests show the males more variable in six of the seven series when the average C. V.s are compared. 


\section{SUBSIIIUTION---DIGIT-SYMBOL.}

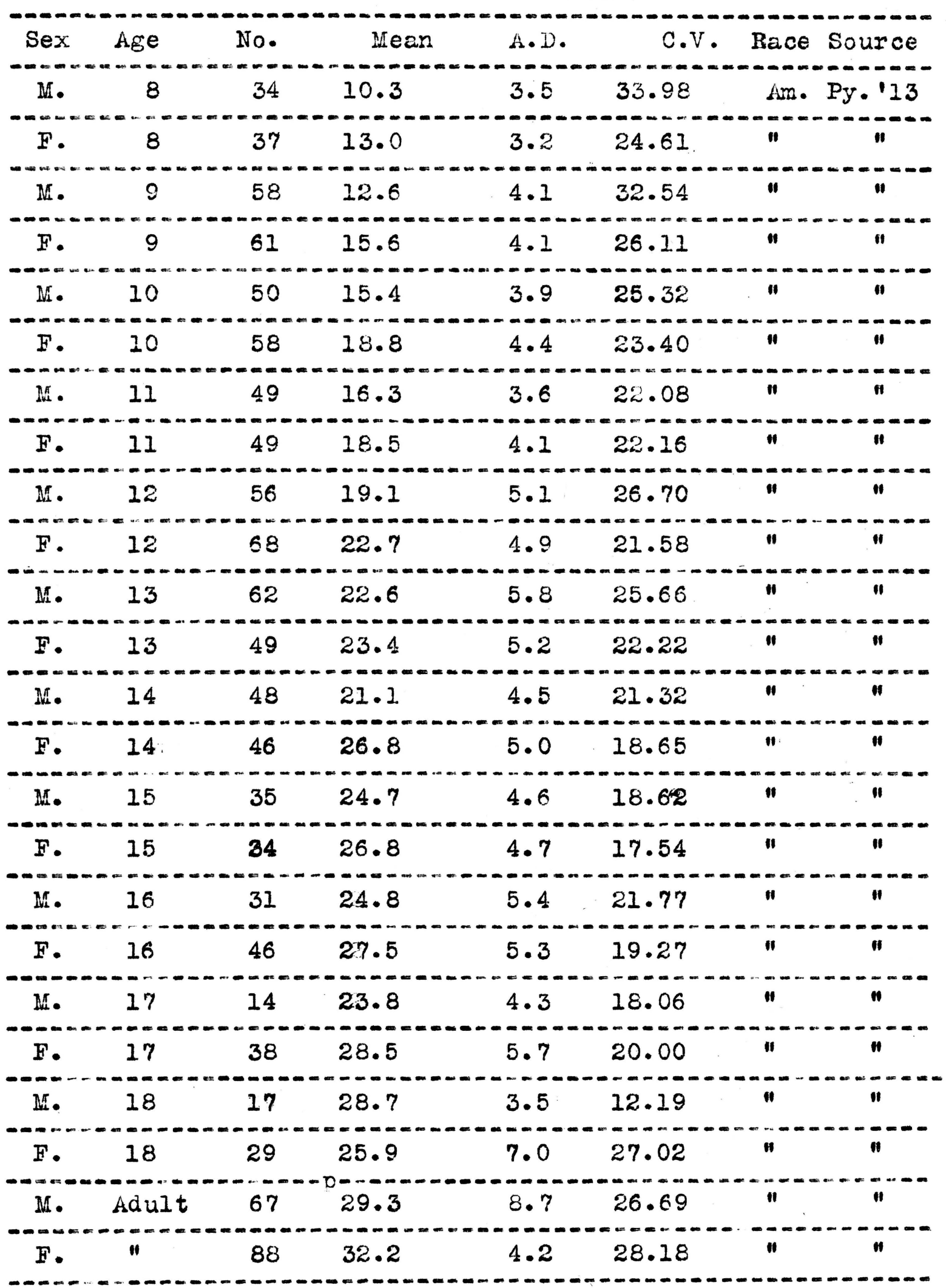


SUBSTITUTION-- SYMBOI-DIGIT.

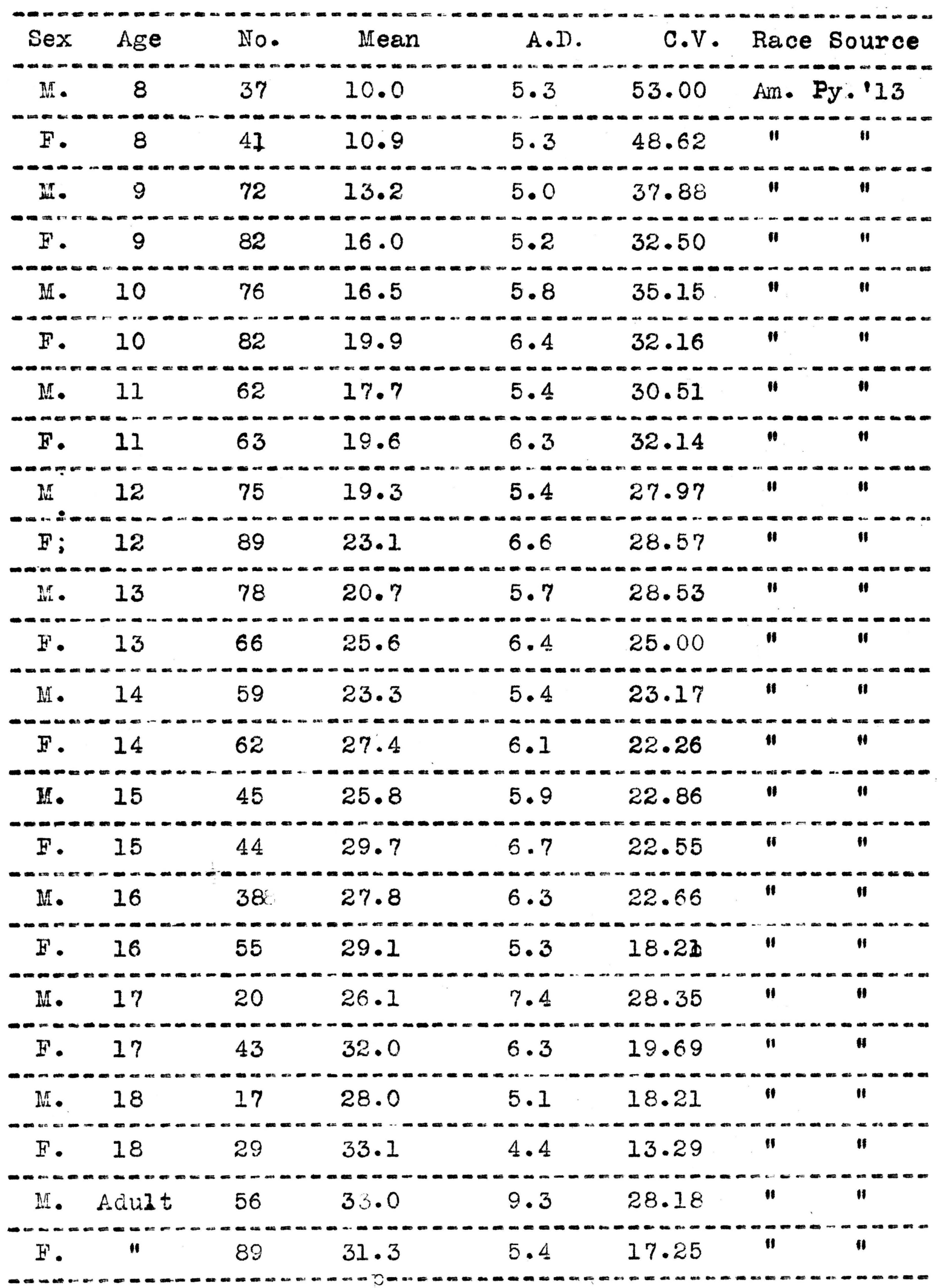




\section{SUBSIIUTION-D-DIGII-SYMBOI.}

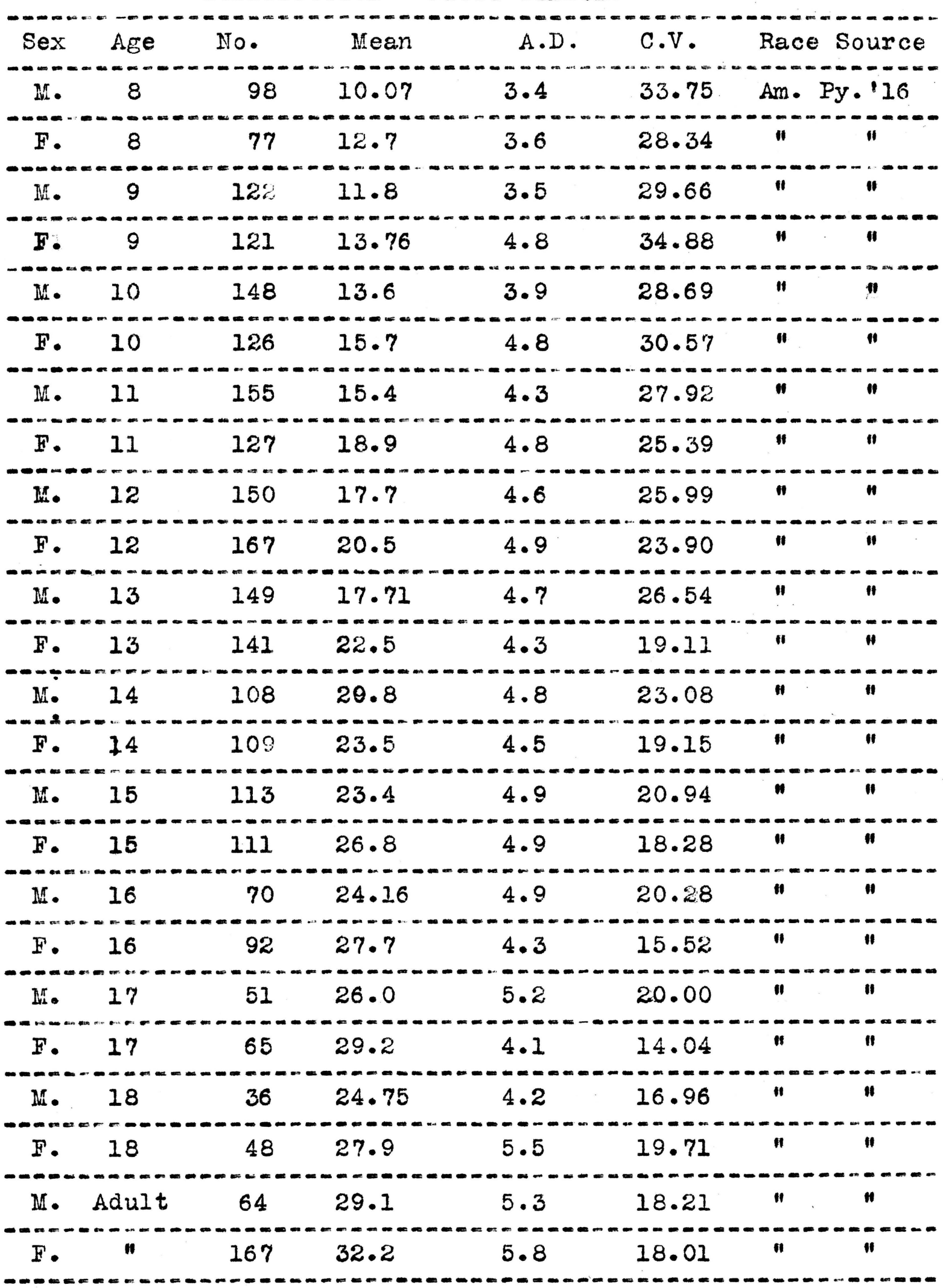


SUBSTITUTION-D-DICIT-SYMBOI.

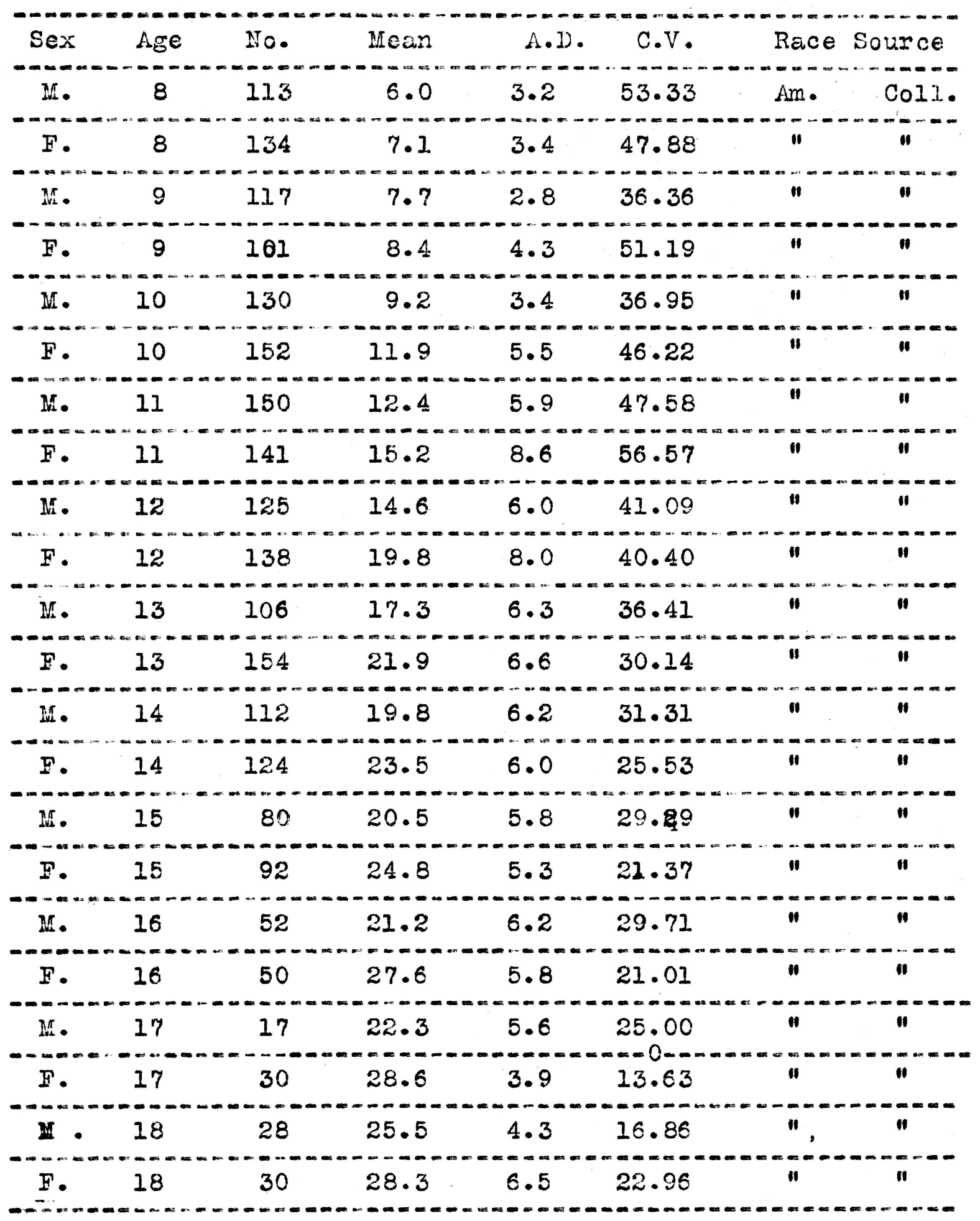




\section{SUBSTIIUTION--- ĐIGIT-SYMBOL. Cont' $d$.}

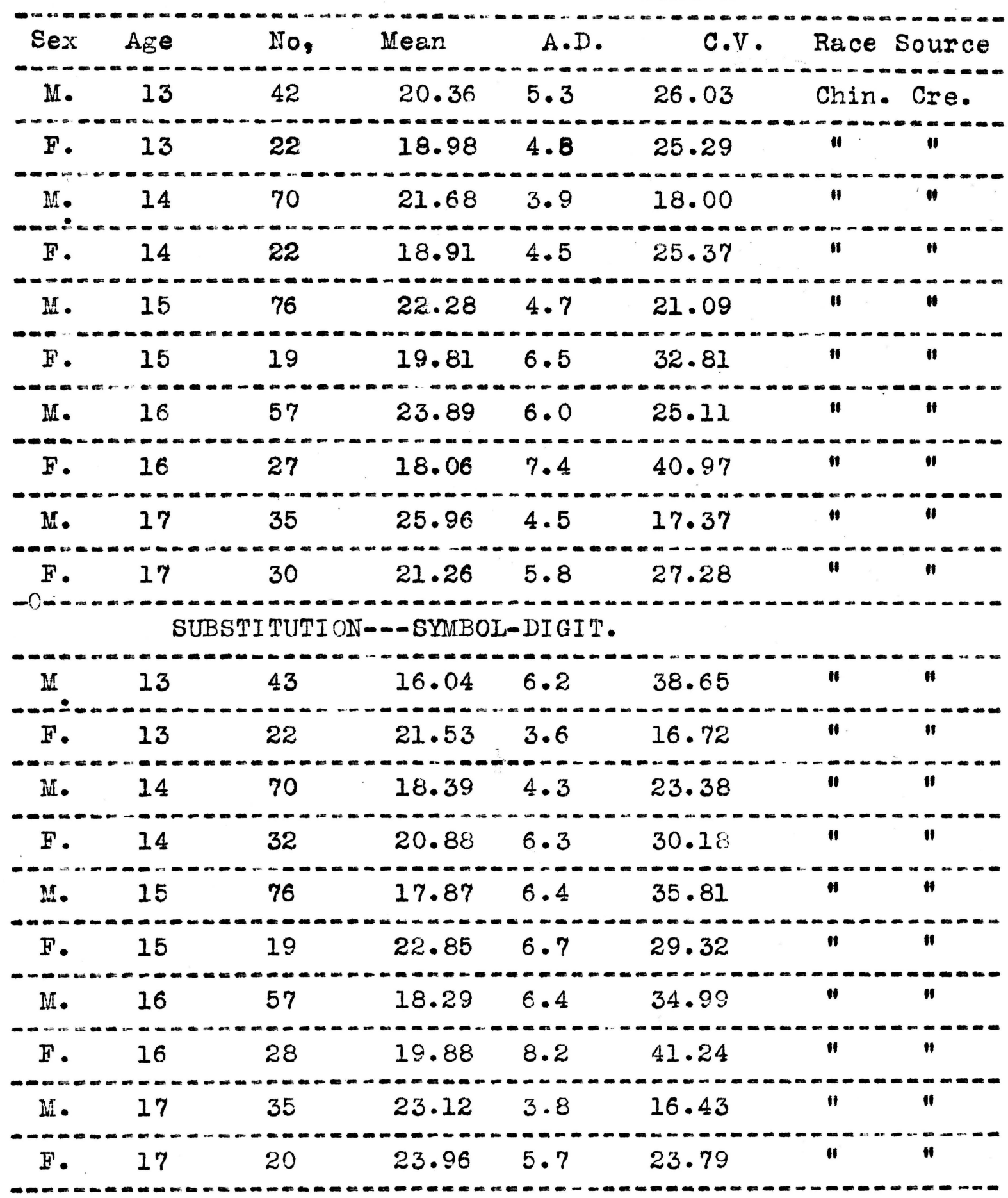


The substitution of symbols for digits and digits for symbols indicates greater male variability in five out of six series--as follows:-

1. Collings found males more variable at all ages except $9,10,11$, and 18, and their average .55 of $1 \%$ greater. 2. Pyle 'I3 found males more variable at all ages tested except 9,10 , and 18, and their average $2.25 \%$ greater in the digit-symbol test. In the symbol-digit test they were more variable at every age except 11 , and 12 , and their average was $2.93 \%$ greater than that of the female.

3. Pyle ' 16 found the males more variable at all ages except 11, 17, and 18, and the average $1.43 \%$ greater for the males.

4. The Chinese data are somewhat contradictory. When all ages are averaged in the symbol-digit test the females are more variable at 14, 16, and 17; the males at 13, and 15; and the average C.V. $1.6 \%$ great $\in \mathrm{r}$ for the males. In the digit-symbol test the females are more variable at ages 14, 15, 16, and 17. The males are more variable at 13, and the average is $6.82 \%$ grecter for the females.

The three American series indicate greater male variability, and the Chinese data shows girls more variable in one test and the boys in the other. 
INVENTI IN-...WORD-BUIIJING.

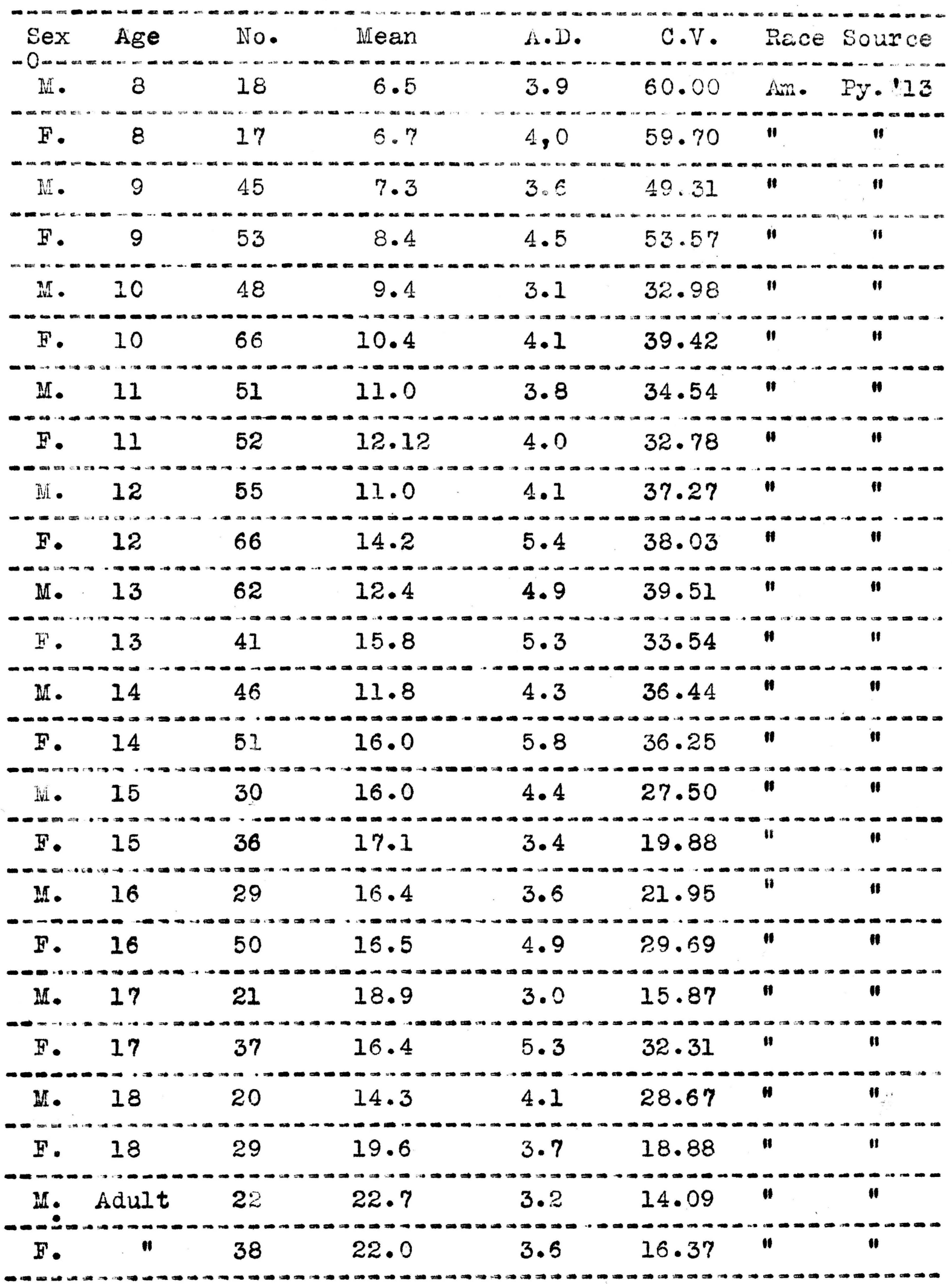


WORD BUIIDING - - Cont 'a.

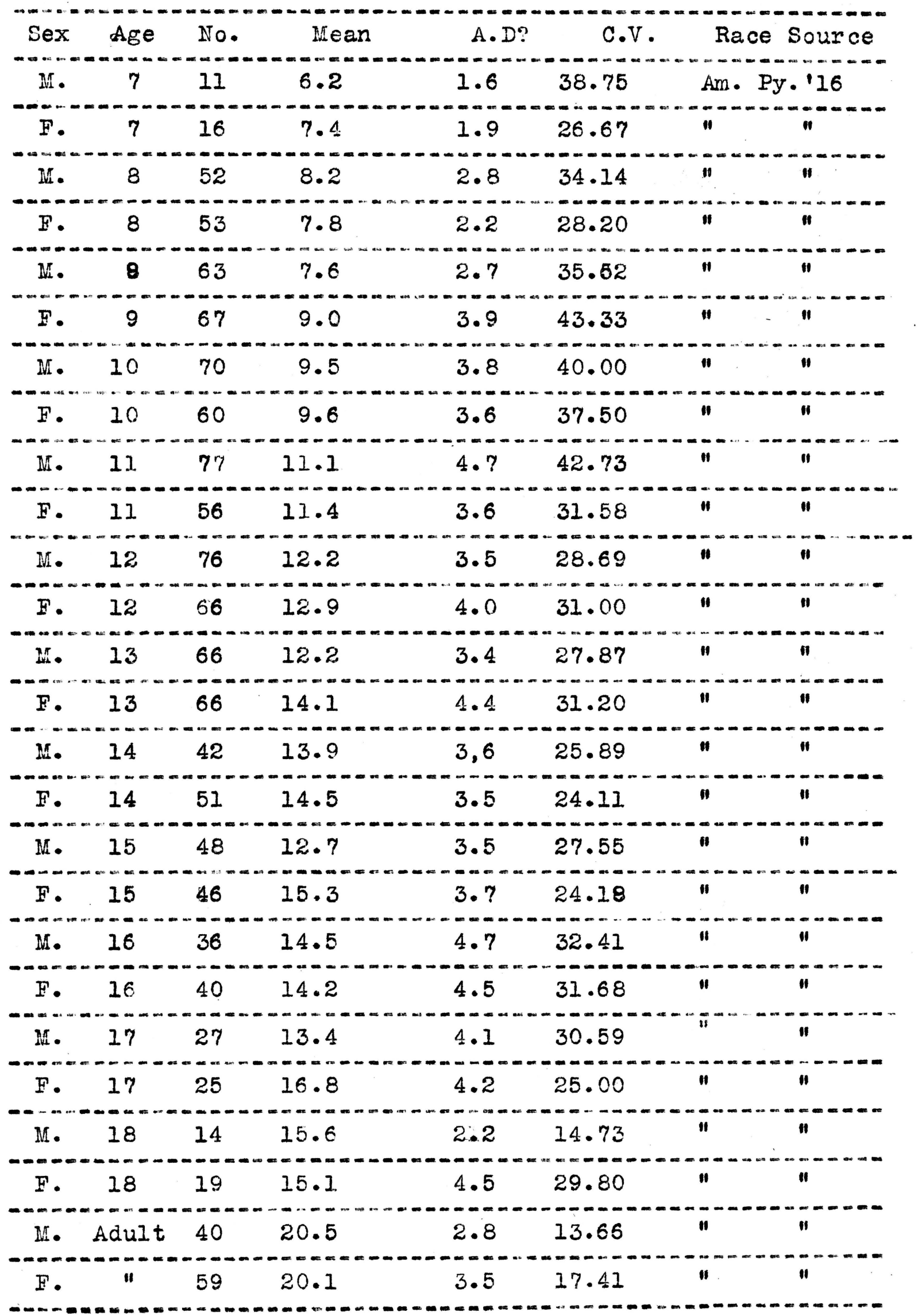




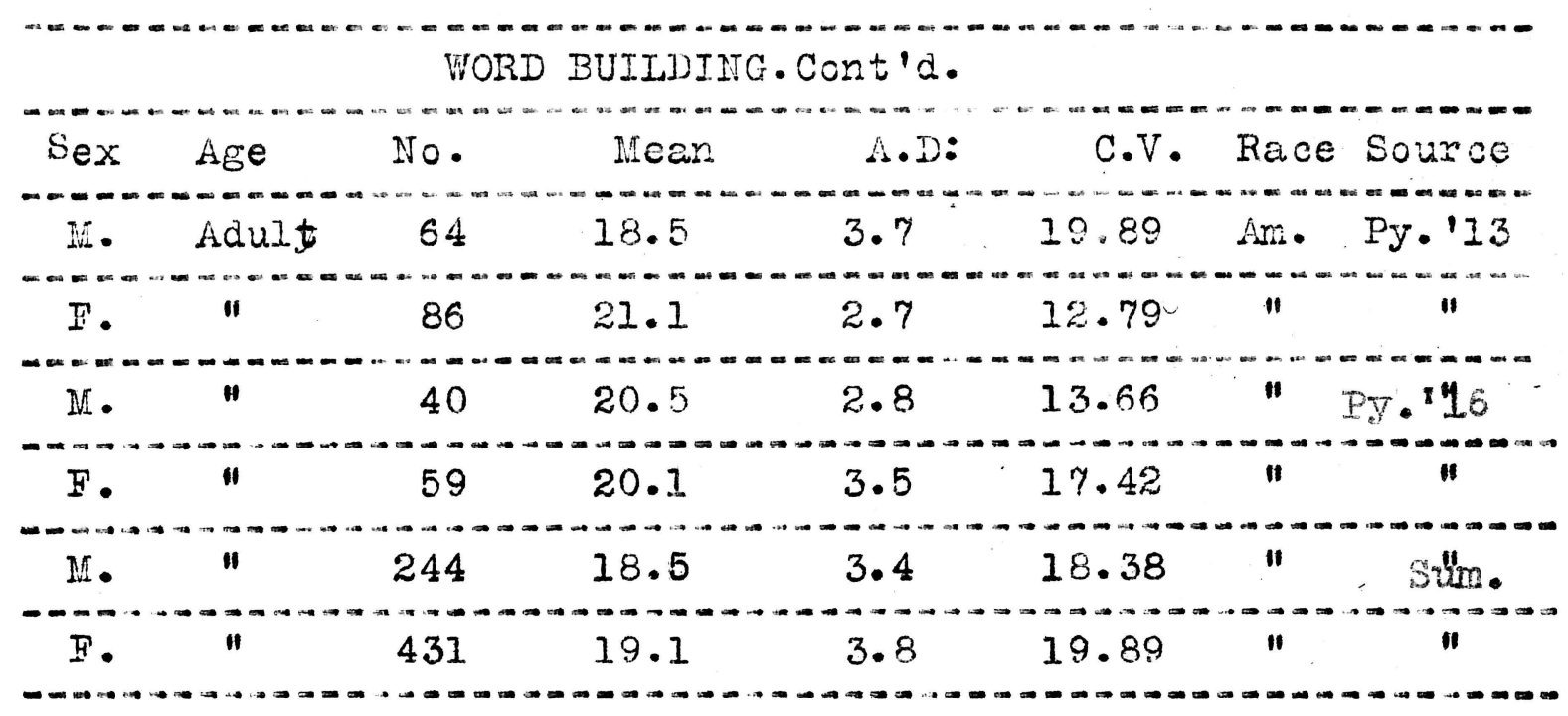

The two groups of results in the word-building test were taken from Dr. Pyle's Manuals.

The 1913 Manual shows girls more variable at 9, 10, 11 , 16, and 17 years; ard the boys more variable at $8,11,13,14$, 15, and 18 years. The average C.V. is .91 of $1 \%$ greater for the giris.

The 1916 Manual indicates greater female variability at 9, 12, 13, and 18 years; and greater male variability at the other ages. The difference in average C.V.s is .18 of $1 \%$ with that of the males predominating.

In the three series of adult data the males are more variable.

The series of results among school children agree that the males are more variable at $8,11,14$, and 15; and the female more variable at 9 , and 12 years. The other ages show contradictory evidence. At least we can say definitely that the male adults are more variable in word-building than female adults. 
CANCYIIAAIION.

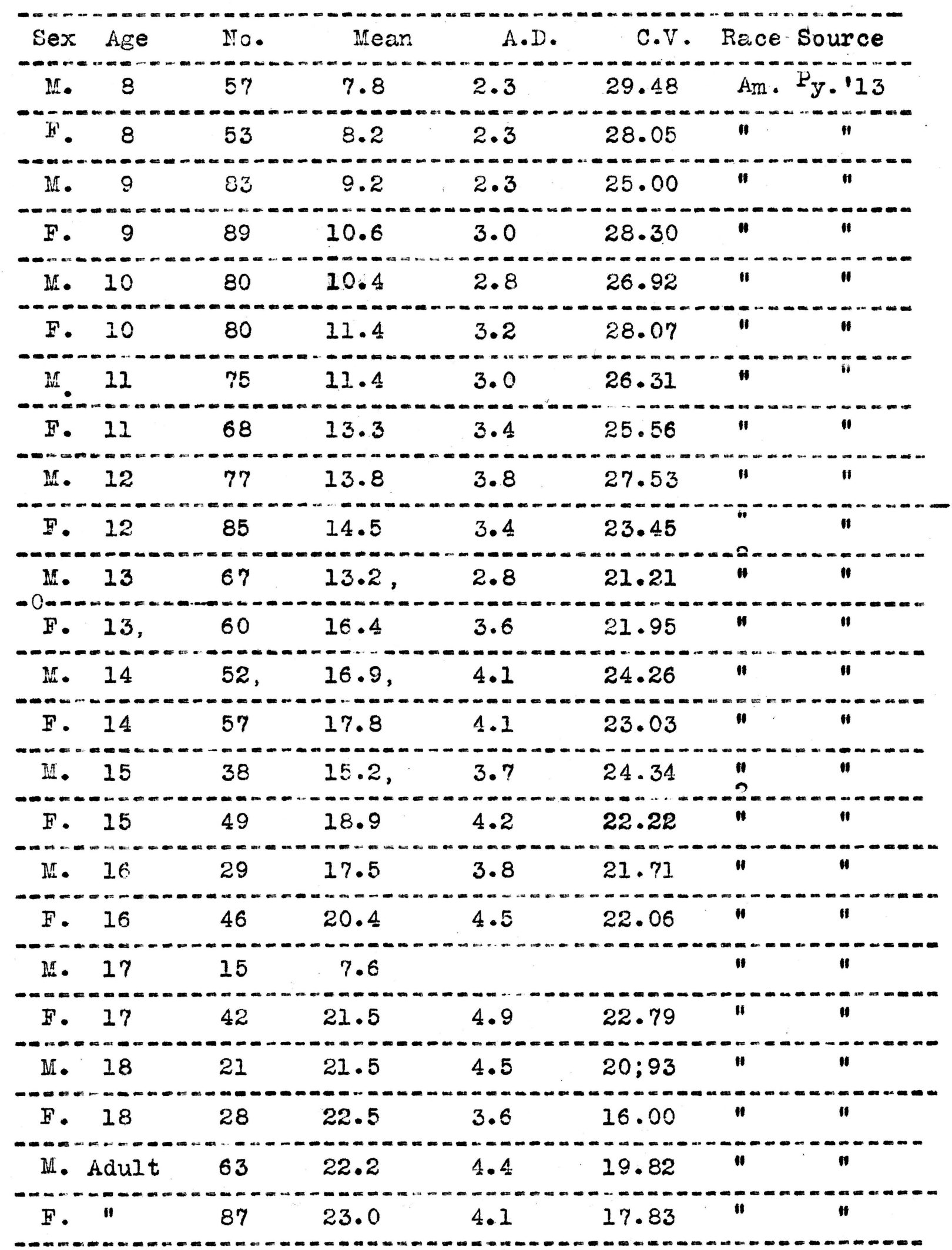


The single series of cancellation tests show the females more variable at the ages $9,10,13$ and 16 . The males are more variable at the remaining seven ages, and anong the adults. The average C. V. is .51 of $1 \%$ greater for the males, but this one series is too limited to permit any generalization concerning preponderating male variability. 
SPEED WRITING.

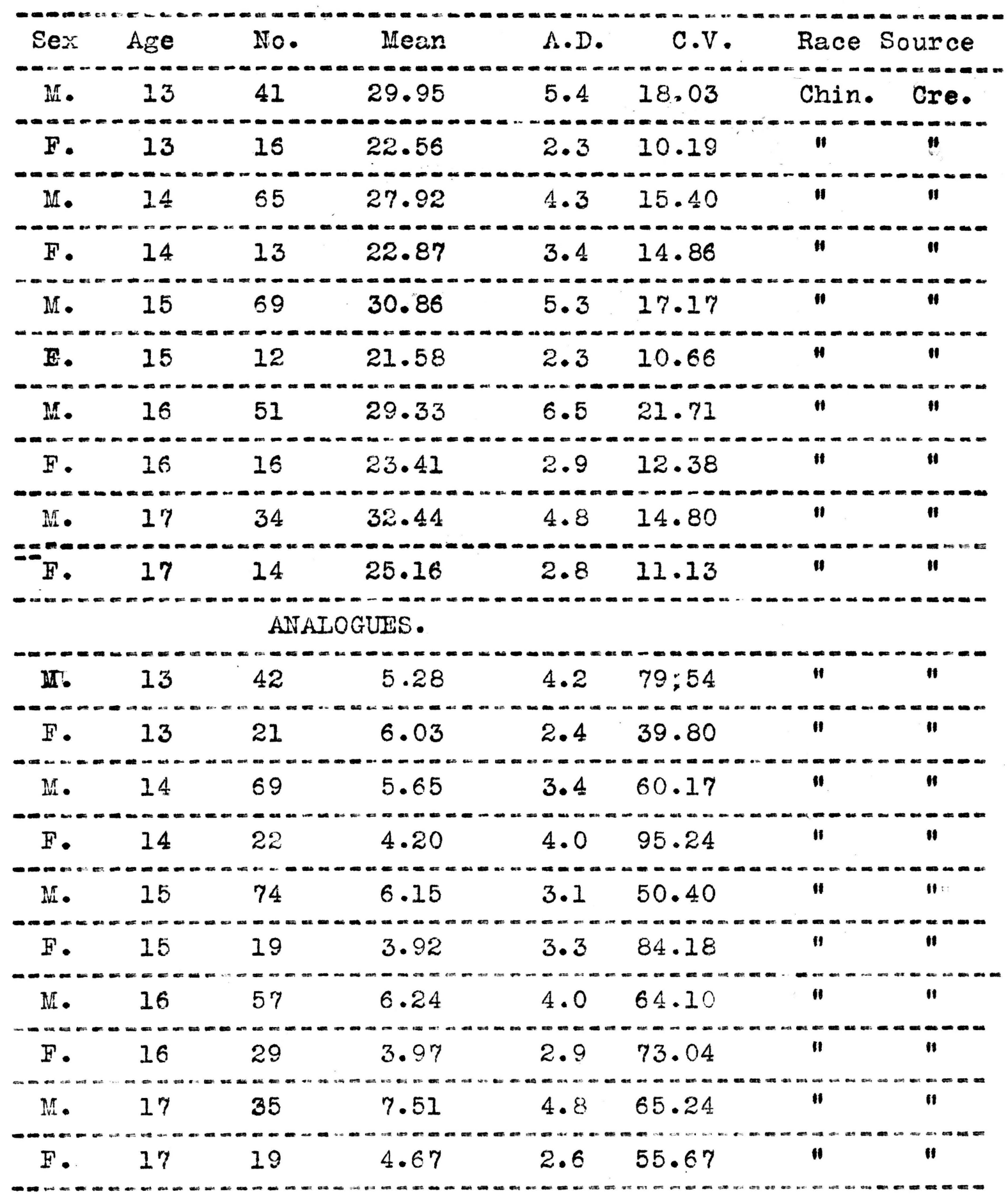


The male Chinese student is more variable in speed of writing at every age, the average C. V. being $5.58 \%$ greater for that sex.

In analogues the females are more variable at 14,15 , and 16 years, the males more variable at 13 , and 17. The average C. V. of the females is $5.7 . \%$ greater than that of the males. 
A summary of the results of the physical measurements would be,for the most part, merely a copy of the data because they are the results of many different investigations. The units and methods were not always uniform, so that combinations and comparisons of them are not justified.

The most extensive series is Porter's data on St. Louis school children. From it we are able to make a study of the various ages with the result that in stature, span, weight, and chest girth, the girls appear more variable at the ages six to thirteen inclusive, and the boys more variable at adolescence.

Girls appear more variable in grip, width of head, arm-bone length; weight of internal organs and brain, strength of pull, and adult weight. Boys show greater variability in sitting height, length of head, facial measurements, leg-bone length, and weight at birth.

In skull capacity and cephalic index the sexes appear equally variable. The bone length data cannot be treated by age, and the strength of pull, weight of internal organs, and some other measurements are for adults only, so that no comparison of variability at various ages is possible.

Therefore, owing to the fact that the physical data are inadequate, I can only say, in conclusion, that the indications are that girls are more variable between six and thirteen years, and the boys show greater variability at adolescence. 
Fortunately the mental dataare uniform as to method and treatment, because it is the result of investigations made by Dr. W. H. Pyle, Professor of Educational Psychology at the University of Missouri, and three of his students. Colling's data obtained from tests given to rural school children in McDonald County, Hissouri. Creighton examined the pupils of a Chinese school in which he was a teacher. Hy own data obtained in the Joplin, Mo. schools with the exception of the adult measurements. The latter came from University records. Dr. Pyle's two groups are the results of testing school chilaren in various lissouri towns and cities.

Collings gave eight tests to eleven ages--making eighty-eight coefficients of variation for each sex. Fiftyseven times out of the eighty-eight the boys' C.V. Was greater than the girls'. When all tests were combined the girls showed greater variability at the ages $8,9,11$, and 18; while the boys were more variakle at 12, 13, 14, 15, 16, and 17 years. However, when the ages were combined, the boys proved more variable in six of the eight tests. The only exceptions were Free Association and Completion.

I also gave eight tests but varied them as to ages so my series gave only fifty-three C. V's for each sex. The boys' C. V. was greater thirty-nine of the fifty-three times. When all my tests were averaged the boys showed greater varibility at all ages except thirteen, and when all ages were everaged they proved more variable in every test except opposites I and that was a small series. 
Dr. Pyle's 113 series has eleven tests et various ages making one hundred and twenty-one in all. Of that number, the boys have a preponderating variability eighty-one times. When all tests were averaged the males were more variable at all ages except 11, 14, and 17, and when the ages were combined they showed greater variability in every test except word building.

The 1916 series show greater variability for the boys, the ratio being seventy-four to thirty-eight with the boys in the majority. When the tests are averaged the boys are more variable at every age except eleven, and when ages are combined they appear more variable in every test.

Creighton's is the only series which shows predominating variability for the girls when ages or tests are combined and out of sixty-two chances the girls are more variable in thirty-three cases.

My general conclusion from the mental data is that the boys show greater variability--especially in adolescence. 


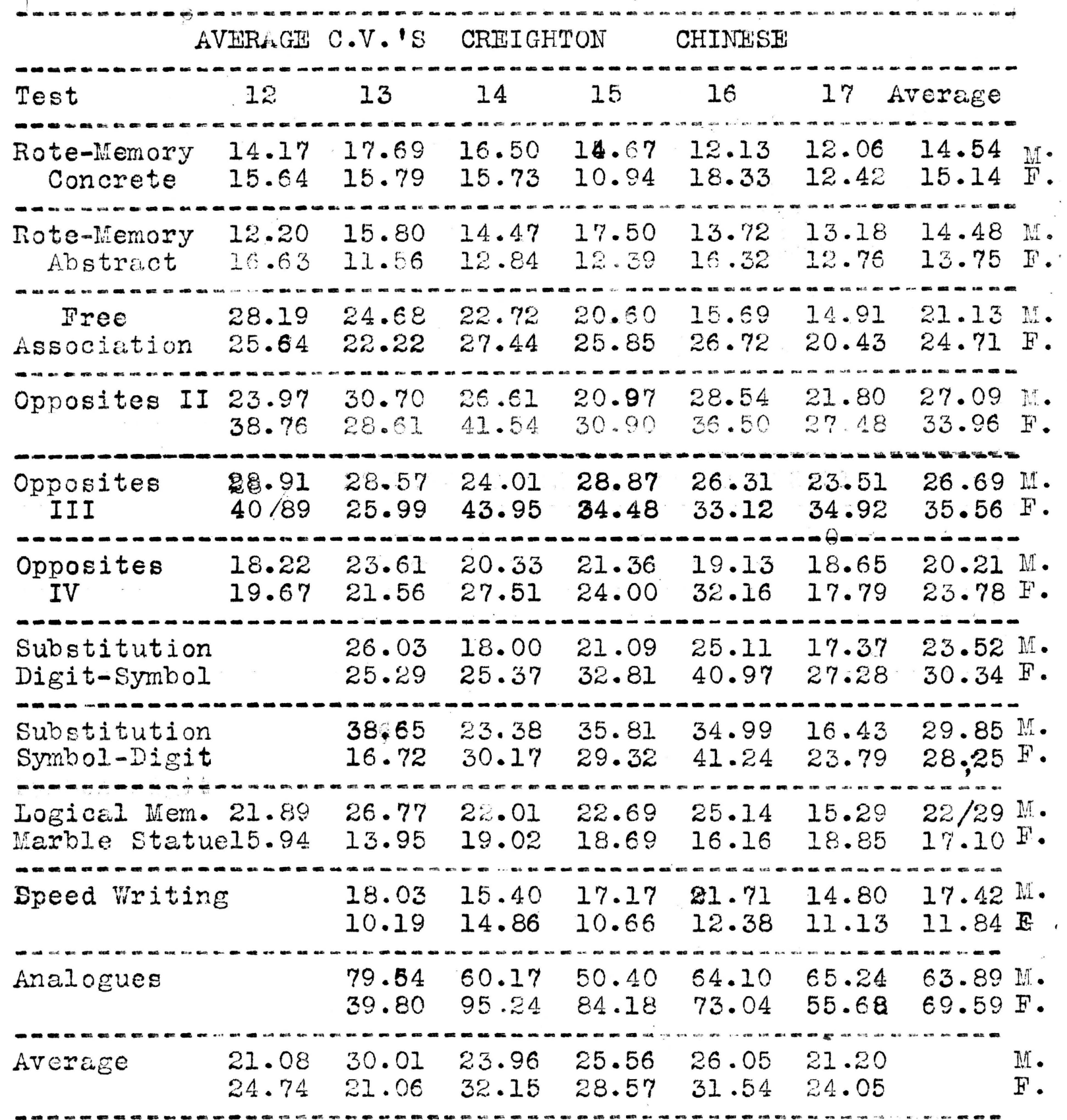

Creighton's Chinese girls are more variable in seven of the elcven tosts when all ages are averaged and when all. the tests are averaged they are moro variableat the ages $12,14,1.5,16$ and 17 


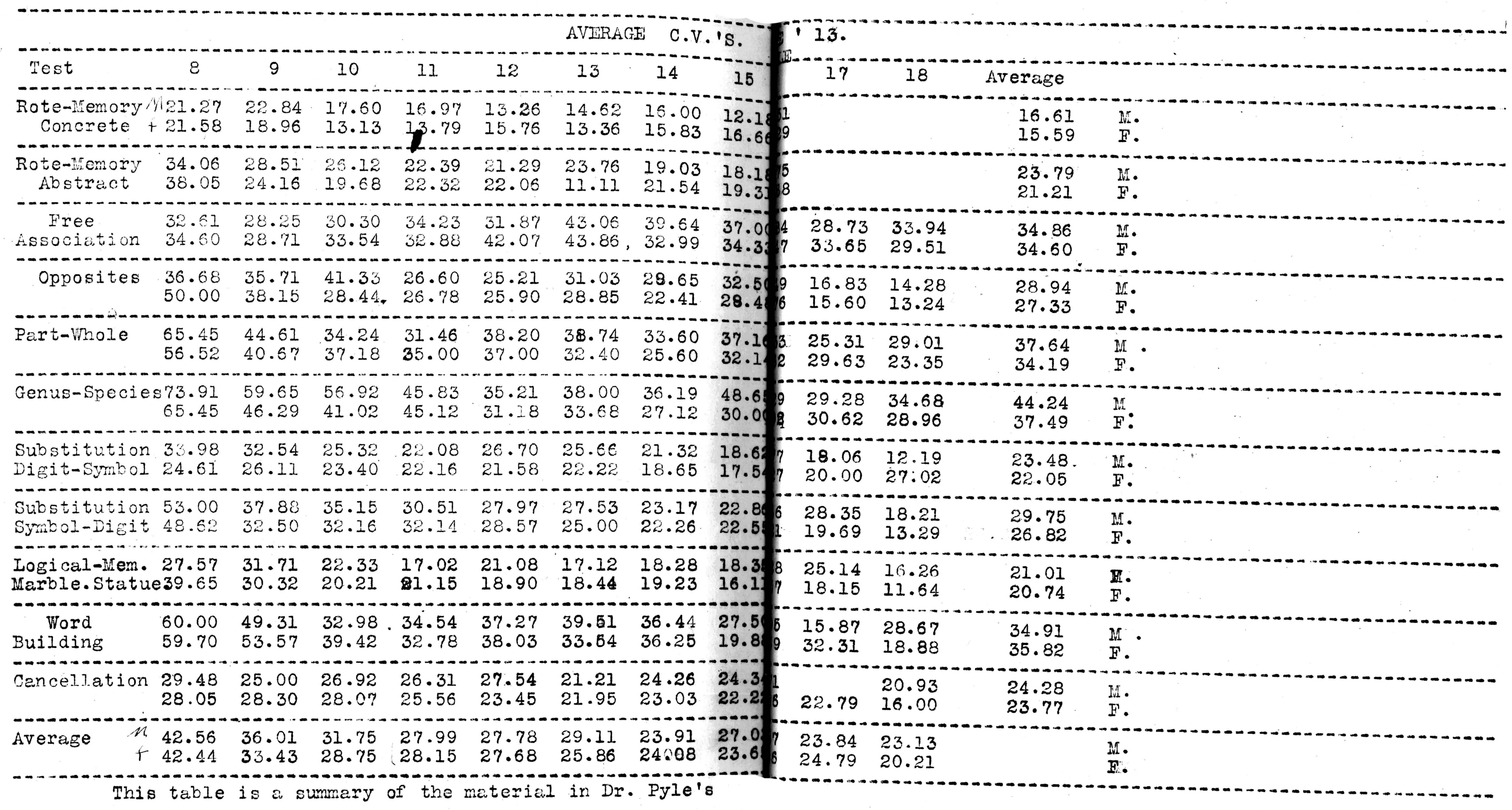

Mianual which was issued in 113.

When all ages are combined the males are more variable

in every test except word building. When the average C.V.'B

of all tests are combined the males are more variable at the age

$8,9,10,2,12,13,15,16$ and 18 . 


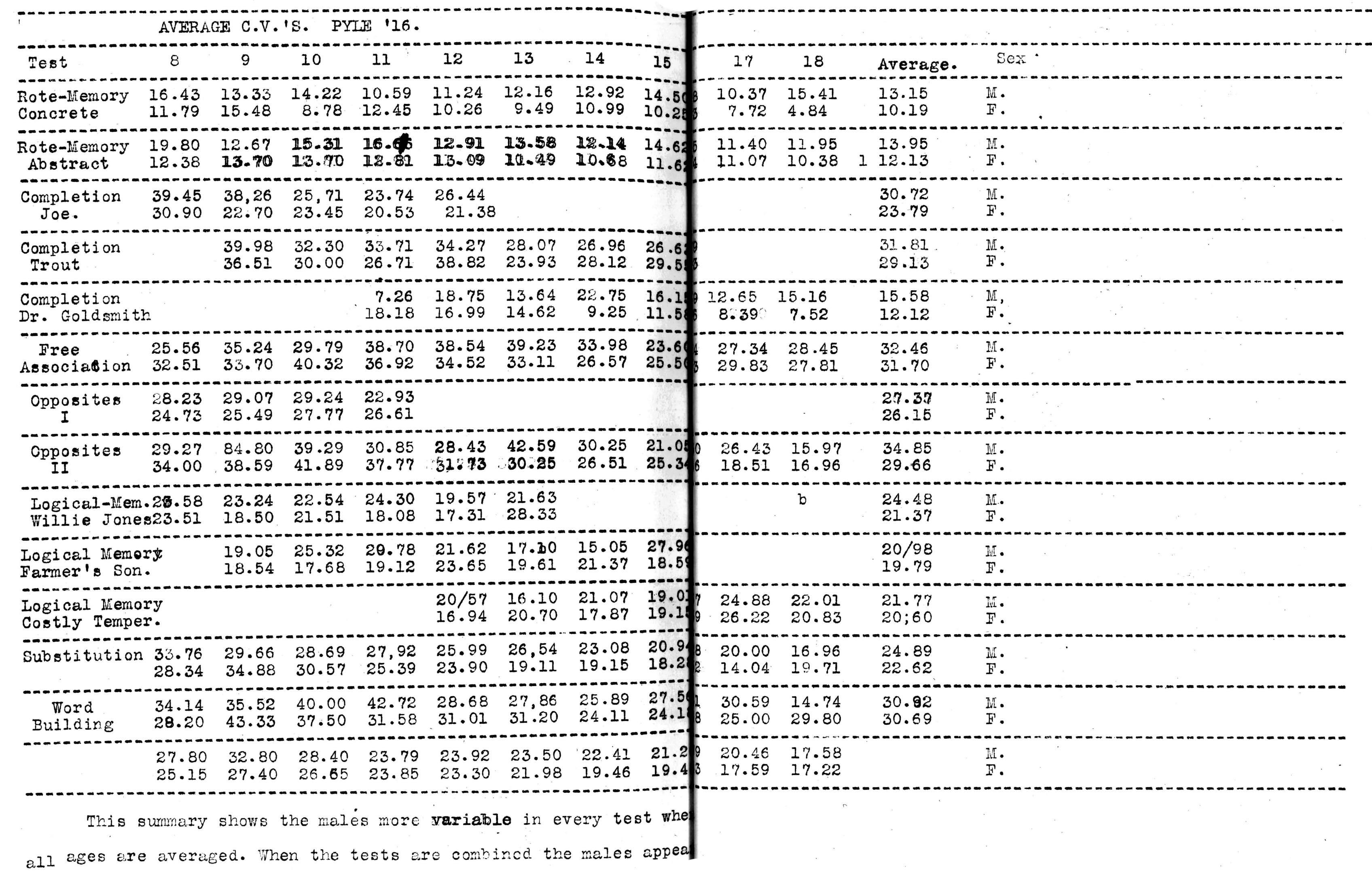

more variable at every age except 11 years. 


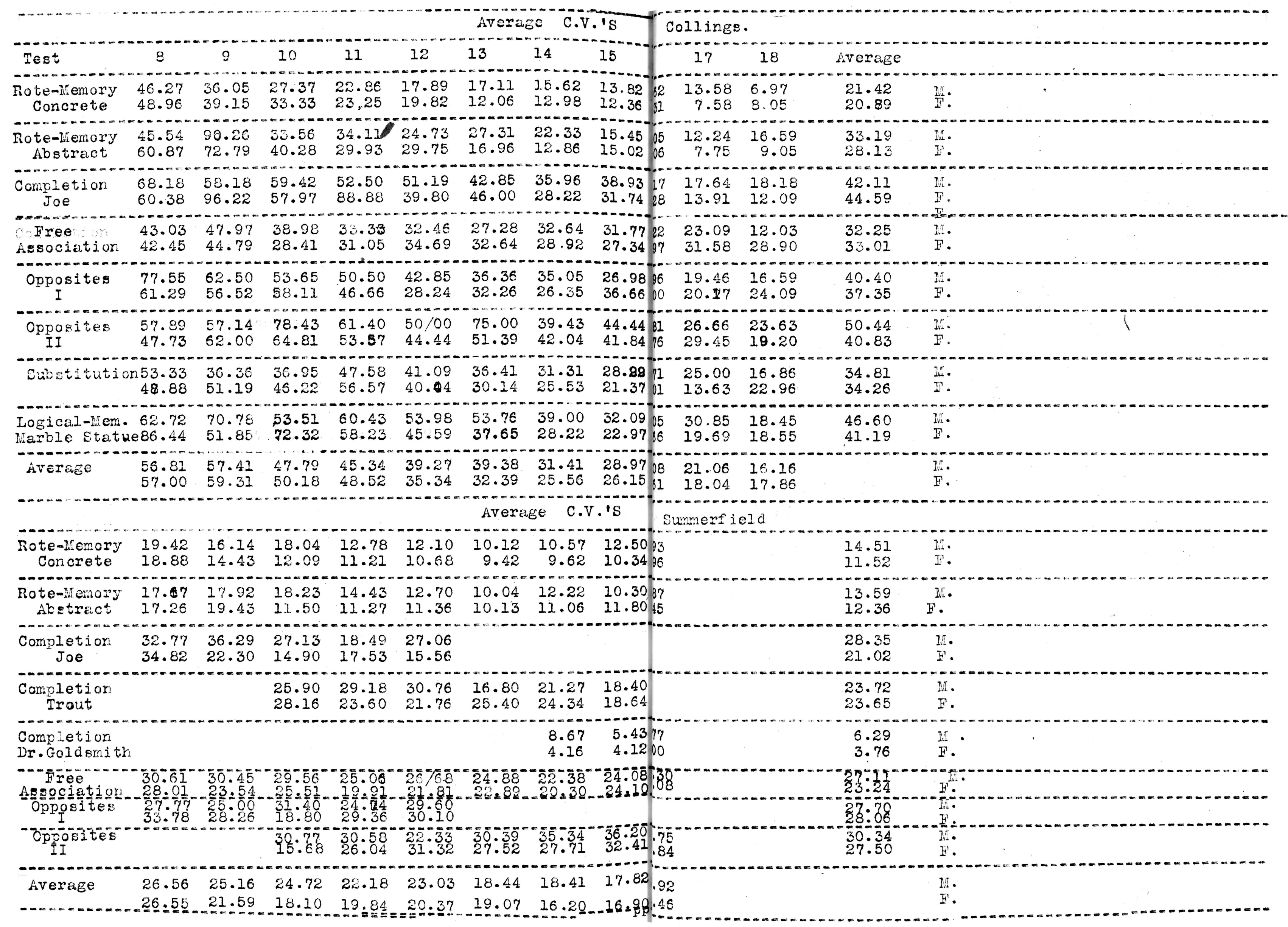




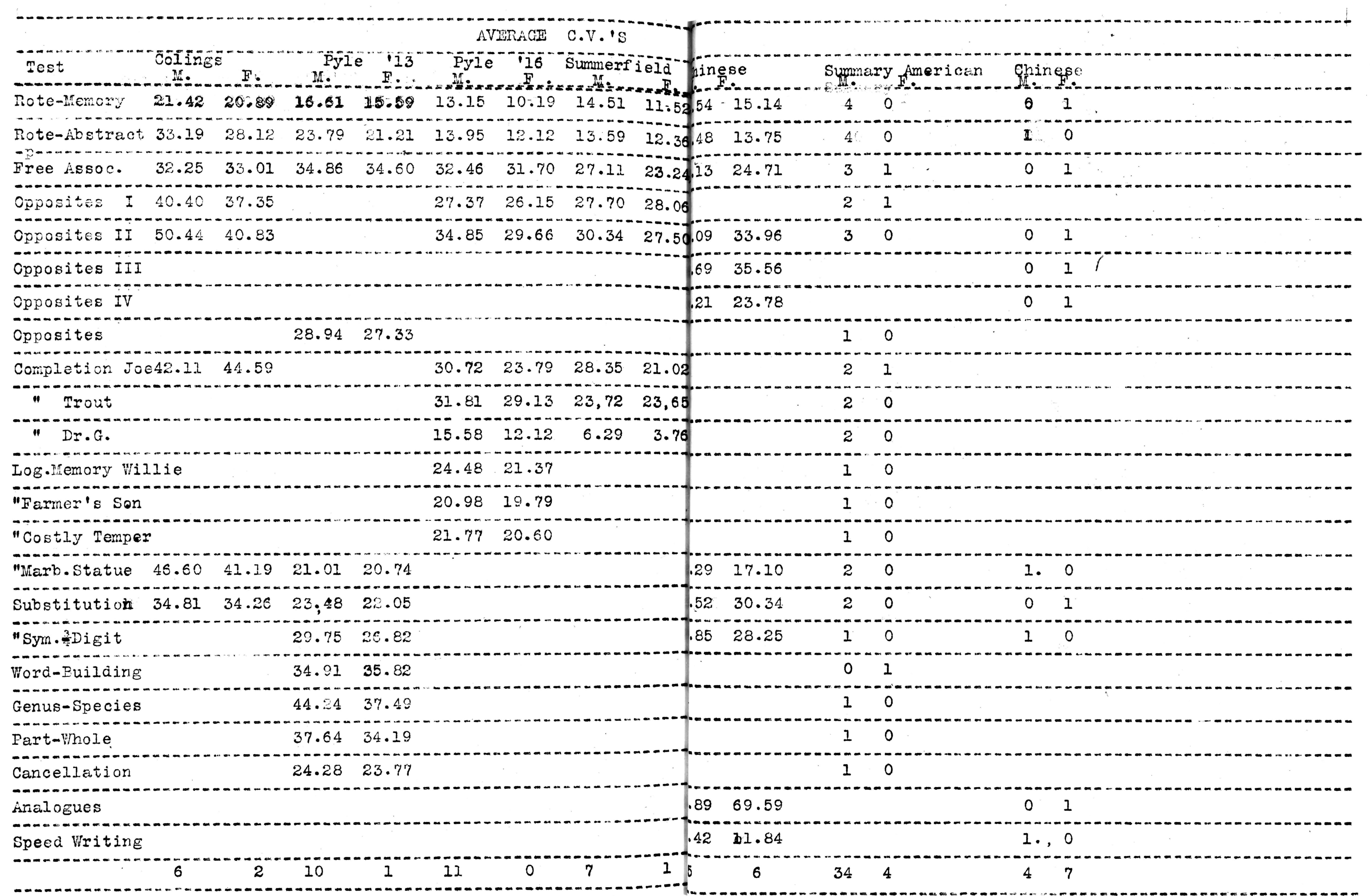


Colling's material shows the boys predominating in variability in six tests when all ages are averaged while the girls are more variable in only two. His teibles also show thet when all the tests are averaged the girls are more variable at the ages $8,9,10,11$, and 18 , while the boys are more so at $12,13,14,15,16$, and 17 . This conforms with my general conclusion that the girls are more variable during the earlier ages and the boys are more variable during adolescence.

In my own data I find the average $C$. $V$. of the boys greater in all tests when all ages are averaged with the exception of Opposites I. When all tests are averaged the males show greater variability at all ages except 13. When these five tables are combined and the number of tests in which each sex shows greater variability is noted, I find the following results:-

$\begin{array}{ccc}\text { Age } & \text { M. } & \text { F. } \\ 8 & 18 & 12 \\ 9 & 21 & 12 \\ 10 & 23 & 13 \\ 11 & 23 & 11 \\ 12 & 21 & 14 \\ 13 & 20 & 10 \\ 14 & 26 & 5 \\ 15 & 21 & 9 \\ 16 & 23 & 6 \\ 17 & 12 & 10 \\ 18 & 14 & 8\end{array}$




\section{BIBLIOGRAPHY}

1. F. Boas....." "he Growth of Toronto Children"

1897-98 Report of the British Association for the Advancement of Science. p.44.

2. F. G. Bonser-..-measoning Abilities of Children of Fourth, 1910 Fifth, and Sixth School Grades-New York School Collection. p.133.

3. E. G. Boring--.-Capacity to Report on Moving Pictures-. 1916 Ir. of Criminal Law and Criminology. V. 6. $p p \cdot 820-834$

4. Warren Brown---Individual and Sex Differences in SugJuly 11, gestion--U. of Cal. v.2. No.6. pp.291-430. 1916.

5. J. C. Brom-..... Investigation of the Value of Irill Work 1912 in the Fundamental Operations of firithmetic-Jr. of Ed. Psych. V.3--pp.485-492 and 562-570.

6. C. Burt--.-Exp. Tests of Higher Mental Processes and Theix 1912 Relations to General Intellieence--Ir. Exp. Ped v. 1--pp.93-112.

7. C. Burt and R. C. Moore---Mental Differences Between the Sexes

8. S. A. Courtis---neport on the Courtis Tests in Arith1911 metic-New York Com. School Inquiry. v. 1--pp.391-546.

9. Davenport-...-Statistical Hethods.

10. Havelock ElIis--.Man and Woman--Iondon-Walter Scott. 1897

11. Havelock Ellis----Studies in the Psychology of Sex. 
12. J. Finot----Problem of the Sexes--N. Y. Putnam1913

13. W. A. Fox and E. L. Thorndike---Relation Between the 1912 Different Abilities Involved in the study of Arithmetic. Sex Differences in Arithmetical Ability.--Columbia Contributions to Phil., Psych., and Education. v. 2--pp.32-40.

14. A. I. Gates----Correlations and Sex Differences in Memory and Substitution--U. of Cal. Pub. in Psych. V. 1--No.6.--pp.345-350.

15. A. I. Gates---Variations in Fifficiency During the Day.

U. of Cal. Press--v. 2.--No. 1.--pp.1-156.

16. F. Galton---Natural Inheritance.

17. H. H. Goddard----1000 Normal Children measured by the 1911 Binet Scale of Intelligence.--Am. Jr. of Psych. v. 18--pp.232-259.

18. G. Heymans---Die Psychologie der Frauen.

19. H. L. Hollingworth----Experimental Studies in Judgment. 1913 Archive of Psych. v.29--pp.6 and 119.

20. H. I. Hollingworth----Judgment of Persuasiveness.

1911 Psych. Review.--v. 28--p.4.

21. Hollingworth----Sex Differences in Mental Tests. 1916 Psych. Bulletin--v.13--p.377.

22. I. S. Hollingworth----Variability as Related to Sex

Differences in Achievement.--Am. Jr. of

Sociology. v. 19--pp.510-530. 
23. I. S. Hollingworth----Irequency of Anentici cs Related 1913 to Sex.--Hedical Record.

24. G. E. Jones---Mental Differences Between the Sexes. 1913 Ped. Sem. v. 20--pp. 401-405.

25. Kempr anà Haggerty----Suppression and Substitution as 1913 a Factor in Sex Differences. Am. Jr. of Psych.--v. 24--pp.414-425.

26. Gertrude Kuper---Group Differences in the Interests of Children.--Jr. of Phil., Psych., and Educ. v. 9--pp. 376-379.

2\%. Genevieve S. Manchester---Dxperiments on Unreflective 1905 Ideas of Men and Women. Psych. Review. v. 3z--pp. 300-30z.

28. E. P. Miller----Sex Selection of Major Subjects under 1906 the Elective System of Leland Standford Jr. University. Ped. Sem. v. 13--pp. 94-106.

29. R. C. Moore and C. Burt---Diental Differences Between 1912 the Sexes. Jr. Exp. Ed. v. I- -pp. 273-284 and $355-388$.

30. Mable I. Nelson---Differences Between Men and Women 1905 in Recognition of Color and Perception of Sound. Psych. Review--v. 12--pp. 271-286.

31. Karl Pearson-.--The Chances of Death. v. I. 189737 Bedford Street--London.

32. W. T. Porter----Growth of St. Louis Children. 1894 Trans. Acad. Science--St. Louis. v. 6--p.263. 33. . K. Strong---An Interesting Sex Difference. 1915 Ped. Sen. v.22--pp. 521-528. 
34. E. I. Thorndike---Educational Psychology. Vol III. 35. F. I. Weils----Sex Differences in the Tapping Tests. Am. Jr. Psych.

36. Clark Wissler--..

1901 Psych. Rev. No. 16

37. Helen Thompson Woolley---Mental. Traits of Sex.

38. Helen Thompson Woolley-n-.The Psychology of Sex.

1914 Psych. Bulletin--vol.II--pp. 353-379. 
$378.7 \mathrm{M} 71$

×S 462 
MU Libraries

Summerfie1d1919specsheet.txt

University of Missouri--Columbia

MU Theses and Dissertations (Pre-1920)

Local identifier

Capture information

Date captured

Scanner manufacturer

Scanner mode 1

Scanning system software

optical resolution

color settings

File types

Source information

Format

Content type

Source ID

Notes
Summerfield1919

20171122

Ricoh

MP C4503

$600 \mathrm{dpi}$

grayscale

tiff

Book

Text

010-100956388

Pages typed and single-sided.

Title page has approval signature and perforated property stamp.

Some pages have handwritten marginalia and corrections.

Information lost because of tight binding on pages 53, 109, 109, 110, 111.

Tiff compressed with LZW before conversion to pdf Adobe Photoshop CS5

$600 \mathrm{dpi}$

Grayscale

pdf

Grayscale pages cropped, canvassed, and images brightened.

Blank pages removed. 